Aus dem Institut für Vegetative Physiologie und Pathophysiologie

(Prof. Dr. med. G. Burckhardt)

im Zentrum Physiologie und Pathophysiologie

der Medizinischen Fakultät der Georg-August-Universität Göttingen

\title{
Einfluss des extrazellulären pH-Werts auf den Transport von para-Aminohippurat über den organischen Anionentransporter 1
}

\section{INAUGURAL - DISSERTATION}

\author{
zur Erlangung des Doktorgrades \\ für Zahnheilkunde \\ der Medizinischen Fakultät der \\ Georg-August-Universität zu Göttingen
}

vorgelegt von

Christian Engelke

aus

Göttingen

Göttingen 2014 
Dekan:

I. Berichterstatterin:

II. Berichterstatter/in:

III. Berichterstatter/in:
Prof. Dr. rer. nat. H. K. Kroemer

Prof. Dr. phil. nat. B. C. Burckhardt

Prof. Dr. rer. nat. R. Kehlenbach

Tag der mündlichen Prüfung: $\quad$ 16.02.2015 


\section{Inhaltsverzeichnis}

\section{Inhalt}

Inhaltsverzeichnis .

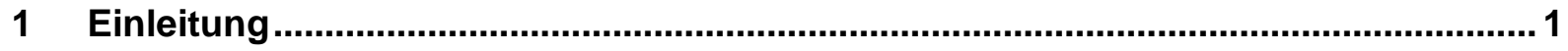

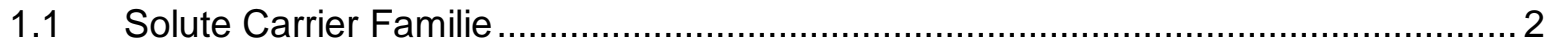

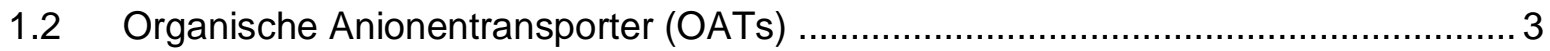

1.3 Der humane organische Anionentransporter 1 (OAT1) ......................................... 5

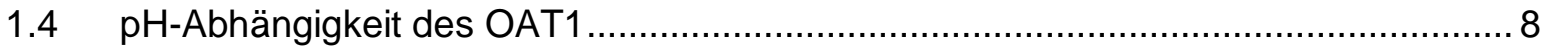

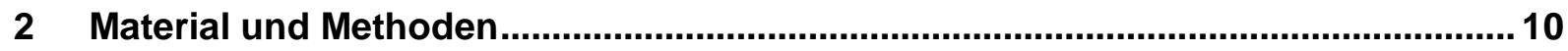

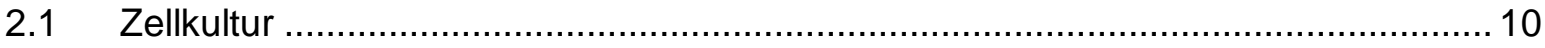

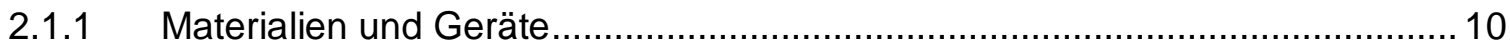

2.1.2 Medien, Ringerlösung, phosphatgepufferte Salzlösung (PBS) ........................ 12

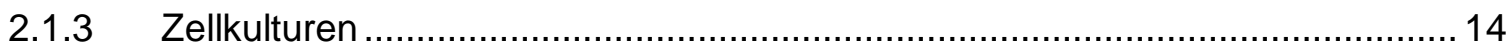

2.2 Versuche zur Aufnahme radioaktiv-markierter Substrate..................................... 17

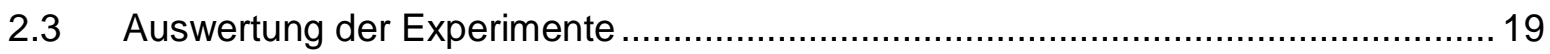

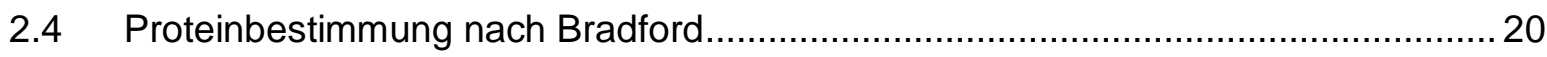

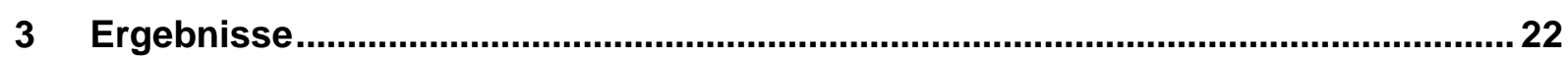

3.1 Aufnahme von PAH als Funktion der Inkubationszeit ............................................ 22

3.2 Aufnahme von PAH in Abhängigkeit von der Zellpassage ................................... 24

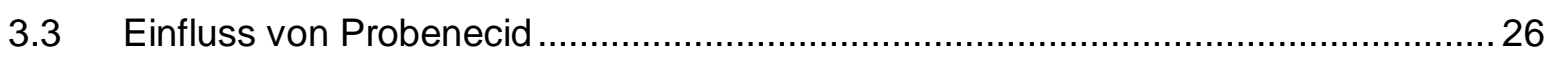

3.4 Bestimmung der Michaelis-Menten-Konstante $\left(\mathrm{K}_{\mathrm{m}}\right)$ bei verschiedenen $\mathrm{pH}-$ Werten 27

3.5 Einfluss von Carbonylcyanid-3-Chlorophenylhydrazon (CCCP) ............................. 32

3.5.1 Einfluss von CCCP bei unterschiedlichen pH-Werten in An- und Abwesenheit

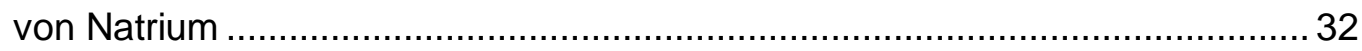

3.5.2 Einfluss von CCCP bei unterschiedlichen pH-Werten in An- und Abwesenheit von Natrium nach 10-minütiger Vorinkubation ............................................. 34

3.5.3 Bestimmung der halbmaximalen inhibitorischen Konzentration $\left(\mathrm{IC}_{50}\right)$ von CCCP 36

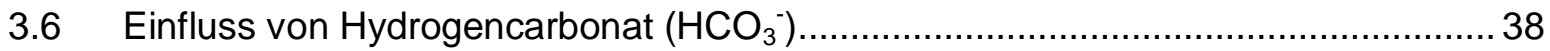

3.7 Einfluss von Acetazolamid und 4-Acetamido-4-Isothiocyanato-Stilben-2,2-

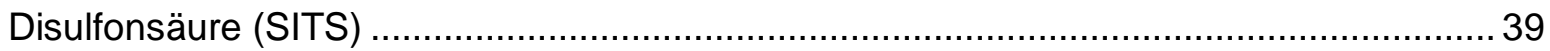

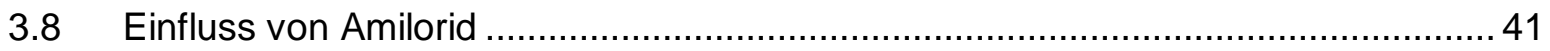

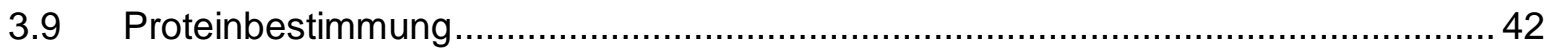

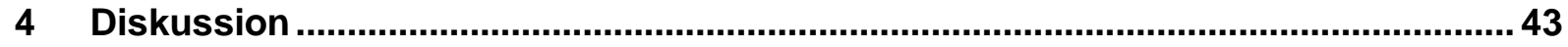

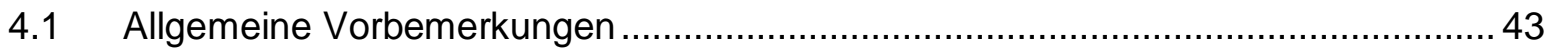

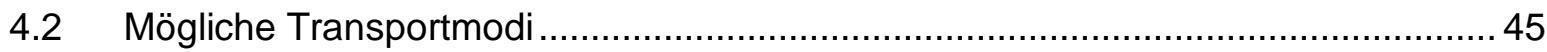




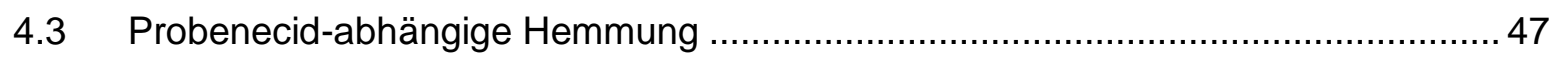

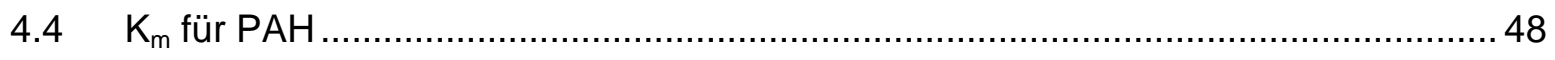

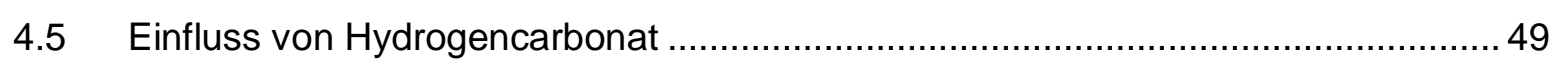

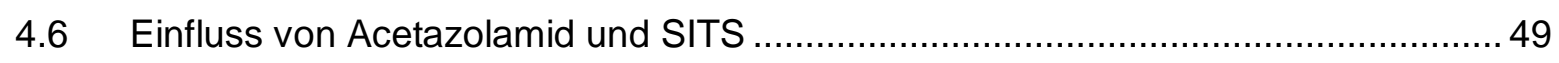

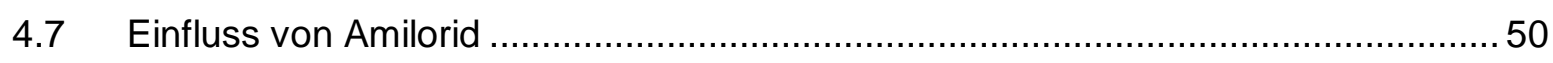

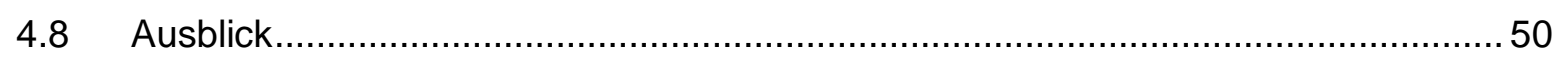

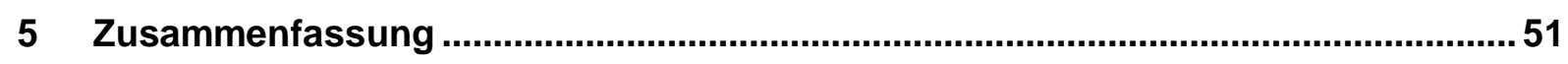

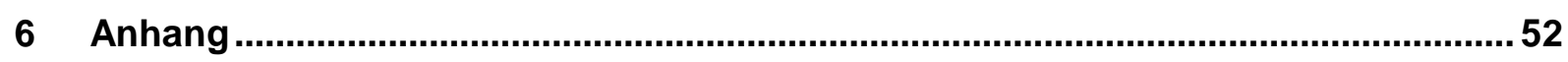

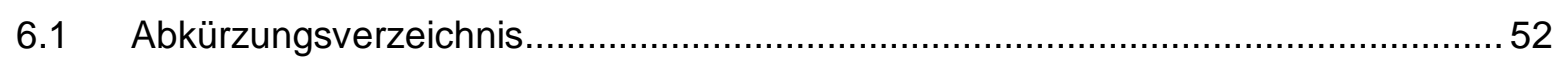

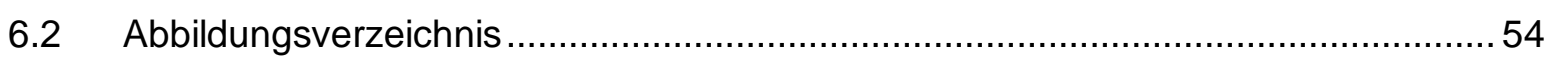

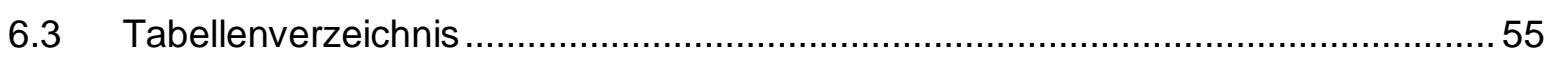

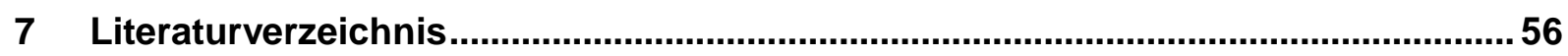




\section{Einleitung}

Zellen bilden die Grundeinheit sämtlicher Organismen. Jede Zelle muss in der Lage sein, nach Bedarf Moleküle in den Intrazellularraum hinein oder heraus zu befördern. Dabei spielen Transporter, die eben dies ermöglichen, eine zentrale Rolle.

Ohne Transporter könnten die meisten Stoffe die Zellmembran nicht passieren. Wir unterscheiden aktive und passive Transporter. Aktive Transporter ermöglichen den Ein- oder Austritt von gelösten Substanzen entgegen ihrem elektrochemischen Gradienten. Erst durch solche aktiven Transporte sind Zellen in der Lage, im Zytoplasma ein sich in der Zusammensetzung teilweise stark vom Extrazellularraum unterscheidendes Milieu aufzubauen. Da über Leber und Nieren zahlreiche im Blut zirkulierende Stoffe aufgenommen, gespeichert, metabolisiert und ausgeschieden werden, spielen diese Organe und natürlich auch die Transporter, die an den Prozessen maßgeblich beteiligt sind, eine wichtige Rolle für den gesamten Organismus.

Die Erforschung der Transporter ist für das Verständnis und die Therapie von Krankheiten von hoher Relevanz. Interagieren mehrere Substanzen mit dem gleichen Transporter, beeinflussen sie sich in ihrer gegenseitigen Aufnahme (Riedmaier et al. 2012, Roth et al. 2012, The International Transporter Consortium 2010). Das kann mit veränderten Plasmaspiegeln der jeweiligen Substanz einhergehen. Auch können Krankheitszustände zu einer veränderten Expression von Transportern führen (Sakurai et al. 2004). 


\subsection{Solute Carrier-Familie}

Die Solute Carrier (SLC) Gen-Familie umfasst 51 Familien und 378 Transporter-Gene (Stand Januar 2013 laut http://www.bioparadigms.org/slc/menu.asp). Ein Transporter wird einer bestimmten SLC-Familie zugeordnet, wenn 20-25\% seiner Aminosäuresequenz mit derjenigen der anderen zu dieser Familie gehörenden Transporter übereinstimmt (Hediger et al. 2004).

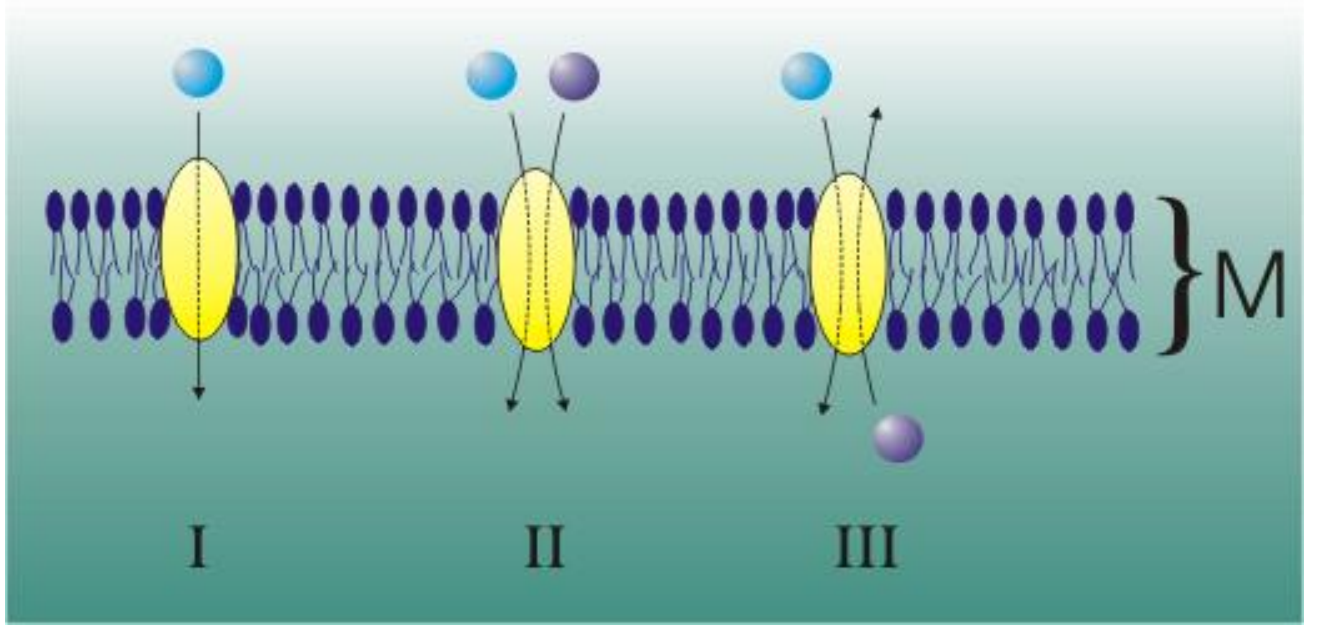

Abbildung 1.1: Transporter. Transporter werden als Symporter bezeichnet, wenn sie zwei oder mehrere Substrate (symbolisiert durch die blaue und die lilafarbene Kugel) in dieselbe Richtung über die Membran transportieren (II). Als Antiporter oder Austauscher werden Transportproteine bezeichnet, bei denen in einem gekoppelten Mechanismus ein Substrat in die Zelle und ein zweites Substrat aus der Zelle heraus transportiert werden (III). Uniporter transportieren jeweils nur ein Substrat entweder in die Zelle hinein oder aus der Zelle heraus (I). (Bild aus: Wikipedia.de) 


\subsection{Organische Anionentransporter (OATs)}

Die organischen Anionentransporter (OATs) sind eine Familie Natrium-unabhängiger Transporter für organische Anionen, die zur Solute Carrier 22 (SLC22) Gen-Familie gehören. Die humane SLC22 Gen-Familie weist zur Zeit 24 Mitglieder auf; funktionell als Transporter für organische Anionen sind bis jetzt jedoch nur OAT1 (SLC22A6), 2 (SLC22A7), 3 (SLC22A8), 4 (SLC22A11), 7 (SLC22A9), 10 (SLC22A13) und URAT1 (SLC22A12) identifiziert und charakterisiert worden (Koepsell 2013).

Die Liste der mit den OATs interagierenden Moleküle und Substrate ist lang und beinhaltet neben häufig verabreichten Medikamenten wie ACE-Inhibitoren, Angiotensin II-RezeptorBlockern, B-Lactam-Antibiotika, Diuretika, entzündungshemmenden Medikamenten (NSAIDs), Immunsuppressiva, Statinen, Virostatika und Zytostatika auch Metabolite wie Harnsäure, Folat, N-Acetyl-Aspartat und Indoxylsulfat (Übersichten in: Burckhardt BC und Burckhardt G 2003, Burckhardt G 2012, Riedmaier et al. 2012, Roth et al. 2012, The International Transporter Consortium 2010, VanWert et al. 2010, Wang und Sweet 2013).

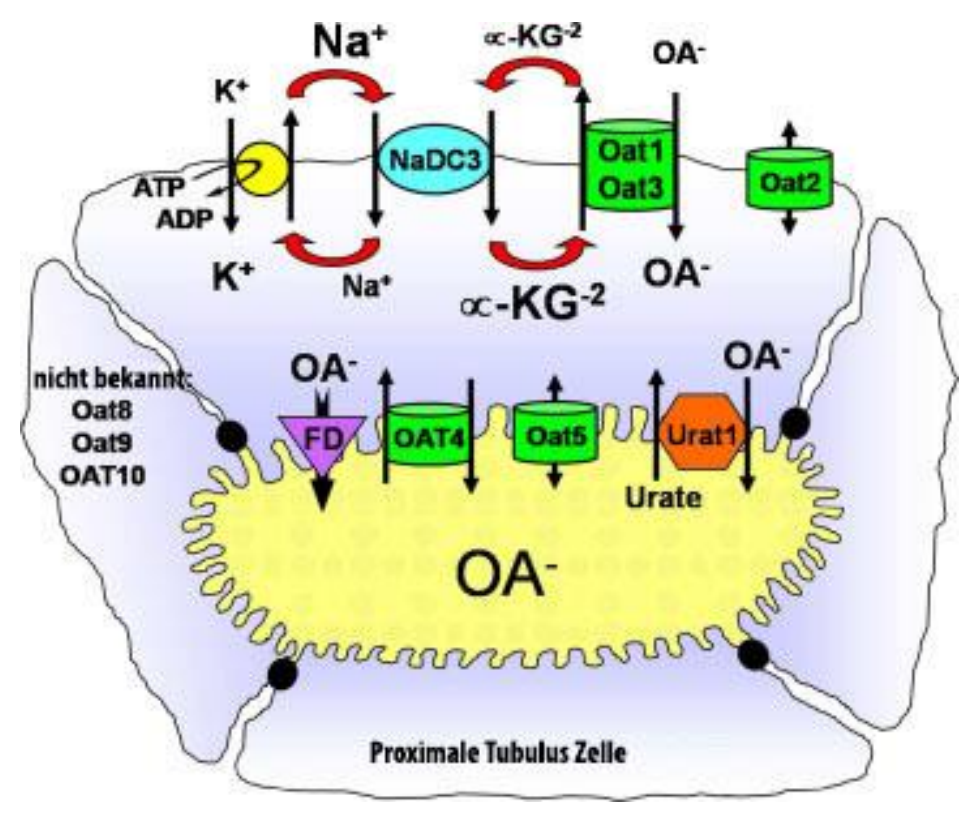

Abbildung 1.2: Schematische Zeichnung einer proximalen Tubuluszelle der Niere. Zum Lumen hin zugewandt sind die organischen Anionentransporter (OATs) OAT4, OAT5 und URAT1. Zusätzlich ist ein Transporter für die erleichterte Diffusion (FD) eingezeichnet. Auf der Blut- bzw. interstitiellen Seite sind OAT1, OAT2, OAT3, der Natrium-abhängige Dicarboxylat-Transporter 3 (NaDC3) und die Natrium-Kalium-ATPase lokalisiert. Die Verwendung der nach VanWert et al. 2010 modifizierten Abbildung erfolgt mit freundlicher Genehmigung von John Wiley \& Sons Ltd. 
Die Nieren sind das Ausscheidungsorgan für viele endo- und exogene organische Anionen und sind daher in besonderer Weise mit OATs ausgestattet. OAT4 konnte in der luminalen Membran (Ekaratanawong et al. 2004), OAT1, 2 und 3 in der basolateralen Membran (Motohashi et al. 2002) proximaler Tubuli der humanen Nieren nachgewiesen werden. Aufgrund dieser Lokalisation sind die basolateralen OATs für die Aufnahme von Substraten aus dem Blut respektive dem interstitiellen Raum verantwortlich. Die Aufnahme der Substrate aus dem Blut geschieht bei OAT1 und $3 \mathrm{im}$ Austausch gegen intrazelluläre Dicarboxylate, vorzugsweise $\alpha$-Ketoglutarat (Kaufhold et al. 2011). OAT2 tauscht gegen das Dicarboxylat Glutarat und das Monocarboxylat Benzoat, aber auch gegen die Aminosäure Glutamat aus (Kobayashi et al. 2005, Pfennig et al. 2013, Sato et al. 2010). Das Zusammenspiel von OAT1, OAT3 und NaDC3 ist der erste Schritt in der Sekretion anionischer Substanzen. Inwieweit OAT2 in diesen Prozess involviert ist, ist zurzeit nicht klar. Der luminal lokalisierte OAT4 kann sowohl organische Anionen in den Primärharn entlassen als auch solche aus dem Primärharn resorbieren. Die Abgabe erfolgt im Austausch gegen Chlorid, die Aufnahme gegen intrazelluläre Dicarboxylate oder HydroxylIonen (Hagos et al. 2008). 


\subsection{Der humane organische Anionentransporter 1 (OAT1)}

OAT1 besteht aus 563 Aminosäuren (Hosoyamada et al. 1999, Jacobsson et al. 2007), die in 12 Transmembranhelices (TMHs) angeordnet sind. Amino- und Carboxy-Terminus sind intrazellulär lokalisiert (Hong et al. 2007). OAT1 besitzt 10 Histidine. Die Histidine liegen vorwiegend in der großen extrazellulären Schleife zwischen der ersten und zweiten TMH und in einer kleinen Schleife zwischen TMH 6 und 7 (Abb 1.3).

A

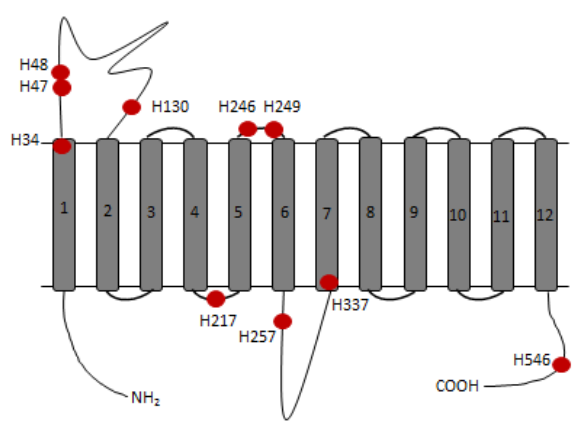

B

\begin{tabular}{ll}
\hline & Position der Histidine \\
\hline extraz. Schleife & $47,48,130,246,249$ \\
intraz. Schleife & $218,275,546$ \\
TMH & 34,337 \\
\hline
\end{tabular}

Abb. 1.3: Lokalisation der Histidine in OAT1. (A) Die Histidine wurden an den Positionen eingetragen, an denen sie nach dem Topologiemodell für OAT1 von Hong (Hong et al. 2007) zu erwarten sind. (B) Die tabellarische Übersicht wurde ebenfalls in Analogie zu Hong angefertigt.

Im Zuge der Untersuchung der Bedeutung zur TMH 1 für Substraterkennung und -transport identifizierten Hong et al. 2004 Histidin 34 als wichtig für die Stabilisierung der großen extrazellulären Schleife. COS-7 Zellen, die transient mit der OAT1-Mutante Histidin34Alanin $(\mathrm{H} 34 \mathrm{~A})$ transfiziert waren, zeigten eine reduzierte Aufnahme des Modellsubstrates für OAT1, dem para-Aminohippurat (PAH) (Hong et al. 2004). Weitere Histidine des OAT1 wurden bisher noch keiner systematischen Analyse unterzogen.

Dass die Positionen 47 bis 50 in der ersten extrazellulären Schleife des OAT1 für die Substraterkennung bzw. den Substrattransport eine Rolle spielen, zeigen Versuche, in denen DNS-Proben unterschiedlicher Ethnien verglichen wurden. In diesen Studien konnten Afrikaner aus der Süd-Sahara, die in OAT1 an Position 50 statt eines Arginins ein Histidin $(\mathrm{R} 50 \mathrm{H})$ aufweisen, identifiziert werden (Bleasby et al. 2005, Cropp et al. 2008, Fujita et al. 2005). Die Injektion von OAT1-cRNS des Polymorphismus R50H in Xenopus laevis-Oozyten resultierte in einem funktionsfähigen OAT1, der im Gegensatz zum Wildtyp eine erhöhte Affinität für Adefovir, Cidofovir und Tenofovir (Bleasby et al. 2005) aufwies. Dieser Befund 
unterstreicht die Bedeutung der Positionen 47 - 50 für die Substraterkennung und Substrataufnahme bei OAT1.

OAT1 wird außer in der basolateralen Membran von proximalen Tubuluszellen der Nieren ebenfalls in Plazenta und Gehirn exprimiert (Koepsell und Endou 2004). In zahlreichen weiteren Geweben können Spuren von OAT1 gefunden werden, jedoch ist die Expression von OAT1 in den Nieren wesentlich höher als in allen anderen Organen (Lopez-Nieto et al. 1997, Sekine et al. 1997, Cihlar et al. 1999, Hosoyamada et al. 1999, Lu et al. 1999, Race et al. 1999, Sun et al. 2001, Buist et al. 2002, Buist und Klaassen 2004, Nishimura und Naito, 2005, Bleasby et al. 2006).

Wie bereits erwähnt, werden über OATs zahlreiche gebräuchliche Antibiotika, Schmerzmittel u.ä. ausgeschieden (siehe Kapitel 1.2). Die Effizienz dieser Präparate könnte bei einem richtigen Verständnis von OAT1 erhöht und unerwünschte Wechselwirkungen vermieden werden. Zum Beispiel könnte dies durch die Co-Medikation mit Substraten oder Inhibitoren von OAT1 erreicht werden. Dabei wäre auch der Übergang von mütterlichem zu fetalem Blut verringert, da OAT1 auch in der Plazenta exprimiert wird (Koepsell und Endou 2004).

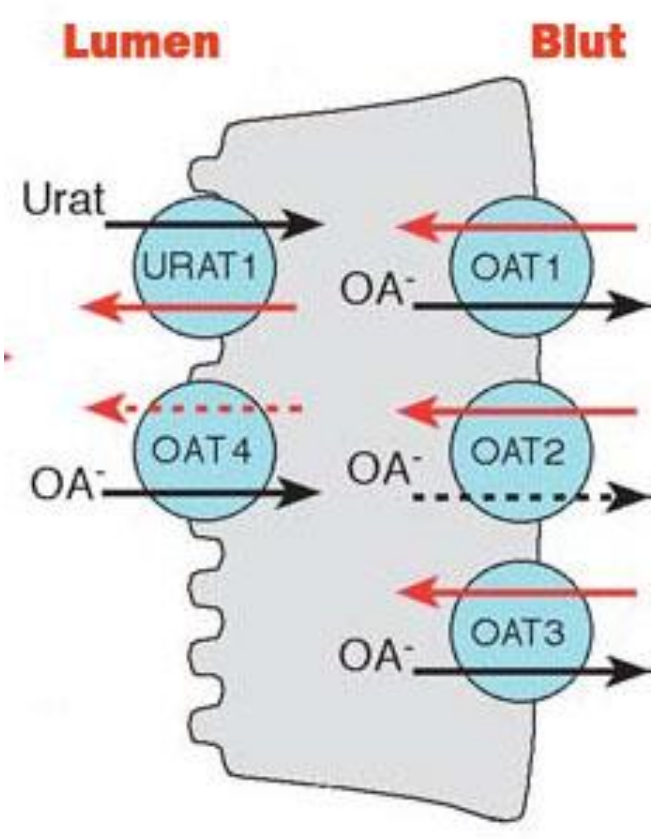

Abbildung 1.4: Schematische Darstellung der Sekretion von Acetylsalicylsäure (ASS). ASS wird wie viele andere Schmerzmittel über unterschiedliche OATs über die Nieren ausgeschieden. Die roten Pfeile stehen für die Aufnahme von ASS, die schwarzen für das entsprechende Gegenanion. Dies ist im Fall von OAT1 und 3 a-Ketoglutarat, im Fall von OAT2 Glutamat, Glutarat oder Benzoat. OAT4 transloziert ASS in den Primärharn. Dies kann beispielsweise im Austausch gegen Chlorid- oder Hydroxyl-lonen erfolgen. Die Verwendung der nach Koepsell und Endou 2004 modifizierten Abbildung erfolgt mit freundlicher Genehmigung von Springer Science+Business Media S.A.. 
Auch Einflüsse von Medikamenten auf die Expression von OAT1 können zu unerwünschten Nebenwirkungen führen. Zum Beispiel werden Patienten mit Herzinsuffizienz häufig mit Furosemid und zusätzlich mit einem Renin-Angiotensin-Aldosteron-System (RAAS)-Inhibitor behandelt, was durch eben diesen RAAS-Inhibitor zu einer verstärkten Ausscheidung von Furosemid führen könnte, da Angiotensin II eine inhibitorische Wirkung auf die OAT1Expression hat (VanWert et al. 2010). Wenn Angiotensin II nun also aufgrund eines RAASInhibitors fehlt und dadurch eine erhöhte Expression von OAT1 bewirkt, kann dies zu einer erhöhten Ausscheidung von Furosemid führen. Furosemid könnte sich im Lumen anreichern und so eine verstärkte Hemmung des luminal gelegenen $\mathrm{Na}^{+} / \mathrm{K}^{+} / 2 \mathrm{Cl}^{-}$-Transporters hervorrufen, was zu einer Diurese führt. 


\section{4 pH-Abhängigkeit des OAT1}

Ob OAT1, 2 und 3 wie einige andere Transporter ihr Substrat im Austausch gegen HydroxylIonen oder im Kotransport mit Protonen aufnehmen können, ist nicht geklärt. An stabil mit OAT1-transfizierten HEK293-Zellen konnte die Arbeitsgruppe eine $\mathrm{pH}$-abhängige Aufnahme des para-Aminohippurats (PAH) nachweisen (Abb. 1.5 A). Die Aufnahme von PAH steigt mit fallendem extrazellulärem $\mathrm{pH}$-Wert $\left(\mathrm{pH}_{\mathrm{ex}}\right)$, um bei $\mathrm{pH}$-Werten unterhalb von 6,4 bzw. $\mathrm{H}^{+}$Ionen-Konzentrationen > $400 \mathrm{nM}$ zu sättigen. Der Sättigungscharakter der Aufnahme von $\mathrm{PAH}$ in Abhängigkeit der extrazellulären $\mathrm{H}^{+}$-lonen-Konzentration ist in Abb. $1.5 \mathrm{~B}$ dargestellt.

A

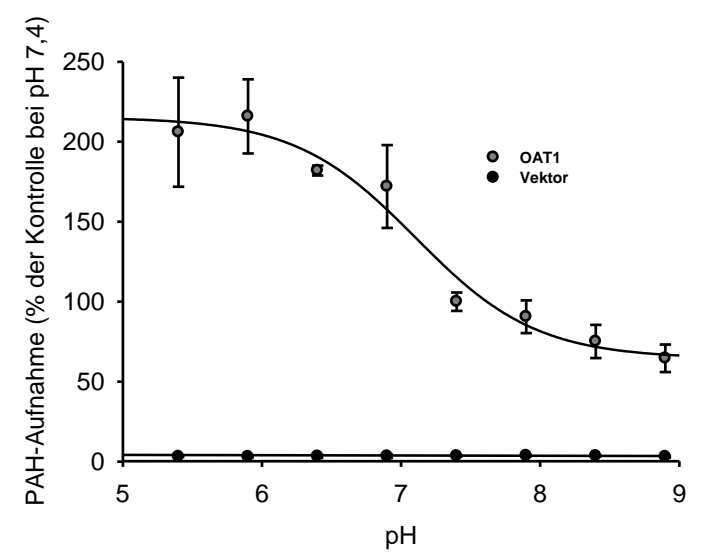

B

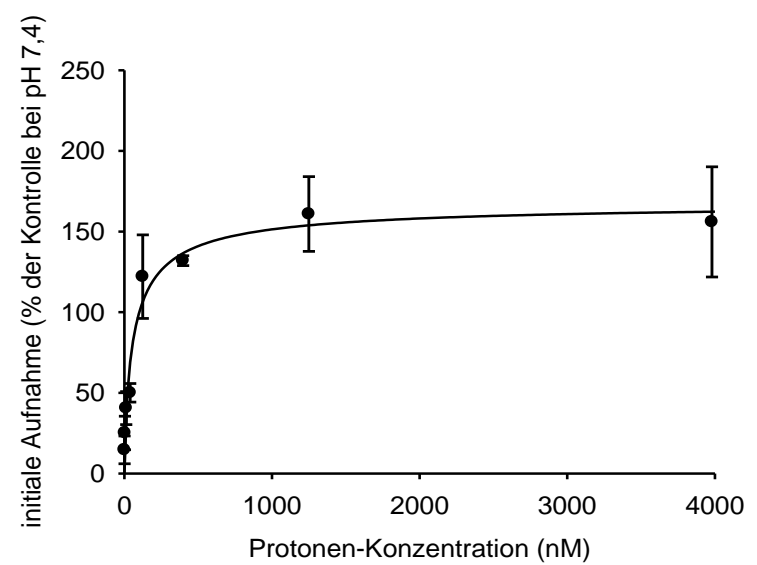

Abbildung 1.5: pH-Abhängigkeit der Aufnahme von PAH in OAT1- und Vektor-transfizierten HEK293-Zellen. (A) Zur Konfluenz angewachsene OAT1- und Vektor-transfizierte HEK293-Zellen wurden für 5 Minuten in Medien unterschiedlicher $\mathrm{pH}$-Werte inkubiert. Anschließend wurde die Aufnahme von 0,5 $\mu \mathrm{M}$ [ $\left.^{3} \mathrm{H}\right]-P A H$ gemessen. Die Aufnahme von PAH in OAT1-transfizierten HEK293Zellen bei $\mathrm{pH}_{\mathrm{ex}}$ 7,4 wurde zu $100 \%$ gesetzt. Alle anderen PAH-Aufnahmen wurden auf diesen Wert normiert. Die sigmoidale Dosis-Wirkungskurve wurde über $y=\min +(\max -\min ) / 1+10^{(\text {log EC50-x) }}$ berechnet, wobei min und max jeweils die niedrigste und höchste Aufnahme von PAH darstellen. Die $E C_{50}$ betrug $7,11 \pm 0,12$. (B) Die in (A) gezeigten PAH-Aufnahmen sind als Funktion der extrazellulären Protonenkonzentration aufgetragen, wobei der $\mathrm{pH}$-unabhängige Anteil der $\mathrm{PAH}$ Aufnahme bereits abgezogen ist. Daraus lässt sich nach $V=V_{\max } \cdot\left[H^{+}\right]^{n} / K_{H_{+}}^{n}+\left[H^{+}\right]^{n}$ ein HillKoeffizient von 0,54 \pm 0,14 berechnen. Die Abbildungen wurden mir freundlicherweise von Birgitta $C$. Burckhardt zur Verfügung gestellt. 
Die halbmaximale Sättigung der PAH-Aufnahme war bei einer extrazellulären ProtonenKonzentration von $79 \pm 12 \mathrm{nM}$ erreicht. Es besteht keine Kooperativität zwischen PAH und Protonen, da der Hill-Koeffizient 0,54 \pm 0,14 beträgt. Für OAT3-transfizierte HEK293-Zellen konnte, in Analogie zu OAT1-transfizierten HEK293-Zellen, ebenfalls eine pH-Abhängigkeit der Substrataufnahme nachgewiesen werden. Für das Modellsubstrat des OAT3, Estronsulfat (10 nM $\left[{ }^{3} \mathrm{H}\right]$-ES), stieg die Aufnahme von $63,4 \pm 14,1$ bei $\mathrm{pH}_{\mathrm{ex}} 7,4$ auf 207,9 \pm $49,0 \mathrm{fmol} \cdot \mathrm{min}^{-1} \cdot \mathrm{mg}^{-1}$ bei $\mathrm{pH}_{\mathrm{ex}} 6,4$ an.

Eine erhöhte Substrataufnahme bei erniedrigtem $\mathrm{pH}_{\mathrm{ex}}$ kann mehrere Ursachen haben:

- Eine Änderung des lonisierungsgrads bedingt eine erhöhte Substratkonzentration

- Das Substrat kann zusammen mit Protonen in die Zelle aufgenommen werden

- Das Substrat kann im Austausch gegen intrazelluläre Hydroxyl- oder Hydrogencarbonatlonen in die Zelle aufgenommen werden

- Das Transportprotein wird durch Protonierung bestimmter Aminosäuren in seiner Konformation verändert, sodass die Substrataufnahme erleichtert wird. Konformationsänderungen können extra- und intrazelluläre Anteile des Transportproteins betreffen

Auch bei Tumorzellen spielt der pH-Wert eine entscheidende Rolle. Es ist zum Beispiel bekannt, dass maligne Tumoren ein saures extrazelluläres Mikromilieu aufweisen (Parks et al. 2011).

Ziel dieser Dissertationsarbeit war es deshalb, die pH-Abhängigkeit der Substrataufnahme des OAT1 zu untersuchen. Diese wurde an dem Modellsystem der stabil mit dem OAT1transfizierten HEK293-Zellen untersucht. Als Modellsubstrat wurde para-Aminohippurat $(\mathrm{PAH})$ genutzt, das in radioaktiv markierter Form erhältlich ist. 


\section{Material und Methoden}

In diesem Teil werden alle verwendeten Materialien aufgelistet und die angewandten Methoden erläutert. Eine Liste mit Geräten und Materialien, die in der Zellkultur benutzt worden sind, findet sich zu Beginn des Abschnitts "Zellkultur“. Tabellen von speziellen Geräten und Chemikalien finden sich in den Abschnitten, in denen sie erwähnt werden.

\subsection{Zellkultur}

\subsubsection{Materialien und Geräte}

Tabelle 2.1: Geräte

\begin{tabular}{|c|c|c|}
\hline Gerät & Informationen/Typbezeichnung & Hersteller \\
\hline 24-Well-Platte & $\begin{array}{l}\text { Cell Culture Cellstar®, Cat.-No. } \\
662160\end{array}$ & $\begin{array}{l}\text { Greiner Bio-One } \\
\text { (Frickenhausen, } \\
\text { Deutschland) }\end{array}$ \\
\hline Absaugpumpe & VDE05 30 & $\begin{array}{l}\text { KNF Neuberger } \\
\text { (Freiburg, Deutschland) }\end{array}$ \\
\hline Brutschränke 1-3 & Typ BB 16 & $\begin{array}{l}\text { Heraeus (Hanau, } \\
\text { Deutschland) }\end{array}$ \\
\hline elektrische Pipetierhilfe & Pipetus® & $\begin{array}{l}\text { Hirschmann Laborgeräte } \\
\text { (Eberstadt, Deutschland) }\end{array}$ \\
\hline Feinwaage & LC 6215 & $\begin{array}{l}\text { Sartorius (Göttingen, } \\
\text { Deutschland) }\end{array}$ \\
\hline Handschuhe & $\begin{array}{l}\text { Nitril NextGen, verschiedene } \\
\text { Größen }\end{array}$ & $\begin{array}{l}\text { Meditrade (Kiefersfelden, } \\
\text { Deutschland) }\end{array}$ \\
\hline Kühlschranke & $\begin{array}{l}\text { Privileg Energiesparer oder Vario } \\
\text { electronic }\end{array}$ & $\begin{array}{l}\text { Quelle (Fürth, } \\
\text { Deutschland) und } \\
\text { Siemens (München, } \\
\text { Deutschland }\end{array}$ \\
\hline Magnetrührer & RETbasic & $\begin{array}{l}\text { Ika Labortechnik } \\
\text { (Staufen, Deutschland) }\end{array}$ \\
\hline $\begin{array}{l}\text { mechanische Pipetten 2,5 - } \\
1000 \mu \mathrm{l}\end{array}$ & Pipetman u.a. & $\begin{array}{l}\text { Eppendorf (Hamburg, } \\
\text { Deutschland) und Gilson } \\
\text { (Middleton, WI, USA) }\end{array}$ \\
\hline Mikroskop & Telaval 31 & $\begin{array}{l}\text { Zeiss (Oberkochen, } \\
\text { Deutschland) }\end{array}$ \\
\hline pH-Meter & inoLab phIIDN & $\begin{array}{l}\text { WTW (Weilheim, } \\
\text { Deutschland) }\end{array}$ \\
\hline $\begin{array}{l}\text { Pipettenspitzen, } \\
\text { Zellkulturschalen und } \\
\text { andere Plastikware }\end{array}$ & & $\begin{array}{l}\text { Sarstedt (Nümbrecht, } \\
\text { Deutschland) }\end{array}$ \\
\hline Pipettierhilfe & & $\begin{array}{l}\text { Eppendorf (Hamburg, } \\
\text { Deutschland) }\end{array}$ \\
\hline Scintilationscounter & Tri Carb 2900 TR & $\begin{array}{l}\text { Packard (Meriden, CT, } \\
\text { USA) }\end{array}$ \\
\hline
\end{tabular}




\begin{tabular}{|c|c|c|}
\hline Scintilationscounter & Tri carb 2810 TR & $\begin{array}{l}\text { Perkin Elmer (Boston, } \\
\text { MA, USA) }\end{array}$ \\
\hline Scintilationsflüssigkeit & Lumasafe $^{\mathrm{TM}}$ Plus & $\begin{array}{l}\text { Lumac LSc B.V. } \\
\text { (Groningen, } \\
\text { Niederlande) }\end{array}$ \\
\hline Thermostat & 3401 & $\begin{array}{l}\text { Eppendorf (Hamburg, } \\
\text { Deutschland) }\end{array}$ \\
\hline Vortexer & Vor-Genie 2 & $\begin{array}{l}\text { Scientific Industries } \\
\text { (Bohemia, New York, } \\
\text { USA) }\end{array}$ \\
\hline Wasserbad & Typ 1083 & $\begin{array}{l}\text { GFL Gesellschaft für } \\
\text { Labortechnik GmbH } \\
\text { (Burgwedel, } \\
\text { Deutschland) }\end{array}$ \\
\hline Zellkulturwerkbank 1 & Biowizard Silverline & $\begin{array}{l}\text { Kojair (Vilppula, } \\
\text { Finnland) }\end{array}$ \\
\hline Zellkulturwerkbank 2 & Scientific Safe 2020 & $\begin{array}{l}\text { Thermo Scientific } \\
\text { (Waltham, MA, USA) }\end{array}$ \\
\hline Zentrifuge & Laborfuge 400R Function Line & $\begin{array}{l}\text { Heraeus (Hanau, } \\
\text { Deutschland) }\end{array}$ \\
\hline
\end{tabular}

Tabelle 2.2: Verwendete Chemikalien

\begin{tabular}{|c|c|}
\hline Stoffbezeichnung & Hersteller, Produkt-Nr. \\
\hline $\begin{array}{l}\text { Acetamido-4-Isothiocyanato-Stilben-2,2- } \\
\text { Disulfonsäure (SITS) }\end{array}$ & $\begin{array}{l}\text { Sigma-Aldrich (Steinheim, Deutschland), } \\
\text { A-0554 }\end{array}$ \\
\hline Acetazolamid & $\begin{array}{l}\text { Sigma-Aldrich (Steinheim, Deutschland, } \\
\text { A-6011 }\end{array}$ \\
\hline Amilorid & $\begin{array}{l}\text { Sigma-Aldrich (Steinheim, Deutschland, } \\
\text { A-7410 }\end{array}$ \\
\hline bovines Serumalbumin (BSA) & Serva (Heidelberg, Deutschland) \\
\hline $\mathrm{CaCl}_{2}$ & Sigma-Aldrich (Steinheim, Deutschland) \\
\hline Carbonylcyanid-3-Chlorophenylhydrazon (CCCP) & $\begin{array}{l}\text { Sigma-Aldrich (Steinheim, Deutschland, } \\
\text { C-2759 }\end{array}$ \\
\hline Dimethylsulfoxid (DMSO) & $\begin{array}{l}\text { Carl Roth GmbH (Karlsruhe, } \\
\text { Deutschland) }\end{array}$ \\
\hline Dulbecco's Modified Eagle’s Medium (DMEM) & $\begin{array}{l}\text { Biochrom AG (Berlin, Deutschland), } \\
\text { T043-50 }\end{array}$ \\
\hline Fetal Calf Serum (FCS) & Invitrogen (Karlsruhe, Deutschland) \\
\hline Glucose & AppliChem (Darmstadt, Deutschland) \\
\hline $\mathrm{HCl}$ & AppliChem (Darmstadt, Deutschland) \\
\hline HEPES & AppliChem (Darmstadt, Deutschland) \\
\hline $\mathrm{KCl}$ & AppliChem (Darmstadt, Deutschland) \\
\hline $\mathrm{MgSO}_{4}$ & AppliChem (Darmstadt, Deutschland) \\
\hline $\mathrm{NaCl}$ & AppliChem (Darmstadt, Deutschland) \\
\hline $\mathrm{NaH}_{2} \mathrm{PO}_{4}$ & AppliChem (Darmstadt, Deutschland) \\
\hline $\mathrm{NaHCO}_{3}$ & Merck (Darmstadt, Deutschland) \\
\hline p-[Glycyl-2- $\left.{ }^{3} \mathrm{H}\right]-$ Aminohippursäure $\left(\left[{ }^{3} \mathrm{H}\right]-\mathrm{PAH}\right)$ & $\begin{array}{l}\text { PerkinElmer (Boston, MA, USA), } \\
1663223\end{array}$ \\
\hline PBS-Puffer (Dulbecco) & $\begin{array}{l}\text { AppliChem (Darmstadt, Deutschland), } \\
\text { A0964 }\end{array}$ \\
\hline
\end{tabular}




\begin{tabular}{ll}
\hline Penicillin & PAA (Pasching, Österreich) \\
Poly-D-Lysin & Sigma-Aldrich (Steinheim, Deutschland), \\
& P1149 \\
Probenecid & Sigma-Aldrich (Steinheim, Deutschland, \\
& P-8761 \\
Streptomycin & PAA (Pasching, Österreich) \\
TMACI & Sigma-Aldrich (Steinheim, Deutschland \\
TMAOH & Sigma-Aldrich (Steinheim, Deutschland \\
Trypsin & Sigma-Aldrich (Steinheim, Deutschland, \\
& $27350-042$ \\
\hline
\end{tabular}

\subsubsection{Medien, Ringerlösung, phosphatgepufferte Salzlösung (PBS)}

Die folgenden Substanzen wurden in destilliertem Wasser gelöst und durchmischt. Die Lösung wurde daraufhin steril-filtriert und in einem sterilen Gefäß bei $+4{ }^{\circ} \mathrm{C}$ aufbewahrt.

\section{Zellmedium/Nährlösung:}

Dulbecco's Modified Eagle's Medium

$\mathrm{NaHCO} 3$

fetal calf serum

Penicillin

Streptomycin
$13,54 \mathrm{~g} / \mathrm{I}$
$3,7 \mathrm{~g} / \mathrm{I}$
$100 \mathrm{ml} / \mathrm{l}$
$100 \mathrm{U} / \mathrm{ml}$
$100 \mu \mathrm{g} / \mathrm{ml}$

Aufbewahrung in einem sterilen Gefäß bei $4{ }^{\circ} \mathrm{C}$.

\section{Ringerlösung:}

$\begin{array}{ll}\mathrm{NaCl} & 130 \mathrm{mM} \\ \mathrm{KCl} & 4 \mathrm{mM} \\ \mathrm{CaCl}_{2} & 1 \mathrm{mM} \\ \mathrm{MgSO}_{4} & 1 \mathrm{mM} \\ \mathrm{HEPES} & 20 \mathrm{mM} \\ \mathrm{NaH}_{2} \mathrm{PO}_{4} & 1 \mathrm{mM} \\ \text { Glucose } & 18 \mathrm{mM}\end{array}$




\section{Natriumfreie Ringerlösung:}

TMACI $\quad 130 \mathrm{mM}$

$\mathrm{KCl} \quad 4 \mathrm{mM}$

$\mathrm{CaCl}_{2} \quad 1 \mathrm{mM}$

$\mathrm{MgSO}_{4} \quad 1 \mathrm{mM}$

HEPES $20 \mathrm{mM}$

$\mathrm{NaH}_{2} \mathrm{PO}_{4} \quad 1 \mathrm{mM}$

Glucose $\quad 18 \mathrm{mM}$

Danach erfolgte die Titration der Lösungen mit NaOH/HCl bzw. TMAOH/HCl auf pH 7,4 bzw. 6,4 bei Raumtemperatur.

Für die Versuche mit hydrogencarbonathaltigem Ringer wurden $25 \mathrm{mM} \mathrm{NaCl}$ durch $25 \mathrm{mM}$ $\mathrm{NaHCO}_{3}$ ersetzt.

Hydrogencarbonathaltige Ringerlösung:

$\mathrm{NaCl} \quad 105 \mathrm{mM}$

$\mathrm{NaHCO}_{3} \quad 25 \mathrm{mM}$

$\mathrm{KCl} \quad 4 \mathrm{mM}$

$\mathrm{CaCl}_{2} \quad 1 \mathrm{mM}$

$\mathrm{MgSO}_{4} \quad 1 \mathrm{mM}$

HEPES $20 \mathrm{mM}$

$\mathrm{NaH}_{2} \mathrm{PO}_{4} \quad 1 \mathrm{mM}$

Glucose $\quad 18 \mathrm{mM}$

Zum Waschen der Zellen wurde phosphatgepufferte Salzlösung (PBS) verwendet:

PBS Dulbecco $\quad 9,55 \mathrm{~g} / \mathrm{I}$ in destilliertem Wasser

Zum Ablösen der Zellen von dem Boden der Petrischalen, wurde eine 0,1 \%ige TrypsinLösung eingesetzt. Zur Herstellung dieser Lösung wurde Trypsin 0,1 \%ig in PBS gelöst. 


\subsubsection{Zellkulturen}

Im Institut für Vegetative Physiologie und Pathophysiologie werden sowohl OAT1- als auch Vektor-transfizierte HEK293-Zellen kultiviert, die ich für meine Versuche verwenden konnte. Die Zellen wurden in kleinen oder großen Zellkulturschalen (Petrischalen) mit 10 bzw. $20 \mathrm{ml}$ Nährmedium versorgt und im Brutschrank bei $37^{\circ} \mathrm{C}$ und einer Atmosphäre von $5 \% \mathrm{CO}_{2}$ in $\mathrm{O}_{2}$ kultiviert. Nach einer 2 - 3-tägigen Inkubation wurden die Zellen unter dem Mikroskop auf ihre Konfluenz untersucht. Bei einer Konfluenz von 50-100 \% wurden die Zellen geerntet und neu ausplattiert.

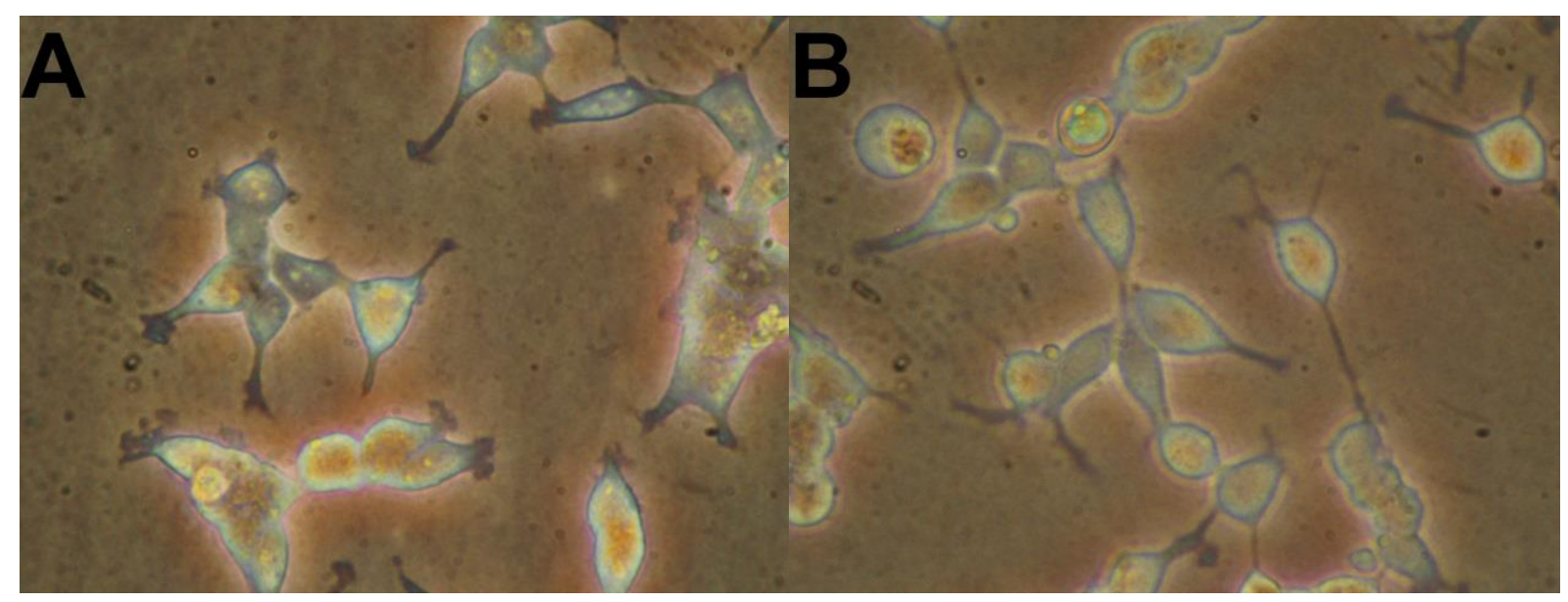

Abbildung 2.1: OAT1-transfizierte Zellen (A) im Vergleich zu den Vektor-transfizierten Zellen (B): In Bezug auf Zellgröße und -form sind keine Unterschiede zwischen OAT1- und Vektortransfizierten Zellen ersichtlich; Vergrößerung: ca. 200-fach

Sämtliche Handhabungen mit Zellen, die sich noch weiter vermehren sollten, wurden unter einer Zellkulturwerkbank (Abb. 2.2) und unter sterilen Bedingungen durchgeführt, um Kontaminationen der Zellinien auszuschließen. Die dabei verwendeten Medien waren sterilfiltiert, Pipettenspitzen und andere Plastikware waren autoklaviert. 


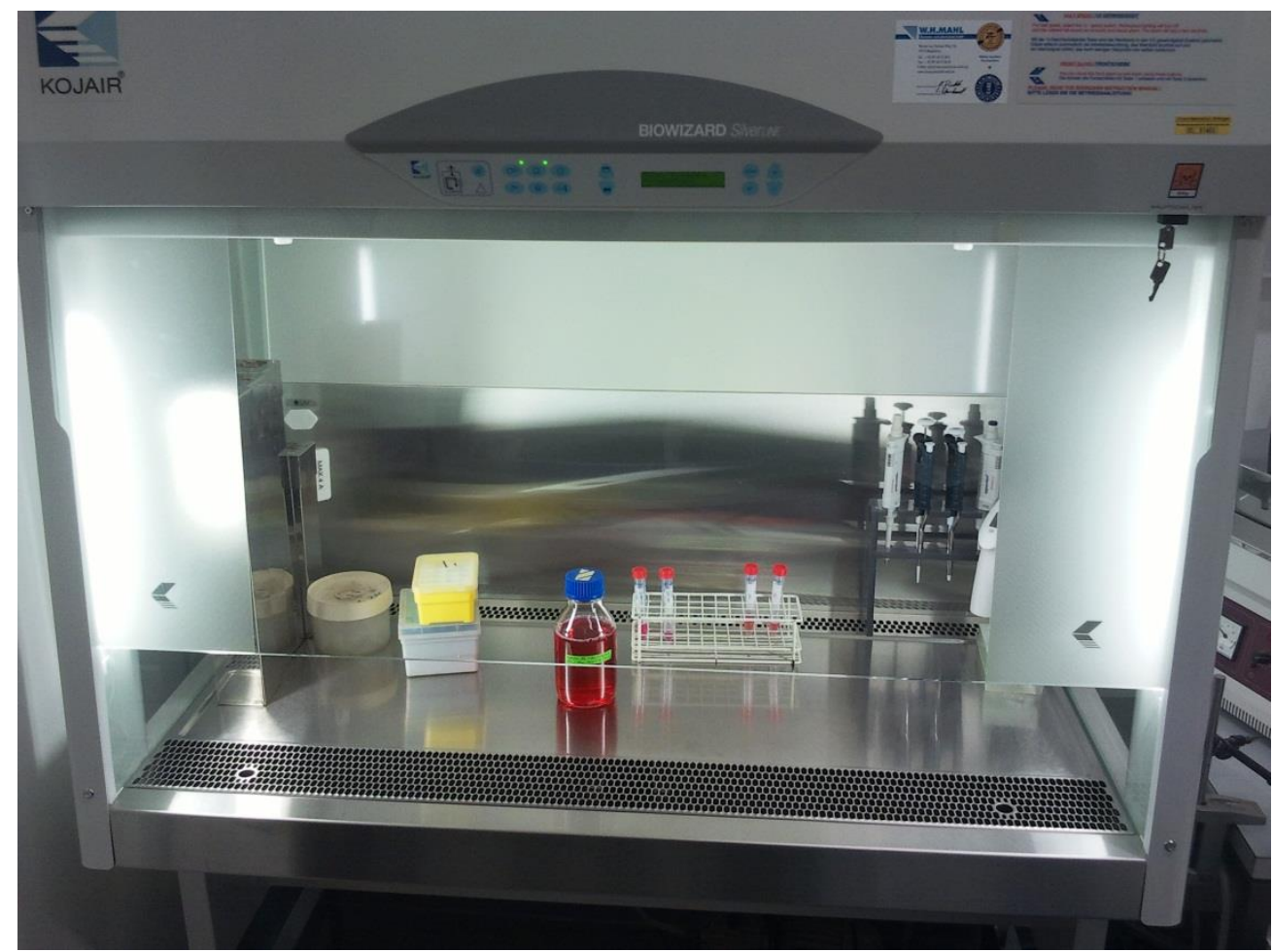

Abbildung 2.2: Zellkulturwerkbank Biowizard Silverline (eigene Photographie)

\section{Zellernte:}

Bei Konfluenz der Zellen zwischen 50 und $100 \%$ (je nachdem, wie viele Zellen für einen Versuch benötigt wurden) wurde zunächst das Nährmedium abgesaugt und die Zellen mit phosphatgepufferter Salzlösung (PBS) gewaschen, um tote, nicht-anhaftende Zellen zu entfernen. Danach wurden die Zellen mit je nach Schalengröße 2 oder $4 \mathrm{ml}$ 0,1\%iger Trypsin-PBS-Lösung beschickt, und eine 3-minütige Inkubationszeit sollte gewährleisten, dass sich die Zellen vom Boden der Schale ablösen. Die Trypsinlösung, in der sich die abgelösten Zellen befanden, wurde in ein $15 \mathrm{ml}$ Reagenzgefäß gegeben und dort mit gleichem Volumen an Nährmedium neutralisiert.

Daraufhin wurden die Zellen für 5 Minuten bei $1000 \mathrm{U} / \mathrm{min}$ zentrifugiert. Der Überstand wurde in ein steriles Gefäß abgegossen und entsorgt, während die Zellen mit $2 \mathrm{ml}$ Nährlösung resuspendiert wurden.

Falls Zellen für einen Versuch benötigt wurden, wurden diese der Lösung entnommen und je nach Versuch weiter verarbeitet. Ein Teil der Zellen wurde zum Erhalt der Zelllinie wieder ausplattiert. Dazu wurde eine kleine oder große Petrischale mit 10 bzw. 20 ml Nährmedium gefüllt und die gewünschte Menge an Zellen dazugegeben. Die Menge der hinzugegeben Zellen richtete sich nach der gewünschten Zeit, bis zu der die Zellen wieder konfluent sein sollten und beruhte auf Erfahrungswerten. Die Petrischalen wurden daraufhin mitsamt den Zellen zur Kultivierung in den Brutschrank gebracht. Nicht mehr benötigte Zellen wurden entsorgt. 


\section{Vorbereitung der 24-Well-Platten:}

Da die für die Versuche benötigten 24-Well-Platten nicht vom Hersteller aus beschichtet waren, wurden diese unter sterilen Bedingungen mit ca. $300 \mu \mathrm{l}$ Polylysin benetzt, um später die Zellhaftung am Plattenboden zu gewährleisten. Das Polylysin wurde nach wenigen Minuten Einwirkzeit wieder abpipettiert und die 24-Well-Platte ca. eine Stunde stehen gelassen, damit Reste des Polylysins verdunsten konnten. Danach wurden die Platten abgedeckt und gelagert, bis sie für Versuche benötigt wurden.

\section{Aussaat der Zellen:}

Für die Aufnahmeversuche wurde ein Teil der bei der Zellernte gewonnenen Zellen in 24Well-Platten ausgesät. Eine Probe der zentrifugierten und resuspendierten Zellen wurde hierzu um den Faktor 20 verdünnt und in der Neubauer-Zählkammer gezählt. Wichtig hierbei ist besonders die gute Durchmischung der Zellen vor Probenentnahme, um ein repräsentatives Ergebnis zu erhalten. Die Zählung von je vier Quadranten der Neubauer Zählkammer wurde gemittelt und aus dem vorherigen Verdünnungsgrad und dem durch die Neubauer Zählkammer definierten Faktor ergab sich die Konzentration der Zellen in der Ausgangslösung wie folgt:

Zellkonzentration der Ausgangslösung [Zellen $/ \mathrm{ml}]=$ Mittelwert der vier Zählungen * $10^{4}$ [Zellen / ml] (Faktor der Neubauer-Zählkammer) * 20 (Verdünnung)

Pro Well sollten $2{ }^{*} 10^{5}$ Zellen in $500 \mu \mathrm{l}$ Nährlösung ausgesät werden. Dazu wurde zunächst die Gesamtzahl $\mathbf{x}$ der benötigten Zellen für alle Wells ermittelt und zusammen aus der Zellenkonzentration der Ausganglösung $\mathbf{y}$ ergibt sich das benötigte Volumen $\mathbf{z}$ an Ausgangslösung wie folgt:

$\mathbf{z}[\mu \mathrm{l}]=\mathbf{x} / \mathbf{y}$

Dieses Volumen wurde in ein Reagenzgefäß pipettiert und mit Nährlösung auf das benötigte Gesamtvolumen (Anzahl der Wells * $500 \mu \mathrm{l}$ ) aufgefüllt. Nach gutem Durchmischen wurden in jedes Well $500 \mu \mathrm{l}$ dieser Lösung pipettiert und die 24-Well-Platte zur Vermehrung der Zellen für 3 Tage in den Brutschrank gegeben. 


\subsection{Versuche zur Aufnahme radioaktiv-markierter Substrate}

Für diese Versuche wurden die Zellen, wie in dem Abschnitt „Aussaat der Zellen“ beschrieben, ausgesät und drei Tage kultiviert. Für jede zu testende Bedingung erfolgte eine 3-fach-Bestimmung. Zur Vorbereitung der Zellen für die Aufnahme wurden sie aus dem Brutschrank entnommen, nach kurzer Akklimatisierungsphase zwei Mal mit PBS gewaschen und daraufhin mit der jeweiligen Ringerlösung benetzt, um sie bis zum Versuchsbeginn in einem zellfreundlichen Milieu zu halten und vor dem Austrocknen zu schützen.

Da para-Aminohippurat (PAH) das prototypische Substrat des OAT1 ist (Literaturreferenzen siehe Einleitung), wurden bei allen Versuchen die Zellen zur Messung der Aufnahme von $\left[{ }^{3} \mathrm{H}\right]-\mathrm{PAH}$ in einer Konzentration von 0,5 $\mu \mathrm{M}$ für - soweit nicht anders angegeben - 5 Minuten (siehe Ergebnisteil) mit $200 \mu$ l Testlösung inkubiert.<smiles>Nc1ccc(C(=O)NCC(=O)O)cc1</smiles>

Abbildung 2.3: Strukturformel [ $\left.{ }^{3} \mathrm{H}\right]-P A H$ (aus Technical Data Sheet AMINOHIPPURIC ACID, $p$ [GLYCYL-2-3H]-, PerkinElmer, Lot Nummer: 1663223):

Für die $\mathrm{K}_{\mathrm{m}}$-Bestimmung von $\mathrm{PAH}$ wurden $\mathrm{zu}$ den $0,5 \mu \mathrm{M}$ radioaktiv-markierten $\mathrm{PAH}$ verschiedene Konzentrationen von nicht markiertem $\mathrm{PAH}$ zugegeben.

Bei jedem Versuch wurde nach Ablauf der Inkubationszeit der Transport durch Absaugen der Lösung und 3-maliges Waschen der Zellen mit PBS gestoppt. Durch das mehrmalige Waschen sollte sichergestellt werden, dass $\left[{ }^{3} \mathrm{H}\right]-\mathrm{PAH}$, das nicht von den Zellen aufgenommen wurde, abgewaschen wird. Anschließend wurden die Zellen durch Zugabe von $500 \mu \mathrm{l} 1 \mathrm{M} \mathrm{NaOH}$-Lösung für 2 Stunden geschüttelt, um die Zellen aufzulösen. Nach Ablauf der Zeit wurden die einzelnen Lösungen in Szintilationsröhrchen überführt und 2,5 ml Szintilationsflüssigkeit hinzugegeben. Die verschlossenen Szintilationsröhrchen wurden kurz geschüttelt und danach in den Szintilationscounter (Abb. 2.4) gebracht. 


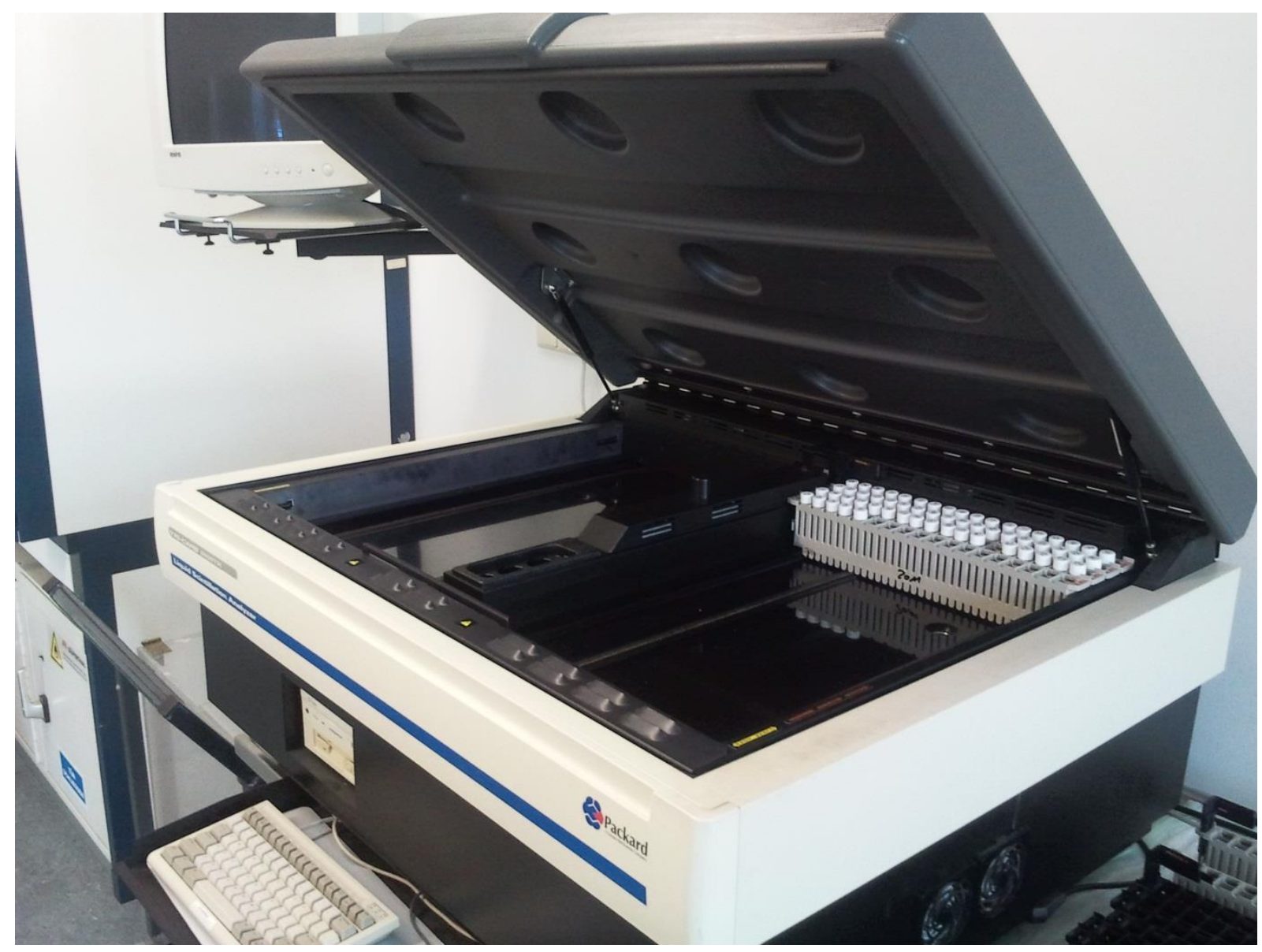

Abbildung 2.4: Der Szintilationscounter Tri Carb 2900 TR von Packard (eigene Photographie)

Zur Bestimmung der spezifischen Aktivität des $\left[{ }^{3} \mathrm{H}\right]-\mathrm{PAHs}$ wurden von den Ausgangslösungen, in denen das radioaktive $\mathrm{PAH}$ zuerst gelöst und die dann auf die einzelnen Röhrchen mit den unterschiedlichen Substanzen verteilt wurden, jeweils 4 Proben von $5 \mu \mathrm{l}$ als Standards entnommen, die mit $500 \mu \mathrm{l} \mathrm{NaOH}$ und 2,5 ml Szintilationsflüssigkeit gemischt und danach die Zerfälle pro Minute (decays per minute; DPM) gezählt wurden. 


\subsection{Auswertung der Experimente}

Zur Auswertung der Daten wurden die decays per minute (DPM) in eine Microsoft ExcelTabelle eingegeben, und über die mitlaufenden Standards des $\left[{ }^{3} \mathrm{H}\right]-\mathrm{PAHs}$ konnte die spezifische Aktivität des $\left[{ }^{3} \mathrm{H}\right]-\mathrm{PAH}$ berechnet werden. Aus der spezifischen Aktivität und den DPMs der einzelnen Messungen ergab sich die PAH-Aufnahme in Mol / Aufnahmezeit. Die Standardabweichung wurde mit der in Excel integrierten Formel berechnet, der Standardfehler (SEM) ergab sich aus der Standardabweichung dividiert durch die Wurzel der Anzahl der Proben je Bedingung und wird in der gesamten Arbeit als Maß dafür angenommen, wie genau der dargestellte Mittelwert ist. Der Grad der Signifikanz wurde mit dem in Excel integrierten ungepaarten t-Test nach Student ermittelt. Die Daten wurden mit SigmaPlot grafisch dargestellt. Sämtliche Regressionen wurden ebenfalls mit SigmaPlot berechnet. Für die Bestimmungen der halbmaximalen inhibitorischen Konzentration $\left(\mathrm{IC}_{50}\right)$ wurde dabei eine hyperbolische Funktion mit $y=\left(a * I C_{50}\right) /\left(I_{50}+x\right)$ verwendet. Für die Bestimmung der Michaelis-Menten-Konstanten $\left(K_{m}\right)$ wurde die Funktion $y=\left(V_{\max }{ }^{*} \mathrm{x}\right) /\left(\mathrm{K}_{\mathrm{m}}+\right.$ $\mathrm{x}$ ) eingesetzt, wobei $\mathrm{V}_{\max }$ für die maximale Umsatzgeschwindigkeit steht.

\section{Tabelle 2.3: Verwendete Software}

\begin{tabular}{ll}
\hline Programm & Hersteller \\
\hline Microsoft Excel 2010 & Microsoft Corporation (Redmond, WA, USA) \\
Sigmaplot Version 12.0 & Systat (Chicago, IL, USA) \\
\hline
\end{tabular}




\subsection{Proteinbestimmung nach Bradford}

Um die Ergebnisse der PAH-Aufnahme nicht ausschließlich pro Well angeben zu können, sondern auch einen Anhaltspunkt zur Menge der Zellen in mg Protein zu haben, wurde repräsentativ für alle Versuche eine Proteinbestimmung von je 6 Wells der ausgesäten und über 3 Tage kultivierten Zellen durchgeführt. Dies diente unter anderem der Vergleichbarkeit der von mir durchgeführten Methodik mit denen anderer Studien.

Die Proteinbestimmung erfolgte unabhängig von den Aufnahmeversuchen. Die Proteinbestimmungen unterlagen sehr geringen Schwankungen, wurden deshalb nicht bei jedem Versuch, sondern repräsentativ für alle Versuche am Ende der Messungen durchgeführt. Bei der verwendeten Proteinbestimmung nach Bradford handelt es sich um ein gängiges Standardverfahren. Durchgeführt wurde die Proteinbestimmung nach dem leicht modifizierten „Standard Operation Protokoll“ von PortaCellTec Biosciences GmbH.

Tabelle 2.4: Materialien für die Proteinbestimmung

\begin{tabular}{|c|c|c|}
\hline Materialien/Chemikalien/Geräte & $\begin{array}{l}\text { Zusätzliche } \\
\text { Angaben }\end{array}$ & Hersteller \\
\hline 1,5 ml Reaktionsgefäße & & $\begin{array}{l}\text { Sarstedt (Nümbrecht, } \\
\text { Deutschland) }\end{array}$ \\
\hline bovines Serumalbumin (BSA) & & Serva (Heidelberg, Deutschland) \\
\hline Ethanol $(96 \%)$ & $\begin{array}{l}\text { unvergällt, zur } \\
\text { Analyse }\end{array}$ & $\begin{array}{l}\text { Carl Roth GmbH (Karlsruhe, } \\
\text { Deutschland) }\end{array}$ \\
\hline Filter & & $\begin{array}{l}\text { Sarstedt (Nümbrecht, } \\
\text { Deutschland) }\end{array}$ \\
\hline Lysispuffer & & $\begin{array}{l}\text { Promega Corporation (Madison, } \\
\text { WI, USA) }\end{array}$ \\
\hline Microplate Reader & Mithras & $\begin{array}{l}\text { Berthold Technologies GmbH } \\
\text { (Bad Wildbad, Deutschland) }\end{array}$ \\
\hline Mikrotiterplatten & Flat bottom & $\begin{array}{l}\text { Sarstedt (Nümbrecht, } \\
\text { Deutschland) }\end{array}$ \\
\hline PBS-Puffer & $\begin{array}{l}1 \times \text { Dulbecco's pH 7,4 } \\
(9,55 \mathrm{~g} / \mathrm{L})\end{array}$ & $\begin{array}{l}\text { AppliChem (Darmstadt, } \\
\text { Deutschland) }\end{array}$ \\
\hline Phosphorsäure (85\%) & & $\begin{array}{l}\text { Carl Roth GmbH (Karlsruhe, } \\
\text { Deutschland) }\end{array}$ \\
\hline Pipetten & $10 \mu \mathrm{l} ; 200 \mu \mathrm{l} ; 1000 \mu \mathrm{l}$ & $\begin{array}{l}\text { Eppendorf (Hamburg, } \\
\text { Deutschland) }\end{array}$ \\
\hline Serva blue $\mathrm{G}$ & $\begin{array}{l}\text { basiert auf } \\
\text { Coomassie Blue G } \\
250\end{array}$ & Serva (Heidelberg, Deutschland) \\
\hline Sterile Pipettenspitzen & $10 \mu \mathrm{l} ; 200 \mu \mathrm{l} ; 1000 \mu \mathrm{l}$ & $\begin{array}{l}\text { Sarstedt (Nümbrecht, } \\
\text { Deutschland) }\end{array}$ \\
\hline
\end{tabular}




\section{Herstellung der Bradford-Reagenz:}

Für 250 ml Bradford-Reagenz wird benötigt:

$70 \mathrm{mg}$ Serva Blue $\mathrm{G}$

$50 \mathrm{ml}$ Ethanol (96\%)

$100 \mathrm{ml}$ Phosphorsäure (85\%)

$30 \mathrm{ml} \mathrm{H}_{2} \mathrm{O}$

Die Inhaltstoffe wurden mehrere Stunden unter Rühren gelöst, filtriert und bei $4{ }^{\circ} \mathrm{C}$ im Dunkeln aufbewahrt.

\section{Lysieren der Zellen:}

Die Zellen der 24-Well-Platte wurden 3 Mal mit PBS gewaschen und anschließend bei $-20^{\circ} \mathrm{C}$ eingefroren. Die Proteinbestimmung der Zellen konnte nach dem Auftauen zu einem beliebigen Zeitpunkt stattfinden.

Dazu wurden die Zellen aufgetaut und mit $100 \mu$ 1:5 in PBS verdünntem Lysispuffer inkubiert und 30 Minuten auf den Schüttler gestellt, um die Zellen aufzulösen.

Danach wurde pro Well $1900 \mu$ I PBS hinzugegeben und die Lösung durch mehrmaliges Aufund Abpipettieren homogenisiert. Nach dem Standardprotokoll wird nur $900 \mu \mathrm{l}$ PBS hinzugegeben, es war jedoch sinnvoll, die Lösung doppelt so stark zu verdünnen, damit die gemessenen Absorptionen nicht außerhalb der Eichgrade liegen. Die doppelte Verdünnung wurde bei Auswertung der Ergebnisse berücksichtigt.

\section{Proteinbestimmung:}

Für die Erstellung einer Eichgrade werden Bovine Serumalbumin (BSA) Standards mit folgenden Konzentrationen (in $\mu \mathrm{g} / \mathrm{ml}$ ) verwendet: 0, 50, 75, 100, 150, 200, 250, 300.

Die BSA-Standards wurden aliquotiert, bei $-20^{\circ} \mathrm{C}$ gelagert und für die Messung aufgetaut. Je zweimal $20 \mu \mathrm{l}$ (Doppelbestimmung) der BSA-Standards und der verdünnten Proben wurden in eine 96-Well-Platte pipettiert. Es erfolgte die Zugabe von $200 \mu l$ 1:4 in PBS verdünnter Bradford-Reagenz in jeden Well. Danach wurde die Platte 20 Minuten bei Raumtemperatur inkubiert und die Absorption bei $590 \mathrm{~nm}$ im Berthold Microplate Reader gemessen. 


\section{Ergebnisse}

\subsection{Aufnahme von PAH als Funktion der Inkubationszeit}

Um eine geeignete Aufnahmezeit für die Versuche zu ermitteln, wurden zunächst Zeitreihen bei $\mathrm{pH}$ 7,4 und pH 6,4 angefertigt. Dabei wurden sowohl OAT1-transfizierte HEK293-Zellen als auch Vektor-transfizierte Zellen für unterschiedliche Zeiträume mit 0,5 mikromolarer $\left[{ }^{3} \mathrm{H}\right]$ $\mathrm{PAH}$-Lösung inkubiert und die Aufnahme von PAH gemessen.

A

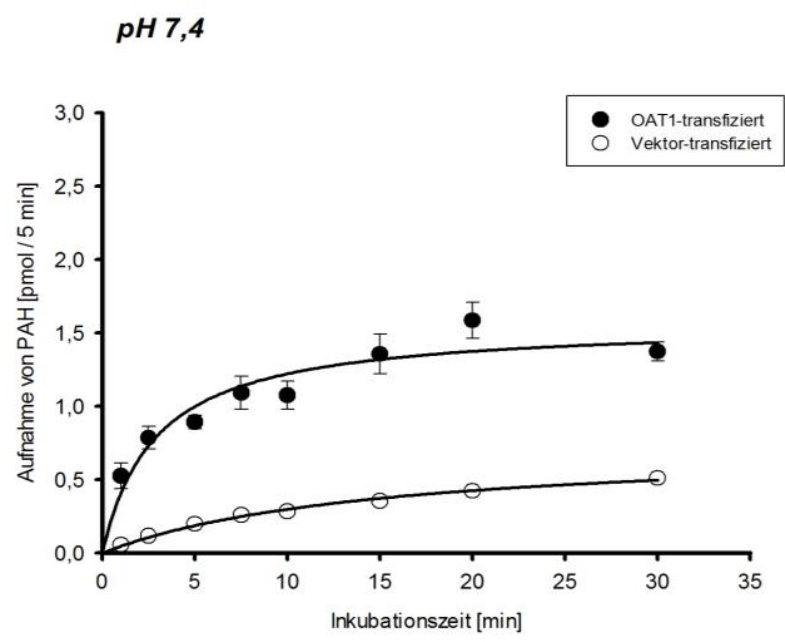

B

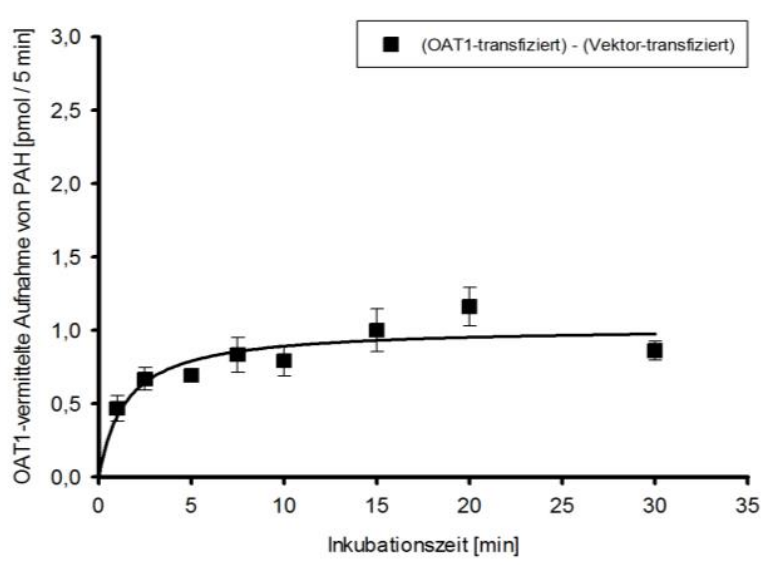

Abbildung 3.1: Aufnahme von 0,5 $\mu$ M [ $\left.{ }^{3} \mathrm{H}\right]-\mathrm{PAH}$ als Funktion der Inkubationszeit bei pH 7,4. In A sind OAT1-transfizierte und Vektor-transfizierte HEK293-Zellen abgebildet, während in B die Differenz der Aufnahme von OAT1-transfizierten und Vektor-transfizierten Zellen gebildet wurde. Jeder Messpunkt stellt das arithmetische Mittel von insgesamt 9 Messwerten aus 3 unterschiedlichen Experimenten mit unterschiedlichen Zellpassagen \pm Standardfehler dar. 
A

pH 6,4

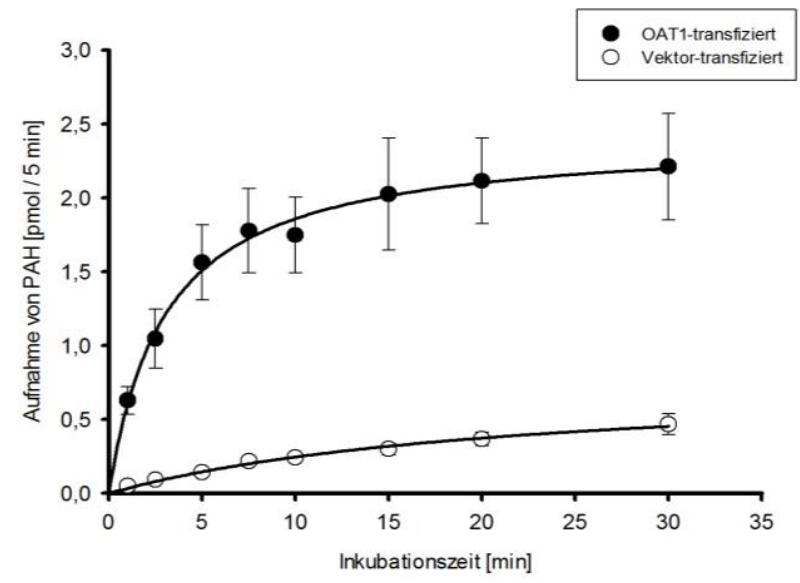

B

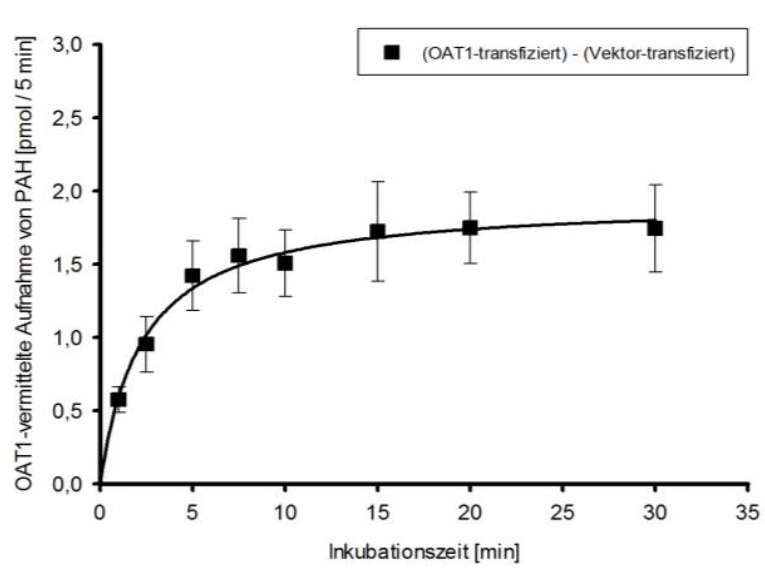

Abbildung 3.2: Aufnahme von 0,5 $\mu \mathrm{M}\left[{ }^{3} \mathrm{H}\right]-\mathrm{PAH}$ als Funktion der Inkubationszeit bei pH 6,4. In A sind OAT1-transfizierte und Vektor-transfizierte HEK293-Zellen abgebildet, während in B die Differenz der Aufnahme von OAT1-transfizierten und Vektor-transfizierten Zellen gebildet wurde. Jeder Messpunkt stell das arithmetische Mittel von insgesamt 6 Messwerten aus 2 unterschiedlichen Experimenten mit unterschiedlichen Zellpassagen \pm Standardfehler dar.

In dem gewählten Zeitrahmen zeigen sowohl OAT1- als auch Vektor-transfizierte HEK293Zellen eine Aufnahme von PAH. Während die Aufnahme von $\mathrm{PAH}$ in den Vektortransfizierten Zellen unabhängig vom pH-Wert war, nahmen OAT1-transfizierte HEK293Zellen bei $\mathrm{pH}$ 6,4 nach 5-minütiger Inkubation mit 1,56 $\pm 0,25$ pmol signifikant ( $p<0,01$ ) mehr PAH auf als bei pH 7,4 (0,89 $\pm 0,05$ pmol). Die Aufnahme von PAH in OAT1transfizierten Zellen nahm in den ersten 5 - 7 Minuten kontinuierlich zu und zeigte, unabhängig vom pH-Wert im Medium, ab ca. 7,5 Minuten Sättigungsverhalten. In allen weiteren Experimenten wurde die Aufnahme von PAH über 5 Minuten gemessen, da in dieser Zeitspanne die PAH-Aufnahme bei beiden $\mathrm{pH}$-Werten annähernd linear erfolgte. 


\subsection{Aufnahme von PAH in Abhängigkeit von der Zellpassage}

In Tabelle 3.1 wurden die PAH-Aufnahmen von OAT1-transfizierten HEK293-Zellen aller Versuche aufgelistet, um diese miteinander zu vergleichen.

Tabelle 3.1: Aufnahme von PAH in Abhängigkeit von der Zellpassage

\begin{tabular}{|c|c|c|c|}
\hline Experiment: & Zeitreihe 1 & Zeitreihe 2 & Zeitreihe 3 \\
\hline Zellpassage & 99 & 101 & 103 \\
\hline PAH-Aufnahme [pmol / $5 \mathrm{~min}]$ & 1,03 & 0,85 & 0,80 \\
\hline Experiment: & $\begin{array}{l}\mathrm{K}_{\mathrm{m}} \text { Bestimmung } \\
1\end{array}$ & $\begin{array}{l}\mathrm{K}_{\mathrm{m}} \text { Bestimmung } \\
2\end{array}$ & $\begin{array}{l}\mathrm{K}_{\mathrm{m}} \text { Bestimmung } \\
3\end{array}$ \\
\hline Zellpassage & nicht bekannt & nicht bekannt & nicht bekannt \\
\hline PAH-Aufnahme [pmol / $5 \mathrm{~min}]$ & 3,6 & 3,7 & 4,0 \\
\hline Experiment: & $\begin{array}{l}\mathrm{K}_{\mathrm{m}} \text { Bestimmung } \\
4\end{array}$ & & \\
\hline Zellpassage & nicht bekannt & & \\
\hline PAH-Aufnahme [pmol / $5 \mathrm{~min}]$ & 1,5 & & \\
\hline Experiment: & Probenecid 1 & Probenecid 2 & Probenecid 3 \\
\hline Zellpassage & 98 & 99 & 101 \\
\hline PAH-Aufnahme [pmol / $5 \mathrm{~min}]$ & 1,54 & 0,97 & 1,18 \\
\hline Experiment: & $\mathrm{HCO}_{3}^{-} 1$ & $\mathrm{HCO}_{3}^{-} 2$ & $\mathrm{HCO}_{3}^{-} 3$ \\
\hline Zellpassage & 92 & 95 & 96 \\
\hline PAH-Aufnahme [pmol / $5 \mathrm{~min}]$ & 0,83 & 0,85 & 1,06 \\
\hline Experiment: & $\mathrm{HCO}_{3}^{-} 4$ & & \\
\hline Zellpassage & 94 & & \\
\hline PAH-Aufnahme [pmol / $5 \mathrm{~min}]$ & 1,1 & & \\
\hline Experiment: & SITS 1 & SITS 2 & SITS 3 \\
\hline Zellpassage & 68 & 68 & 69 \\
\hline PAH-Aufnahme [pmol / $5 \mathrm{~min}]$ & 1,27 & 1,06 & 1,55 \\
\hline Experiment: & $\mathrm{CCCP} \mathrm{IC}_{50} 1$ & CCCP IC ${ }_{50} 2$ & CCCP IC 50 \\
\hline Zellpassage & 94 & 95 & 96 \\
\hline PAH-Aufnahme [pmol / $5 \mathrm{~min}]$ & 1,43 & 1,46 & 1,18 \\
\hline Experiment: & СССР 1 & СССР 2 & СССР 3 \\
\hline Zellpassage & 97 & 98 & 99 \\
\hline PAH-Aufnahme [pmol / $5 \mathrm{~min}]$ & 0,9 & 1,17 & 2,31 \\
\hline Experiment: & СССР (vorink.) 1 & СССР (vorink.) 2 & CCCP (vorink.) 3 \\
\hline Zellpassage & 100 & 102 & 104 \\
\hline PAH-Aufnahme [pmol / $5 \mathrm{~min}]$ & 0,62 & 1,72 & 1,07 \\
\hline Experiment: & Amilorid 1 & Amilorid 2 & Amilorid 3 \\
\hline Zellpassage & 71 & 71 & 72 \\
\hline PAH-Aufnahme [pmol / $5 \mathrm{~min}]$ & 1,30 & 1,88 & 1,88 \\
\hline
\end{tabular}


In allen in Tab. 3.1 aufgeführten Experimenten betrug die Konzentration an [ $\left.{ }^{3} \mathrm{H}\right]-\mathrm{PAH}$ 0,5 $\mu \mathrm{M}$ und die Zeit, über die die PAH-Aufnahme gemessen wurde, 5 Minuten. Die angegebenen Werte beziehen sich jeweils auf die Proben, denen nichts weiter als das $\left[{ }^{3} \mathrm{H}\right]-\mathrm{PAH}$ in Ringerlösung zugesetzt wurde. Da an einigen Tagen mehrere unterschiedliche Versuche durchgeführt wurden, und jeweils die Aufnahme von PAH gemessen werden musste, erscheinen einige Passagen mehrfach. Dies erklärt sich auch dadurch, dass teilweise frische Zellen aus niedrigeren Passagen aufgetaut werden mussten, wodurch sich Passagen wiederholen. Die Abkürzungen stehen für die einzelnen unterschiedlichen Bedingungen, die in den folgenden Versuchen ausführlich erklärt werden.

Es wurden insgesamt 29 Versuche zur Aufnahme von 0,5 $\mu \mathrm{M}\left[{ }^{3} \mathrm{H}\right]-\mathrm{PAH}$ bei $\mathrm{pH} 7,4$ durchgeführt. Als niedrigste Zellpassage wurde Passage 68, als höchste Passage 104 verwendet. Bei vier Versuchen war die Passagennummer unbekannt. Zellpassage 99 wurde insgesamt dreimal, die Passagen 68, 71, 94, 95, 96, 98, 101 und 103 zweimal und alle anderen Passagen einmal eingesetzt. Die absolute Aufnahme von PAH unterlag großen Schwankungen; es war jedoch keine Tendenz auszumachen, dass niedrigere Zellpassagen mehr PAH aufnehmen als höhere. Auch innerhalb der Zellpassage 99 variierte die Aufnahme von $\mathrm{PAH}$ von 0,97 auf 1,03 und 2,31 pmol / 5 min. 


\subsection{Einfluss von Probenecid}

Die Aufnahme von $\mathrm{PAH}$ wurde bei $\mathrm{pH} 7,4$ und $\mathrm{pH}$ 6,4 in An- und Abwesenheit von Probenecid gemessen, um zu testen, ob die Wirkung von Probenecid pH-abhängig ist.

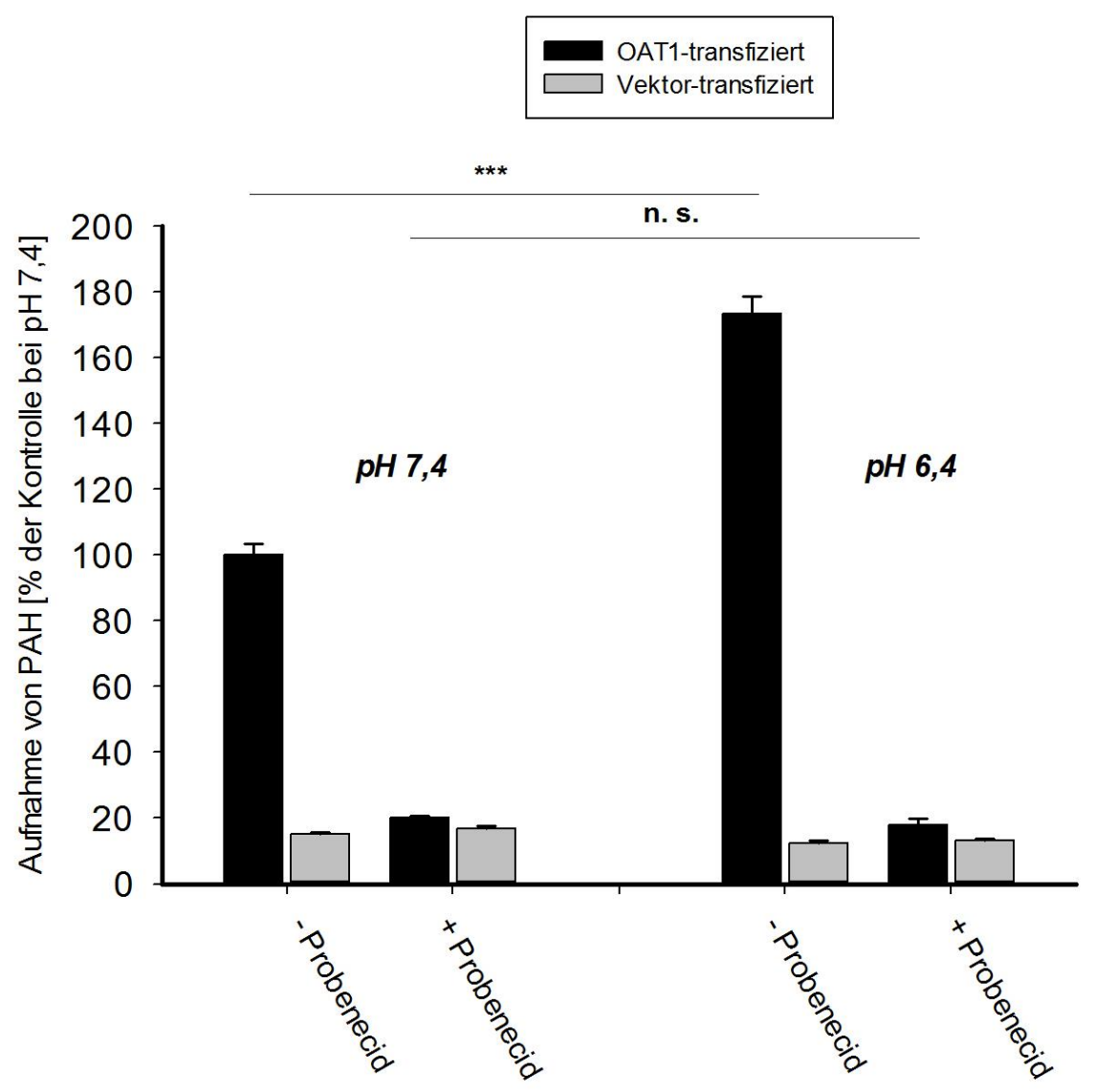

Abbildung 3.3: Probenecid-abhängige Hemmung der Aufnahme von PAH. Die Aufnahme von 0,5 $\mu M\left[{ }^{3} \mathrm{H}\right]-P A H$ wurde über 5 Minuten in Ab-und Anwesenheit von $100 \mu M$ Probenecid bei $p H$ 7,4 und pH 6,4 gemessen. Jede Säule fasst insgesamt 9 Messwerte aus 3 Experimenten unterschiedlicher Zellpassagen \pm Standardfehler zusammen; ${ }^{* * *} p<0,001 ; n$. s. nicht signifikant

Während die Aufnahme von $\mathrm{PAH}$ bei $\mathrm{pH} 6,4$ gegenüber $\mathrm{pH} 7,4$ auf $173 \pm 5,4 \%$ gesteigert war, hemmten $100 \mu \mathrm{M}$ Probenecid bei beiden pH Werten die Aufnahme von PAH annähernd auf das Niveau der PAH-Aufnahme Vektor-transfizierter Zellen. So wurde die Aufnahme von $\mathrm{PAH}$ in Anwesenheit von Probenecid bei pH 7,4 im Mittel auf 20,2 \pm 0,6\% und bei pH 6,4 auf $18,0 \pm 2,0 \%$ des Ausgangswertes in Abwesenheit von Probenecid gehemmt. Zum Vergleich lagen die Vektor-transfizierten Zellen bei $\mathrm{pH} 7,4$ bei 16,8 $\pm 0,7 \%$ und $13,2 \pm 0,7 \%$ bei $\mathrm{pH}$ 6,4. In Anwesenheit von Probenecid konnte kein signifikanter Unterschied in der PAHAufnahme bei $\mathrm{pH}$ 6,4 und 7,4 festgestellt werden. 


\subsection{Bestimmung der Michaelis-Menten-Konstante $\left(\mathrm{K}_{\mathrm{m}}\right)$ bei verschiedenen $\mathrm{pH}-$ Werten}

Der experimentelle $\mathrm{K}_{\mathrm{m}}$-Wert schwankt je nach Studie relativ stark (siehe Diskussion). Wie sich dieser Wert bei unterschiedlichen $\mathrm{pH}$-Werten verhält, kann helfen, die Transportmechanismen genauer zu verstehen. Zur Bestimmung der Michaelis-MentenKonstanten wurden PAH Konzentrationen von 0,5 bis 50 bzw. $100 \mu \mathrm{M}$ eingesetzt. Um nicht zu viel Radioaktivität verwenden zu müssen, wurde jedem Ansatz nur 0,5 $\mu \mathrm{M}\left[{ }^{3} \mathrm{H}\right]-\mathrm{PAH}$ zugesetzt und der restliche Teil mit nicht-markiertem PAH aufgefüllt. Bei der Auswertung der Daten wurde dann ein entsprechender Faktor berücksichtigt.
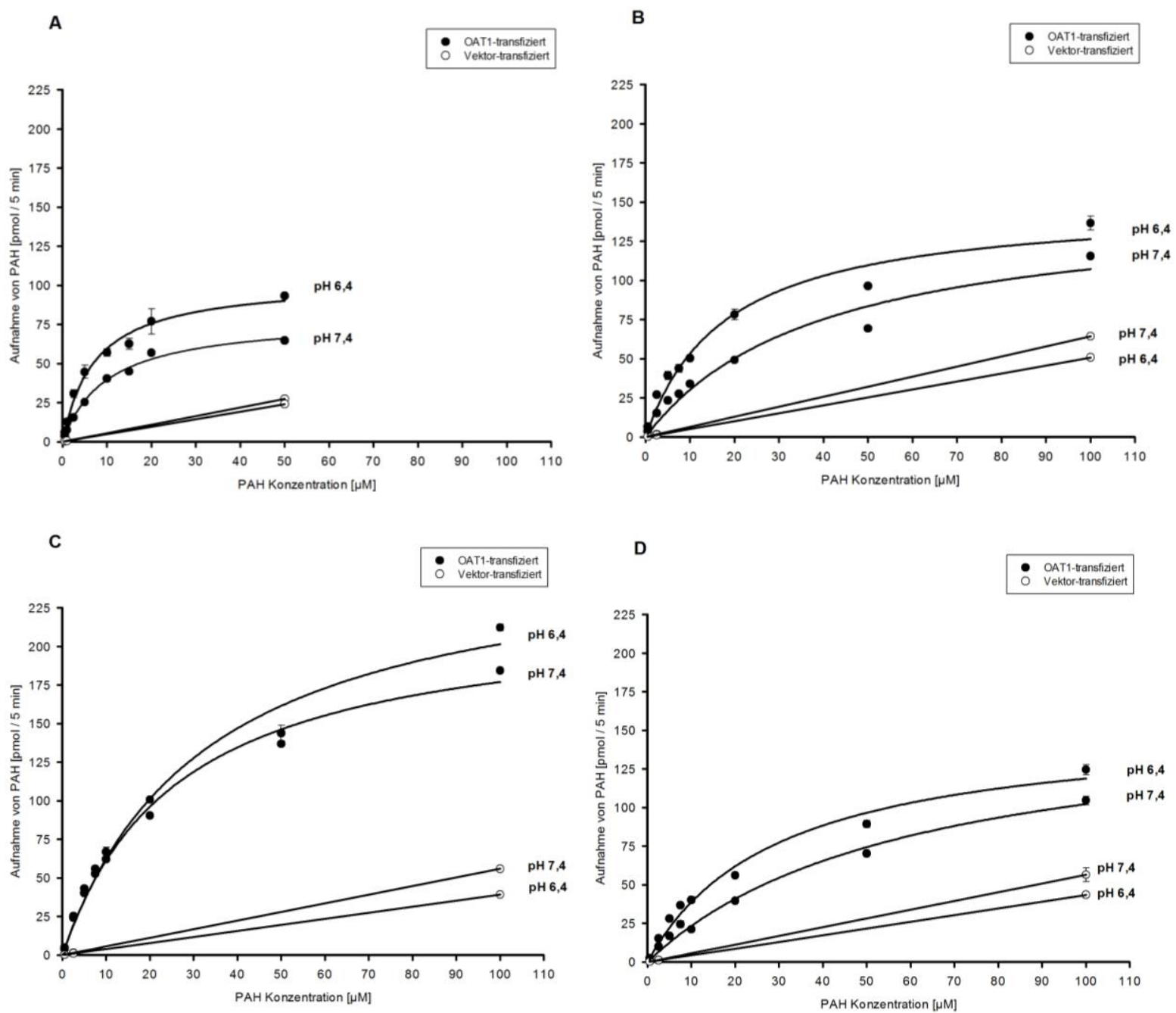

Abbildung 3.4: Konzentrationsabhängigkeit der Aufnahme von $P A H$ bei $p H 7,4$ und 6,4. In $A-D$ sind die vier Experimente zur Bestimmung der $K_{m}$ dargestellt. Die PAH-Aufnahme der Vektortransfizierten Zellen wurde jeweils bei den beiden niedrigsten und der höchsten Konzentration gemessen, wobei eine lineare Zunahme der intrazellulären PAH-Aufnahme angenommen wurde. Jeder Messpunkt stellt das arithmetische Mittel aus 3 Messwerten innerhalb des Experimentes \pm Standardfehler dar. 

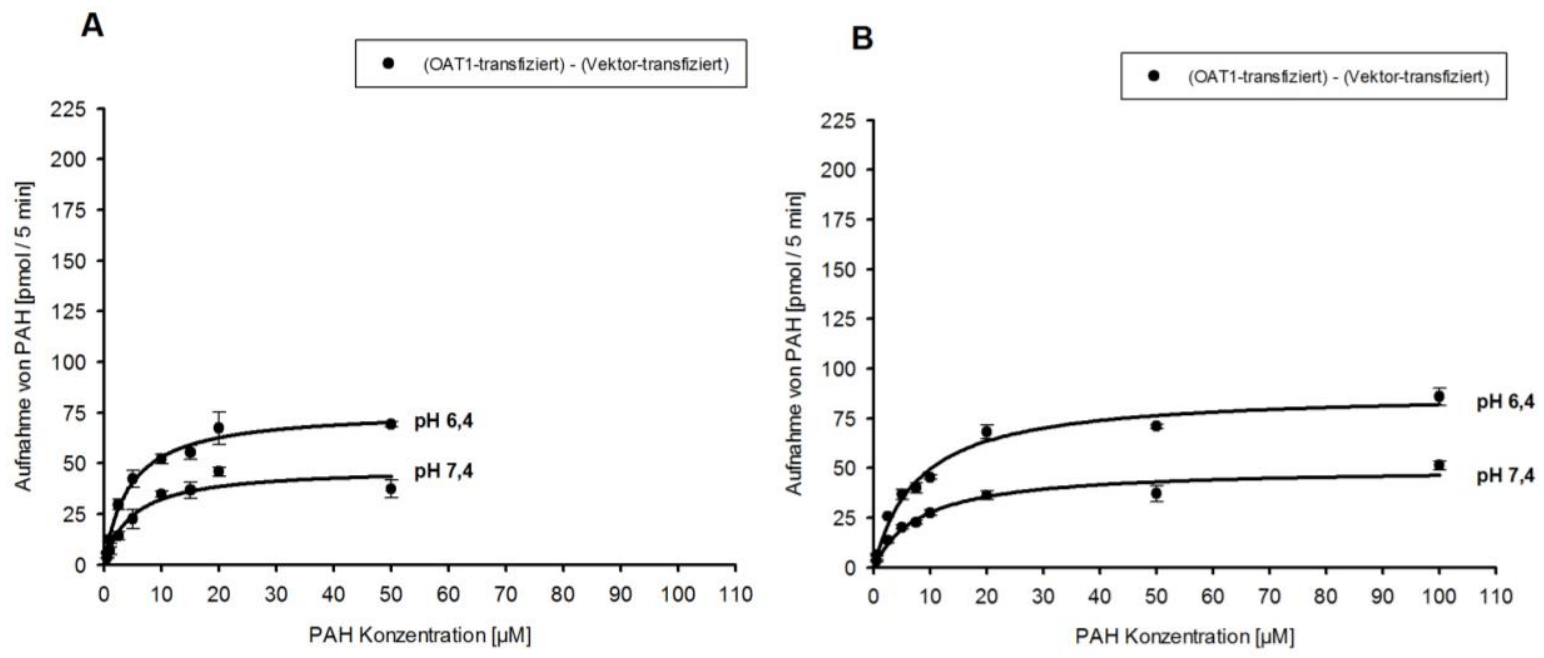

C

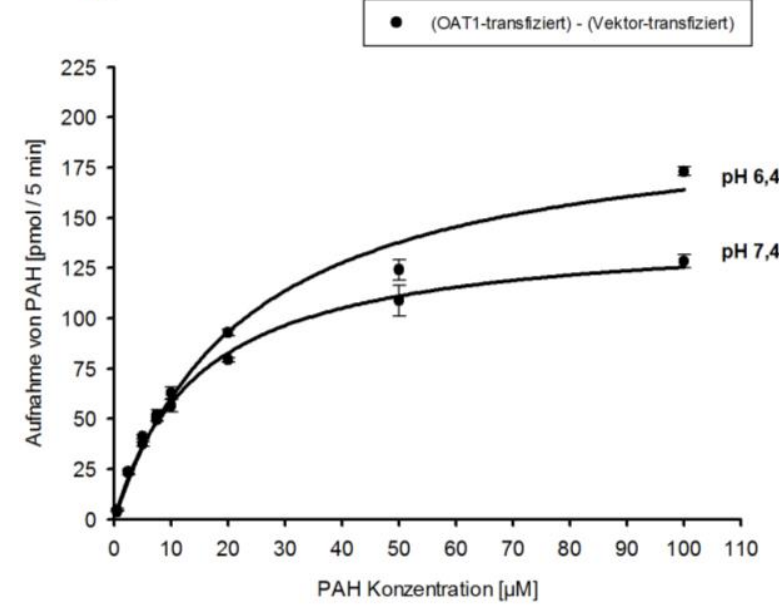

D

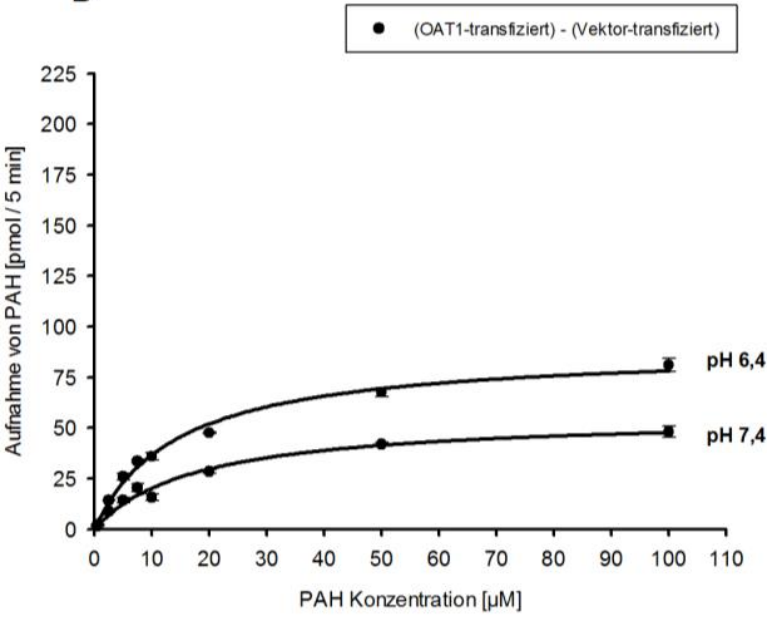

Abbildung 3.5: Aufnahme von PAH nach Abzug der Vektor-transfizierten Zellen. In A-D sind die vier Experimente zur Bestimmung der Konzentrationsabhängigkeit dargestellt, nachdem von den Werten für die Aufnahme von PAH von den OAT1-transfizierten Zellen die Aufnahme der Vektortransfizierten Zellen abgezogen wurde. Jeder Messpunkt stellt das arithmetische Mittel aus 3 Messwerten innerhalb des Experiments \pm Standardfehler dar. 
A

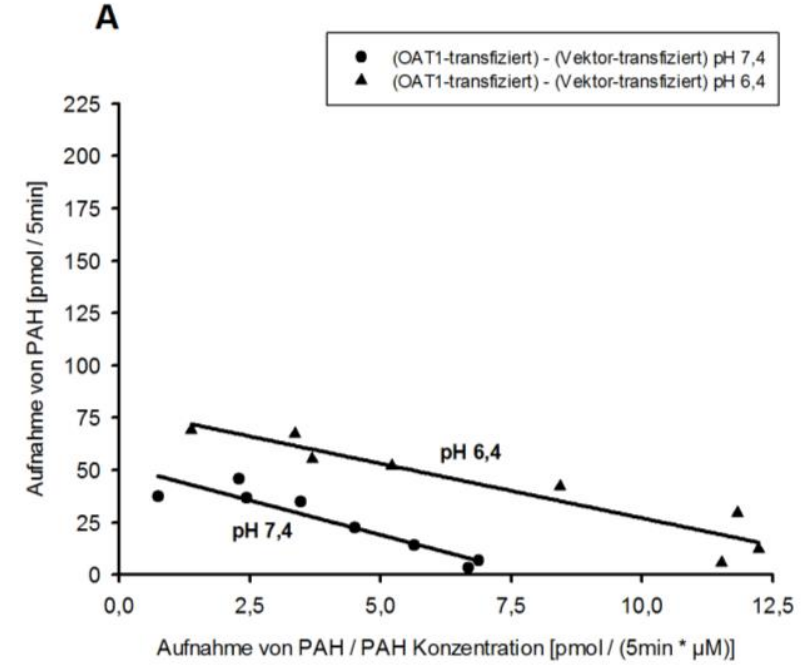

C

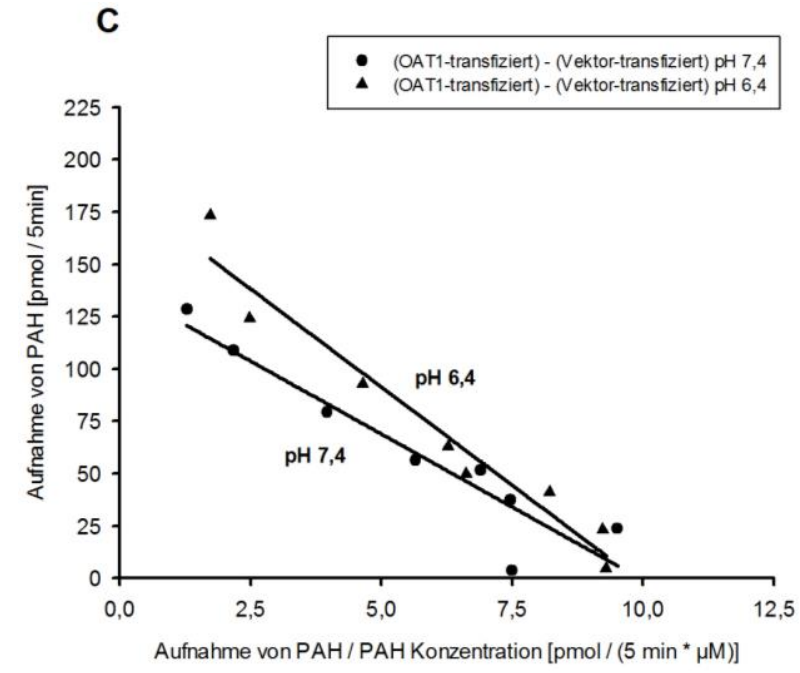

B

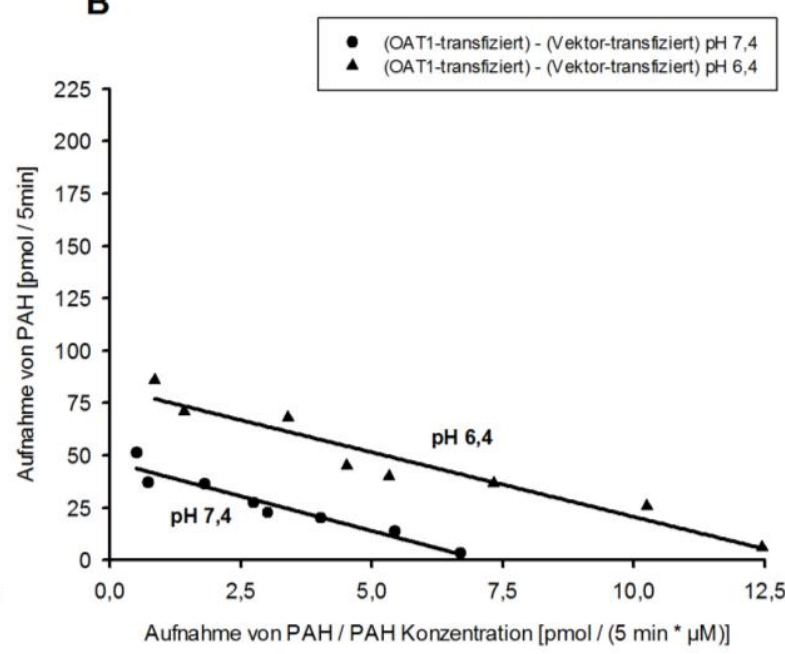

D

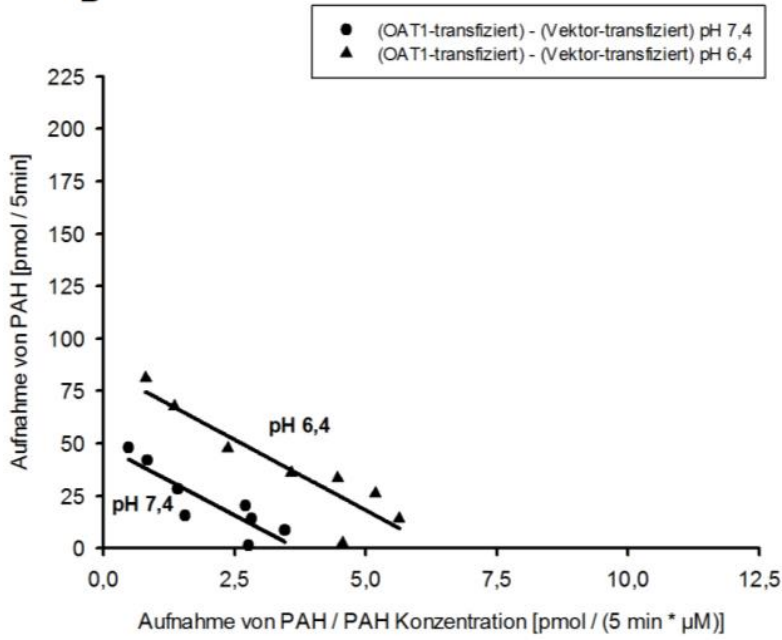

Abbildung 3.6: Auftragen der Daten nach Eadie-Hofstee. In A-D sind die aus Abb. 3.5 bekannten Daten als Eadie-Hofstee-Diagramm aufgetragen. Auf der y-Achse wird die Umsatzgeschwindigkeit und auf der $x$-Achse die Umsatzgeschwindigkeit geteilt durch die Substratkonzentration aufgetragen. Die Steigung der Graden entspricht der $K_{m}{ }^{*}-1$.

In Abb. 3.6 wurden die Daten nach Eadie-Hofstee aufgetragen. An den 2 parallelen Graden in $A, B$ und $D$ ist dort gut erkennbar, dass nur die maximale Aufnahme, nicht aber die Steigung und damit die $\mathrm{K}_{\mathrm{m}}$ verändert sind. Warum das Ergebnis $\mathrm{C}$ herausfällt, konnte nicht geklärt werden. 
Die $\mathrm{K}_{\mathrm{m}}$-Werte für die OAT1-vermittelte Aufnahme von PAH in OAT1-transfizierten HEK293Zellen wurden aus den in Abb. 3.5 dargestellten Daten berechnet und sind in Tab. $3.3 \mathrm{zu}$ sehen.

Tabelle 3.3: $\mathrm{K}_{\mathrm{m}}$-Werte

\begin{tabular}{lll}
\hline Versuch Nr. & $\mathrm{K}_{\mathrm{m}}$ bei $\mathbf{p H ~} \mathbf{6 , 4}[\boldsymbol{\mu M}]$ & $\mathbf{K}_{\mathrm{m}}$ bei $\mathbf{p H ~ 7 , 4}[\boldsymbol{\mu M}]$ \\
\hline 1 & 4,37 & 4,82 \\
2 & 7,83 & 8,17 \\
3 & 23,4 & 14,86 \\
4 & 14,41 & 17,83 \\
\hline
\end{tabular}

Der Mittelwert für die $\mathrm{K}_{\mathrm{m}}$ lag bei $\mathrm{pH} 6,4$ bei $12,50 \pm 3,63 \mu \mathrm{M}$, bei pH 7,4 bei $11,42 \pm 2,59 \mu \mathrm{M}$. Der Unterschied war nicht signifikant. Die $\mathrm{K}_{\mathrm{m}}$ schwankte bei pH 6,4 zwischen 4,37 und 23,40 $\mu \mathrm{M}$, bei $\mathrm{pH} 7,4$ zwischen 4,82 und $17,83 \mu \mathrm{M}$.

In Tab. 3.4 sind die maximalen Umsatzgeschwindigkeiten $\left(\mathrm{V}_{\max }\right)$ für die OAT1-vermittelte Aufnahme von PAH der 4 Versuche aufgelistet, die ebenfalls aus den in Abb. 3.5 dargestellten Daten berechnet wurden.

Tabelle 3.4: $\mathrm{V}_{\max }-$ Werte

\begin{tabular}{lll}
\hline Versuch Nr. & $\mathbf{V}_{\max }$ bei pH 6,4 [pmol / 5 min] & $\mathbf{V}_{\max }$ bei pH 7,4 [pmol / 5 min] \\
\hline 1 & 76,35 & 47,85 \\
2 & 88,35 & 50,08 \\
3 & 202,35 & 144,19 \\
4 & 89,39 & 56,23 \\
\hline
\end{tabular}

Der Mittelwert für die $\mathrm{V}_{\max }$ lag bei $\mathrm{pH} 6,4$ bei $114,11 \pm 25,60 \mathrm{pmol} / 5 \mathrm{~min}$, bei $\mathrm{pH} 7,4$ bei $74,59 \pm 20,15$ pmol $/ 5$ min. Die $V_{\max }$ schwankte bei pH 6,4 zwischen 76,35 und 202,35, bei $\mathrm{pH}$ 7,4 zwischen 47,85 und 144,19 pmol / 5 min. In allen Experimenten war die $\mathrm{V}_{\max }$ bei $\mathrm{pH}$ 6,4 höher als bei pH 7,4 (siehe auch Abb. 3.7). Aufgrund der relativ großen Abweichungen der Transportrate zwischen den einzelnen Experimenten (besonders in Experiment 3), war die Änderung jedoch nicht signifikant. 


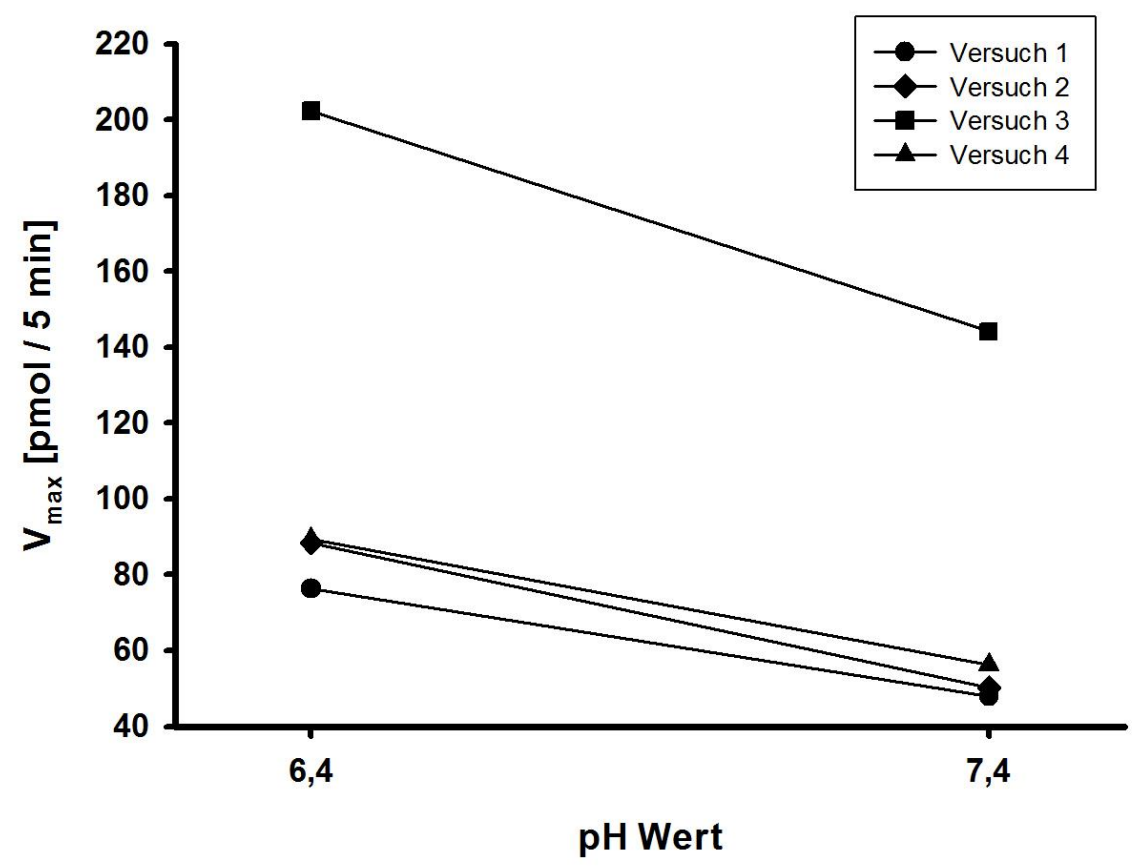

Abbildung 3.7: Vergleich der $V_{\max }$ bei $\mathrm{pH}$ 6,4 und 7,4. Bei allen Experimenten war die $V_{\max }$ bei $p H$ 7,4 im Vergleich zu pH 6,4 reduziert. 


\subsection{Einfluss von Carbonylcyanid-3-Chlorophenylhydrazon (CCCP)}

CCCP ermöglicht als Protonophor den Übertritt von Protonen über die Zellmembran und führt dadurch zu einem Angleichen von extra- und intrazellulärem $\mathrm{pH}$-Wert. In den folgenden Versuchen wurde der Einfluss von CCCP auf den OAT1 in HEK293-Zellen untersucht.

\subsubsection{Einfluss von CСCP bei unterschiedlichen $\mathrm{pH}-$ Werten in An- und Abwesenheit von Natrium}

Zunächst wurde getestet, wie sich die Aufnahme von PAH bei Zugabe von 2,5 $\mu \mathrm{M}$ CCCP bei $\mathrm{pH} 7,4$ und $\mathrm{pH} 6,4$ in An- und Abwesenheit von Natrium verhält (siehe Abbildung 3.8). Die Natriumabhängigkeit wurde mit in die Versuchsreihe aufgenommen, da HEK293-Zellen einen endogenen $\mathrm{Na}^{+} / \mathrm{H}^{+}$-Austauscher besitzen, dessen Aktivität die Versuchsergebnisse unter Umständen verfälschen könnte.

Natrium im Inkubationsmedium hatte weder bei $\mathrm{pH} 7,4$ noch bei $\mathrm{pH}$ 6,4 einen Einfluss auf die Aufnahme von PAH in OAT1-transfizierten HEK293-Zellen. Die PAH-Aufnahme in den Vektor-transfizierten Zellen war bei beiden $\mathrm{pH}$-Werten unter natriumfreien Bedingungen signifikant reduziert. Die Zugabe von CCCP reduzierte bei beiden $\mathrm{pH}-$ Werten die Aufnahme von PAH in den OAT1-transfizierten Zellen. Bei natriumhaltigem Ringer und einem pH-Wert von 7,4 ging die Aufnahme durch Zugabe von 2,5 $\mu \mathrm{M}$ CCCP von $100 \pm 1,6 \%$ auf 73,3 $\pm 2,0$ $\%$, unter natriumfreien Bedingungen von 99,4 $\pm 6,0 \%$ auf $56,4 \pm 2,8 \%$ zurück. Beide Rückgänge waren signifikant ( $p<0,001$ ). Bei $\mathrm{pH} 6,4$ ging mit natriumhaltigem Ringer das Niveau durch Zugabe von 2,5 $\mu \mathrm{M}$ CCCP von 136,9 $\pm 5,2 \%$ auf $110,3 \pm 4,6 \%$ signifikant zurück $(\mathrm{p}<0,01)$. Unter natriumfreien Bedingungen war bei $\mathrm{pH} 6,4$ ein signifikanter Rückgang von 143,2 \pm 9,9\% auf 94,1 $\pm 7,3 \%$ unter Einfluss von CCCP zu verzeichnen ( $p<$ 0,01). Unter natriumfreien Bedingungen war die Aufnahme bei $\mathrm{pH} 6,4 \mathrm{im}$ Vergleich zu pH 7,4 - wie auch in allen anderen Experimenten in denen natriumhaltiger Ringer eingesetzt wurde - signifikant erhöht $(p<0,001)$. Die geringste Aufnahme von PAH war unter natriumfreien Bedingungen und CCCP zu beobachten. CCCP hatte keinen Einfluss auf die PAH-Aufnahme in Vektor-transfizierten Zellen. 


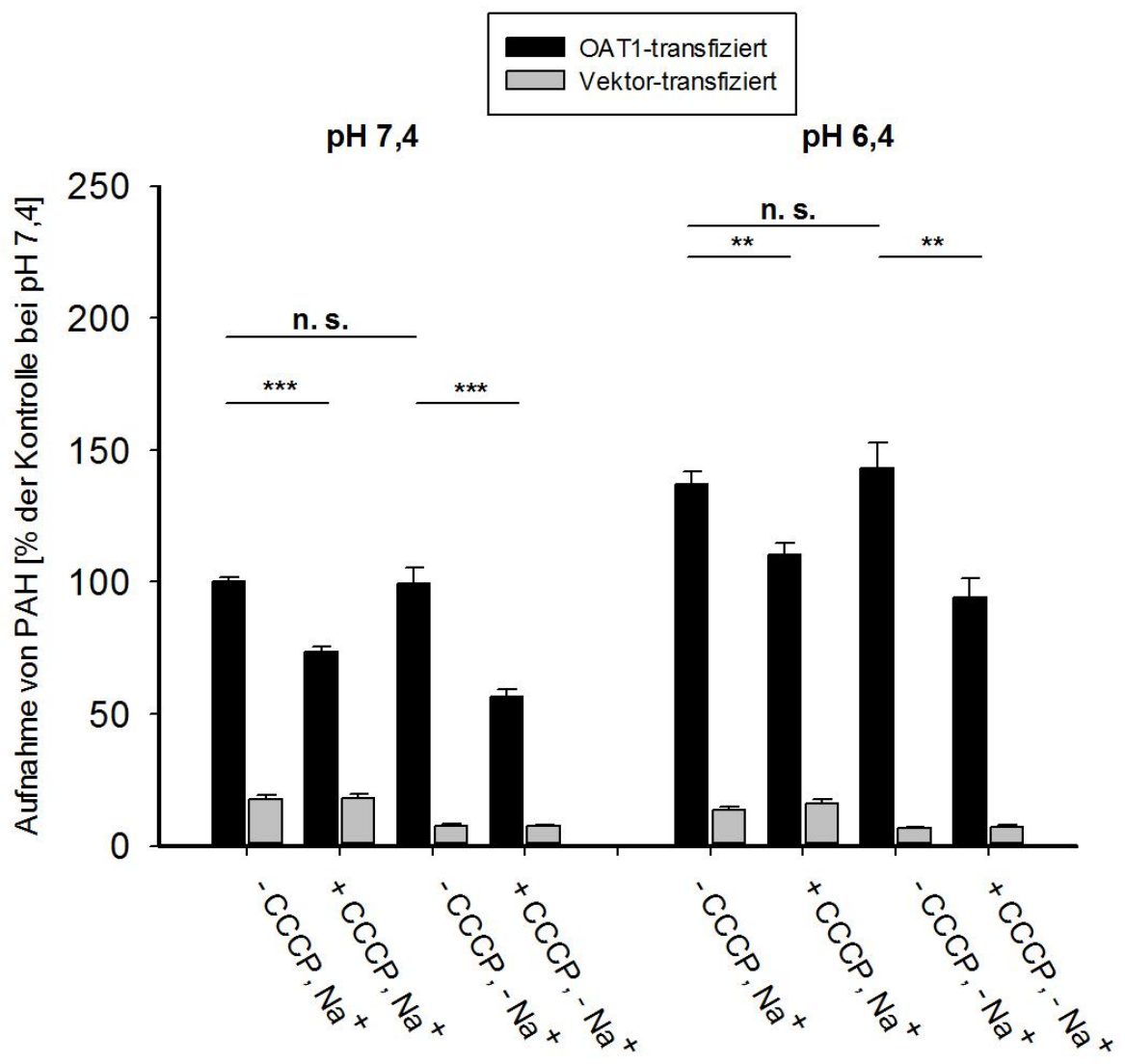

Abbildung 3.8: Einfluss von CCCP auf die PAH-Aufnahme. Jede Säule fasst 9 Messwerte aus 3 Experimenten mit unterschiedlichen Zellpassagen \pm Standardfehler zusammen. In jedem Experiment wurden die Messwerte auf die Standardbedingung $\mathrm{pH}$ 7,4 mit natriumhaltigem Ringer normiert. Natriumfreie Bedingungen wurden durch den Ersatz von Natrium durch N-Methyl-D-Glucamin erzielt. Die Aufnahmezeit betrug 5 Minuten, die Konzentration an $\left[{ }^{3} H\right]-P A H ~ 0,5 \mu M ;{ }^{* *} p<0,01 ;{ }^{* *} p<0,001$; n. s. nicht signifikant 


\subsubsection{Einfluss von CCCP bei unterschiedlichen pH-Werten in An- und Abwesenheit von Natrium nach 10-minütiger Vorinkubation}

Da in den in 3.5.1 beschriebenen Experimenten auch nach Zugabe von CCCP die Aufnahme von $\mathrm{PAH}$ bei $\mathrm{pH}$ 6,4 höher als bei $\mathrm{pH}$ 7,4 war, wurde spekuliert, dass bei simultaner Applikation von CCCP und dem Substrat PAH, der pH-Gradient über der Membran noch nicht zusammen gebrochen war. Deshalb wurden die Zellen 10 Minuten mit 2,5 $\mu \mathrm{M}$ CCCP vorinkubiert und anschließend die Aufnahme von $\mathrm{PAH}$ bei $\mathrm{pH} 6,4$ und 7,4 in An- und Abwesenheit von Natrium gemessen.

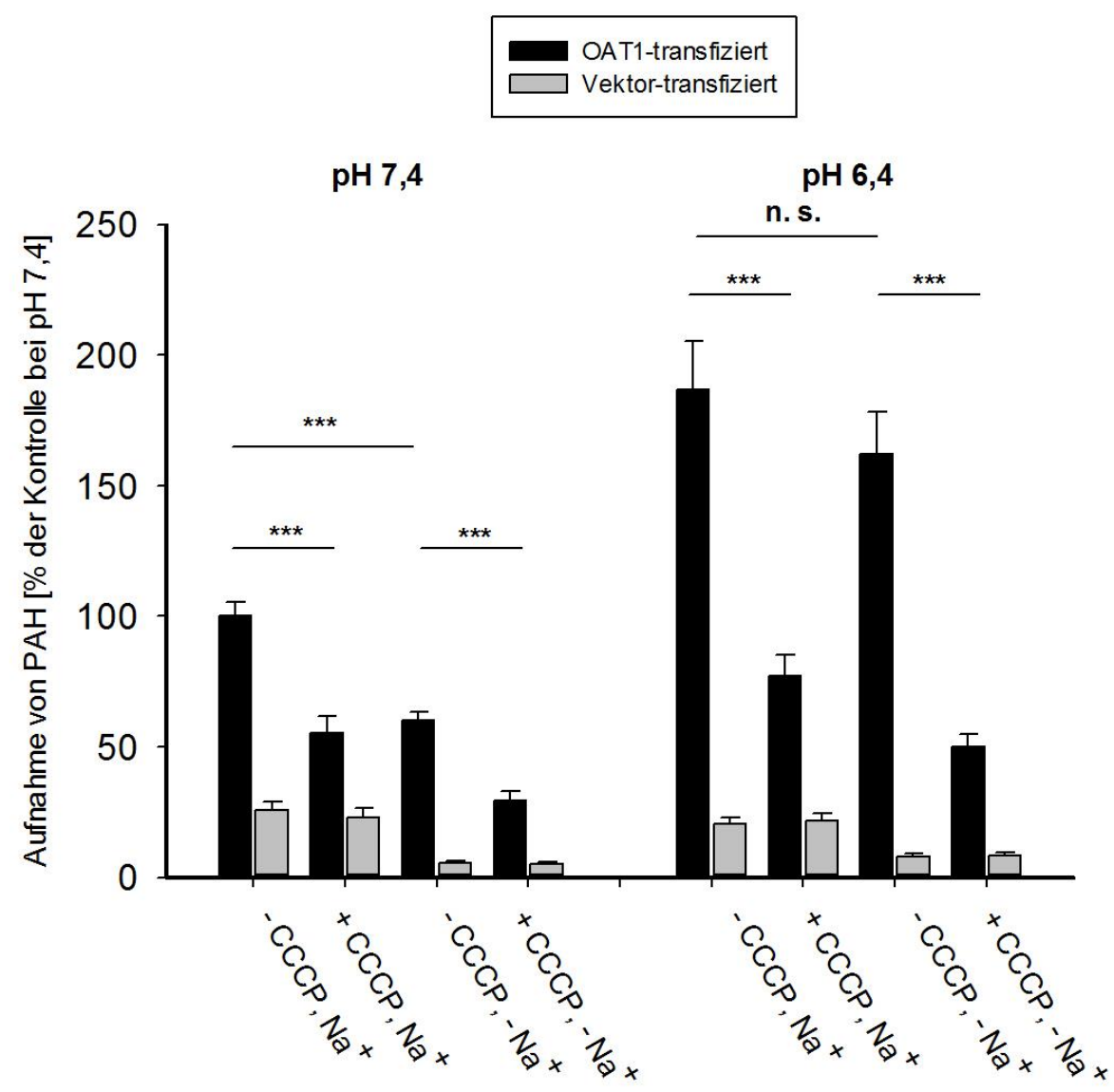

Abbildung 3.9: Einfluss von CCCP auf die PAH-Aufnahme bei 10-minütiger Vorinkubation. Alle Zellen wurden für 10 Minuten mit der jeweiligen Lösung (ohne $\left[{ }^{3} \mathrm{H}\right]-\mathrm{PAH}$ ) vorinkubiert, bevor das eigentliche Experiment startete. Jede Säule fasst 9 Messwerte aus 3 Experimenten mit unterschiedlichen Zellpassagen \pm Standardfehler zusammen. In jedem Experiment wurden die Messwerte auf die Standardbedingung $p H$ 7,4 mit natriumhaltigem Ringer normiert; ${ }^{\star \star \star} p<0,001 ; n$. s. nicht signifikant 
Bei 10-minütiger Vorinkubation ließen sich - im Gegensatz zum gleichen Experiment ohne Vorinkubation - signifikante Unterschiede von natriumhaltigen zu natriumfreien Ringer bei $\mathrm{pH}$ 7,4 feststellen ( $p<0,001$ ). Bei $\mathrm{pH} 6,4$ war die Transportrate zwar verringert, jedoch nicht signifikant. Die Hemmung durch 2,5 $\mu$ M CCCP war im Vergleich zu CCCP-freiem Ringer bei beiden $\mathrm{pH}$-Werten sowohl in An- als auch in Abwesenheit von Natrium signifikant $(\mathrm{p}<$ 0,001). Bei $\mathrm{pH} 7,4$ wurde eine Hemmung von $100 \pm 5,6 \%$ auf $55,2 \pm 6,4 \%$ bei natriumhaltigem und unter natriumfreien Bedingungen eine Hemmung von $60 \pm 3,5 \%$ auf $29,4 \pm 3,6 \%$ gemessen. Bei pH 6,4 fiel das Niveau von 186,8 $\pm 18,6 \%$ auf $76,9 \pm 8,4 \%$ bei natriumhaltigem und von $162,2 \pm 16,2 \%$ auf $49,9 \pm 4,8 \%$ bei natriumfreiem Ringer. Vergleicht man die Werte bei $\mathrm{pH} 6,4$ und $\mathrm{pH} 7,4$ unter Einfluss von CCCP, so war die Aufnahme unter natriumhaltigen Bedingungen bei $\mathrm{pH} 6,4$ zwar erhöht, jedoch nicht signifikant. Unter natriumfreien Bedingungen war die Aufnahme bei $\mathrm{pH} 6,4 \mathrm{im}$ Vergleich zu $\mathrm{pH} 7,4$ - wie auch in allen Experimenten in denen natriumhaltiger Ringer eingesetzt wurde signifikant erhöht $(p<0,001)$. 


\subsubsection{Bestimmung der halbmaximalen inhibitorischen Konzentration $\left(\mathrm{IC}_{50}\right)$ von CCCP}

In den vorangegangen Versuchsreihen war unter Einfluss von CCCP jeweils eine signifikante Reduktion der Aufnahme von PAH in OAT1-transfizierten HEK293-Zellen beobachtet worden. Um zu testen, ob durch höhere Dosen an CCCP eine vollständige Hemmung der Aufnahme von PAH zu erzielen ist und bei welcher Konzentration von CCCP die Aufnahme von $\mathrm{PAH}$ zu 50 \% gehemmt ist, wurde eine $\mathrm{IC}_{50}$ bestimmt.
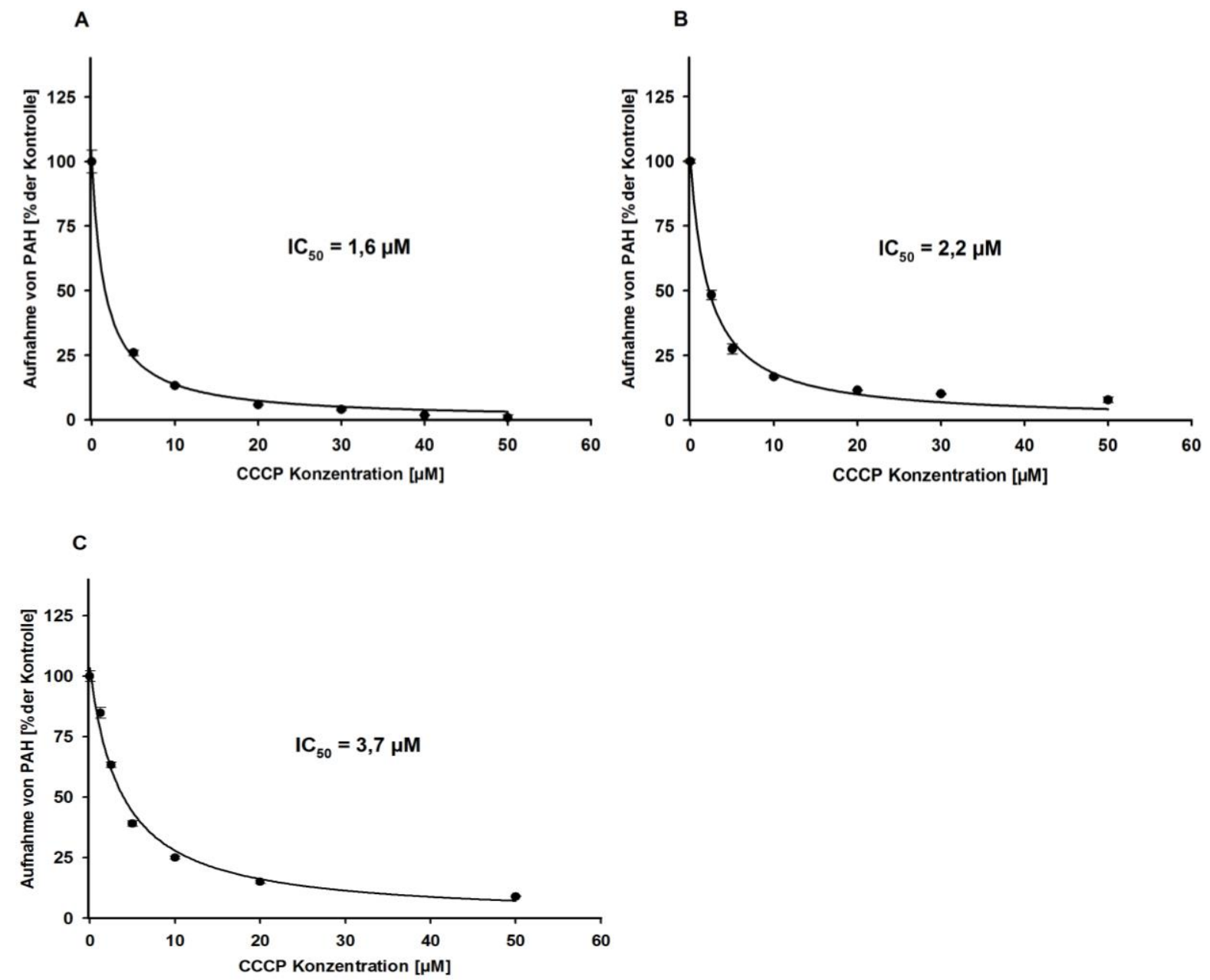

Abbildung 3.10: Bestimmung der IC $C_{50}$ von CCCP. Es wurde die PAH-Aufnahme in Abhängigkeit der CCCP Konzentration von 3 Versuchen $(\boldsymbol{A}-\boldsymbol{C})$ aufgetragen. Von den absoluten Werten wurden die Werte der Vektor-transfizierten abgezogen und als 100\% wurde der Ausgangswert ohne CCCP mit 0,1\% DMSO definiert. Jeder Messpunkt stellt das arithmetische Mittel aus 3 Messungen \pm Standardfehler bei $\mathrm{pH}$ 7,4 dar. 
Das erste Experiment ergab für CCCP eine $\mathrm{IC}_{50}$ von 1,6 $\mu \mathrm{M}$. Da im Bereich des größten Gefälles nur sehr wenige Messpunkte vorlagen, wurde die CCCP Konzentration in den folgenden Experimenten angepasst. CCCP ist in Dimethylsulfoxid (DMSO) gelöst. Die maximale DMSO-Konzentration, der die Zellen ausgesetzt waren, betrug $0,1 \%$. Um auszuschließen, dass DMSO einen Einfluss auf die Aufnahme von PAH hat, wurde die Aufnahme von PAH in Ab- und Anwesenheit von DMSO gemessen. Wurde die Aufnahme von PAH in Anwesenheit von 0,1\% DMSO zu $100 \%$ gesetzt, so lag die Aufnahme in Abwesenheit von DMSO bei $97,5 \pm 7,1 \%$.

Aufgrund dieses Ergebnisses wurde der Unterschied zwischen DMSO-haltigem und DMSOfreiem Ringer bei einer Konzentration von 0,1\% DMSO im Folgenden als vernachlässigbar angenommen. Das zweite Experiment ergab eine $\mathrm{IC}_{50}$ von 2,2 $\mu \mathrm{M}$ und das dritte eine $\mathrm{IC}_{50}$ von $3,7 \mu \mathrm{M}$ CCCP.

Insgesamt schwankte die $\mathrm{IC}_{50}$ also von 1,6 - 3,7 $\mu \mathrm{M}$. Der Mittelwert lag bei 2,5 $\pm 0,5 \mu \mathrm{M}$. Fasst man alle Werte der 3 Experimente zusammen, so ergibt sich die in Abb. 3.11 dargestellte Kurve mit einer $\mathrm{IC}_{50}$ von $2,8 \mu \mathrm{M}$.

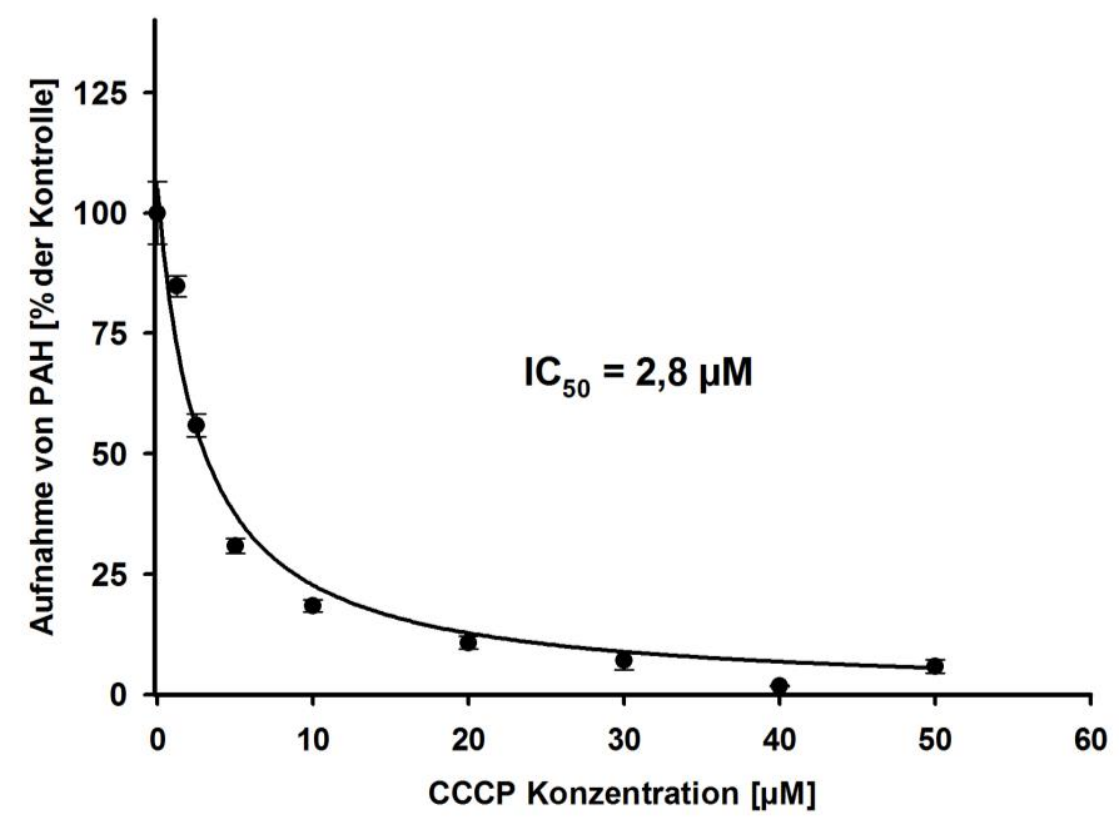

Abbildung 3.11: Zusammenfassung der 3 Experimente zur Bestimmung der $I_{50}$ von CCCP. Hierbei wurden die gesamten Daten aus den 3 vorangegangenen Experimenten zusammengefasst und mittels Regression ein $1 C_{50}$-Wert errechnet. Jeder Messpunkt stellt das arithmetische Mittel von 39 Messwerten (manche Bedingungen wurden nicht in jedem Versuch mitgeführt bzw. erst in späteren Versuchen hinzugefügt) mit 3 unterschiedlichen Zellpassagen bei $\mathrm{pH}$ 7,4 dar. 


\subsection{Einfluss von Hydrogencarbonat $\left(\mathrm{HCO}_{3}{ }^{-}\right)$}

Ein alternativer Transportmechanismus, bei dem $\mathrm{HCO}_{3}{ }^{-}$gegen ein organisches Anion austauschen könnte, wird für den OAT1 diskutiert, um dessen pH-Abhängigkeit zu erklären. Deshalb wurden Aufnahme-Experimente mit $\mathrm{HCO}_{3}{ }^{-}$-haltigem Ringer durchgeführt, indem 25 $\mathrm{mM} \mathrm{NaCl}$ des Ringers durch $25 \mathrm{mM} \mathrm{NaHCO}_{3}$ ersetzt wurde. Die Experimente wurden bei einem pH-Wert von 7,4 durchgeführt.

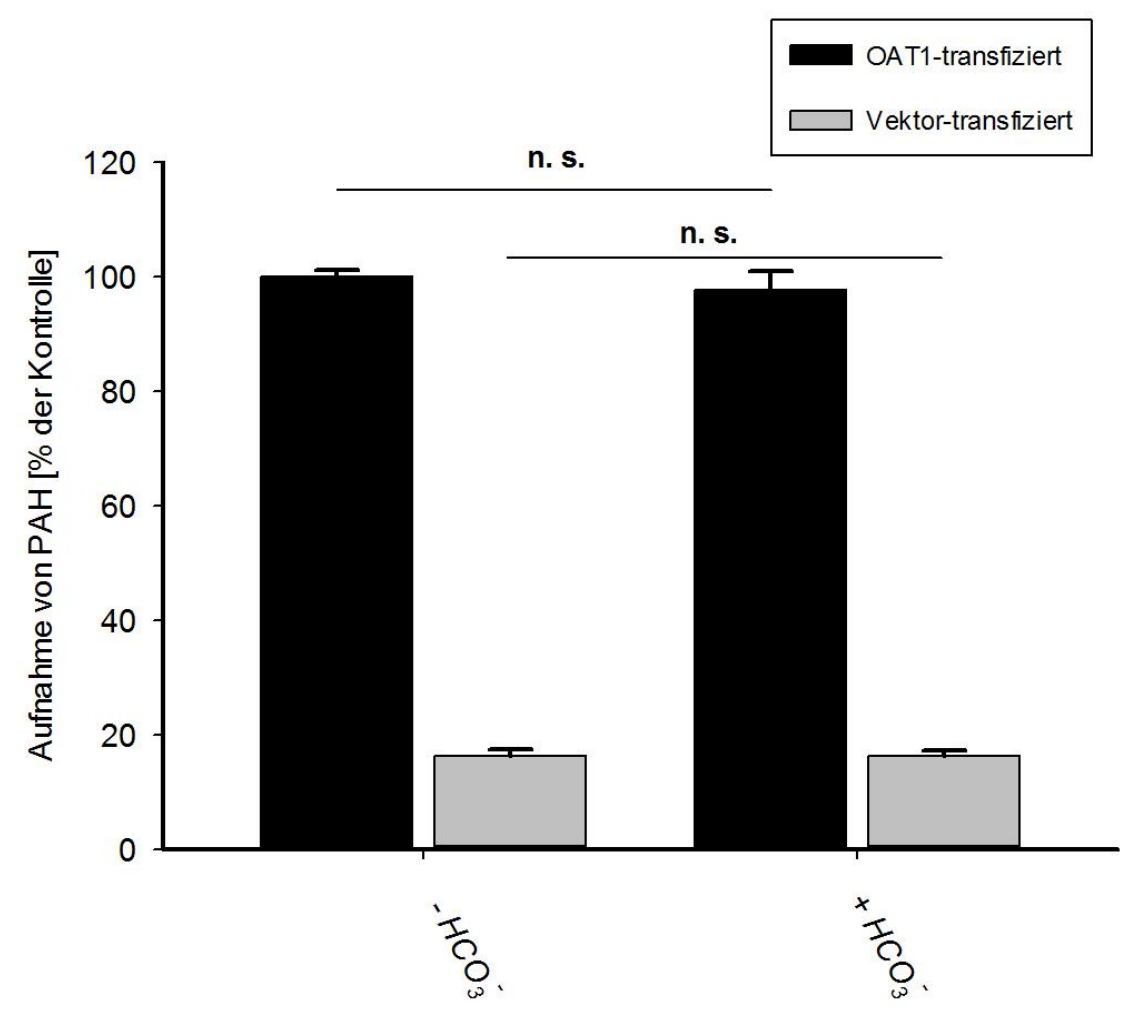

Abbildung 3.12: Aufnahme von PAH in An- und Abwesenheit von Hydrogencarbonat. Jede Säule fasst 24 Messwerte aus 4 Experimenten unterschiedlicher Zellpassagen \pm Standardfehler zusammen. Die Messwerte wurden in jedem Experiment auf das Niveau des ausschließlich chloridhaltigen Ringers bei $\mathrm{pH}$ 7,4 normiert.

Wie in Abb. 3.12 zu sehen, wurden keine signifikanten Unterschiede bei $\mathrm{NaHCO}_{3}$-haltigem Ringer im Vergleich zu ausschließlich chloridhaltigem Ringer festgestellt. Das Niveau des $\mathrm{HCO}_{3}$-haltigen Ringers lag bei $97,7 \pm 3,2 \%$ des Niveaus ausschließlich chloridhaltigen Ringers. Weitere Versuche zur Abhängigkeit von Hydrogencarbonat wurden deshalb nicht durchgeführt. 


\subsection{Einfluss von Acetazolamid und 4-Acetamido-4-Isothiocyanato- Stilben-2,2-Disulfonsäure (SITS)}

Acetazolamid ist ein kompetitiver Hemmstoff des OAT1 (Hasannejad et al. 2004) und konnte für den rOAT1 auch als Substrat verifiziert werden (Uwai et al. 2000), während SITS ein unspezifischer Hemmstoff des Anionentransportes ist (Wohlrab und Hein 2000).

Bei diesem Experiment gab es 4 unterschiedliche Bedingungen: Ringerlösung in Ab- und in Anwesenheit von entweder $1 \mathrm{mM}$ Acetazolamid, $1 \mathrm{mM}$ SITS oder 0,5\% DMSO, da Acetazolamid in DMSO gelöst war. Jede Lösung enthielt $0,5 \mu \mathrm{M}\left[{ }^{3} \mathrm{H}\right]-\mathrm{PAH}$ und wurde unter natriumhaltigen und natriumfreien Bedingungen getestet. Dadurch kamen insgesamt 8 Bedingungen zustande.

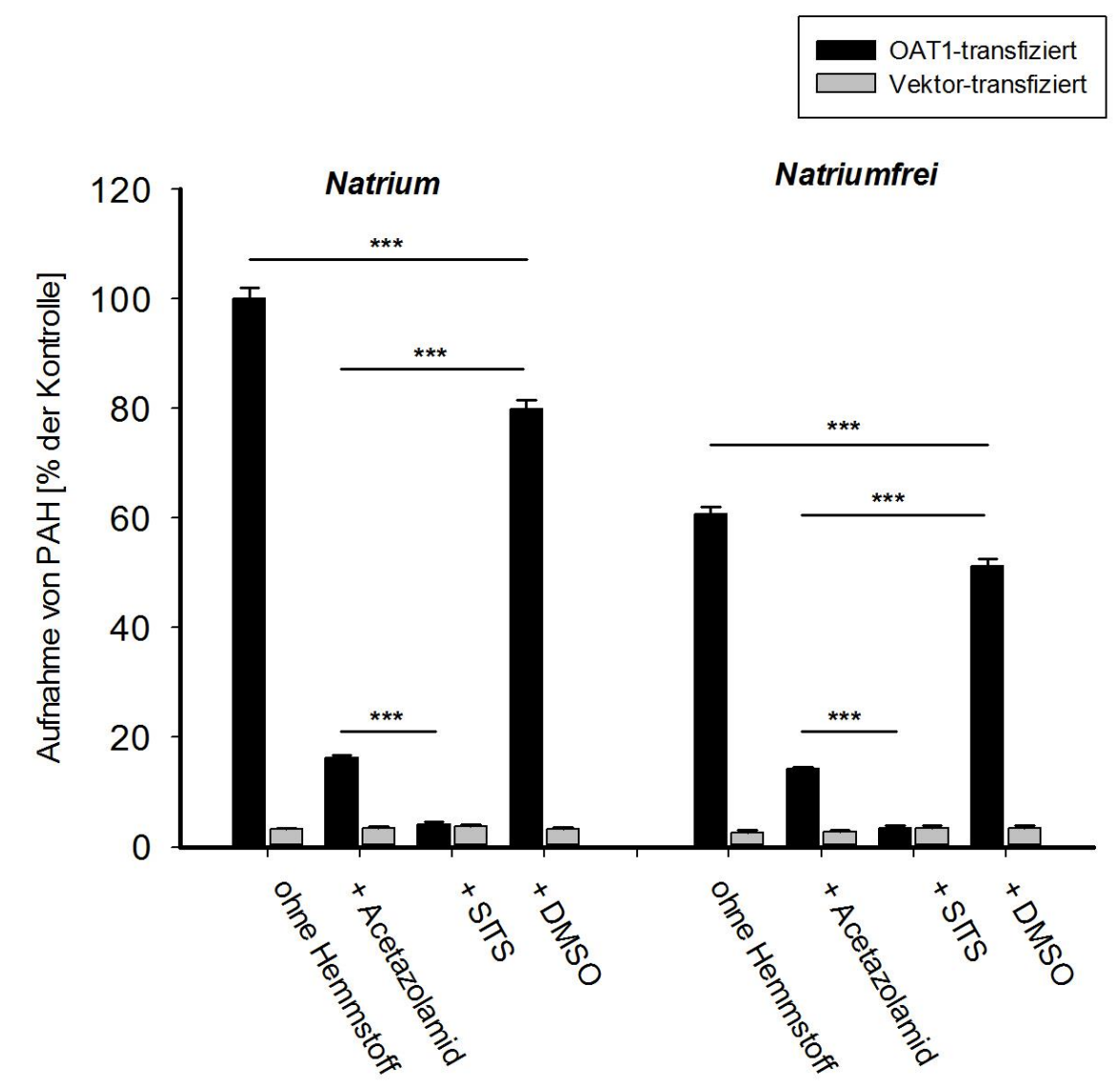

Abbildung 3.13: Relative Aufnahme von PAH bei unterschiedlichen Hemmstoffen. Jede Säule fasst 9 Messwerte aus 3 Experimenten mit unterschiedlicher Zellpassage \pm Standardfehler zusammen. Die Werte wurden in jedem Experiment auf das Niveau des Ringers mit 0,5 $\mu M\left[{ }^{3} \mathrm{H}\right]-P A H$ normiert; $\mathrm{pH}: 7,4 ;{ }^{* * *} \mathrm{p}<0,001$. 
Die PAH-Aufnahme von OAT1-transfizierten HEK293-Zellen ging in Anwesenheit von Natrium von $100 \pm 1,96 \%$ auf $16,2 \pm 0,57 \%$ bei $1 \mathrm{mM}$ Acetazolamid und auf $4,1 \pm 0,45 \%$ bei 1 mM SITS zurück. Beide Rückgänge vom Ausgangsniveau sowie der Unterschied zwischen Acetazolamid und SITS waren signifikant $(p<0,001)$.

In Abwesenheit von Natrium war das Ausgangsniveau 60,7 $\pm 1,39 \%$ und ging durch Acetazolamid auf $14,2 \pm 0,45 \%$ und durch SITS auf 3,5 $\pm 0,53 \%$ zurück. Wieder waren die Rückgänge vom Ausgangsniveau und der Unterschied zwischen Acetazolamid und SITS signifikant $(p<0,001)$.

Auch ein Einfluss des 0,5 \%igen DMSOs war zu erkennen: In Anwesenheit von Natrium ging das Niveau von $100 \pm 1,96 \%$ auf 79,9 $\pm 1,56 \%$ zurück. Ohne Natrium wurde ein Rückgang von $60,7 \pm 1,39 \%$ auf $51,1 \pm 1,49 \%$ erfasst. Beide Rückgänge waren signifikant $(p<0,001)$. Die Zugabe von SITS hemmte die OAT1-transzierten Zellen auf das Niveau der Vektortransfizierten Zellen, während bei der Hemmung durch Acetazolamid eine Restaktivität der durch den OAT1-vermittelten Aufnahme von PAH vorhanden blieb. 


\subsection{Einfluss von Amilorid}

Amilorid blockiert den epithelialen Natriumkanal und ist ein Hemmstoff des $\mathrm{Na}^{+} / \mathrm{H}^{+}-$ Austauschers. Daher wurde es dazu verwendet, die Rolle des Natriums beim Transport von PAH näher zu bestimmen. Dazu wurden OAT1-transfizierte HEK293-Zellen mit der Konzentration von $0,5 \mu \mathrm{M}\left[{ }^{3} \mathrm{H}\right]-\mathrm{PAH}$ für 5 Minuten inkubiert und die Werte in Anwesenheit von $1 \mathrm{mM}$ Amilorid mit den Kontrollwerten verglichen. Das Experiment wurde sowohl mit natriumhaltigem als auch mit natriumfreiem Ringer durchgeführt.

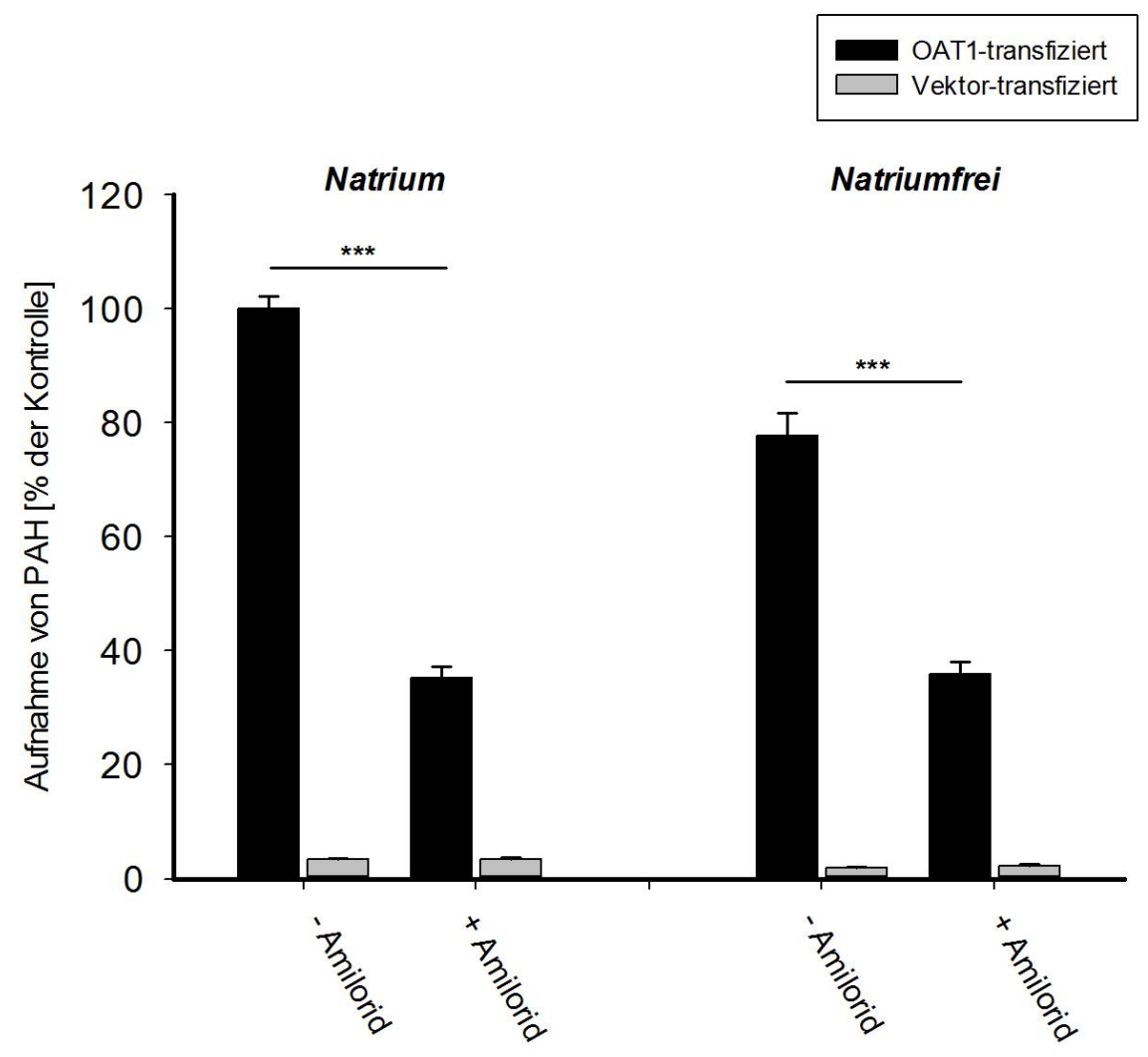

Abbildung 3.14: Relative Aufnahme von PAH unter Einfluss von Amilorid. Jeder Balken fasst 9 Messwerte aus 3 Experimenten unterschiedlicher Zellpassage \pm Standardfehler zusammen. Die Werte wurden in jedem Experiment auf die Aufnahme von PAH in Abwesenheit von Amilorid mit 0,5 $\mu \mathrm{M}\left[{ }^{3} \mathrm{H}\right]-$ PAH normiert; $p H: 7,4 ;{ }^{* * *} p<0,001$.

Die PAH-Aufnahme von OAT1-transfizierten HEK293-Zellen sank in Anwesenheit von $1 \mathrm{mM}$ Amilorid signifikant von $100 \pm 2,2 \%$ auf 35,3 $\pm 1,9 \%(p<0,001)$ ab. Die Aufnahme von PAH war unter natriumfreien Bedingungen reduziert und betrug nur noch 77,8 $\pm 4 \%$ des Wertes in Anwesenheit von Natrium. Die PAH-Aufnahme unter natriumfreien Bedingungen und 
Amilorid betrug 35,9 $\pm 2,2 \%$ des Wertes unter Kontrollbedingungen, d.h. die Aufnahme von $\mathrm{PAH}$ wurde unabhängig von Natrium auf ca. 35\% des Wertes unter Kontrollbedingungen reduziert.

\subsection{Proteinbestimmung}

Bei der durchgeführten Proteinbestimmung lag die Masse pro Well der Vektor-transfizierten Zellen bei 0,191 \pm 0,007 mg Protein. Die OAT1-transfizierten Zellen lagen bei 0,190 \pm 0,007 mg Protein pro Well, d.h. der Proteingehalt OAT1- und Vektor-transfizierter HEK293-Zellen war nicht signifikant voneinander verschieden. 


\section{Diskussion}

Sowohl der OAT1 (Ho et al. 2000) als auch der OAT2 (Sato et al. 2010) zeigen eine erhöhte Substrataufnahme, wenn der pH-Wert des Aufnahmemediums in den sauren Bereich verschoben ist. Diese pH-Abhängigkeit ist bis jetzt unverstanden, da - bis auf die oben zitierten Arbeiten - keine weiteren publizierten Daten zu dieser Thematik vorliegen. Im Mittelpunkt dieser Dissertationsarbeit standen deshalb Versuche zur Erforschung der pHabhängigen Substrataufnahme bei OAT1. Die in dieser Arbeit beschriebenen Versuche sind eine Weiterführung der in der Einleitung erwähnten, von der Arbeitsgruppe bereits durchgeführten Versuche (Abb. 1.5).

\subsection{Allgemeine Vorbemerkungen}

Alle in dieser Arbeit beschriebenen Versuche wurden an stabil mit OAT1-transfizierten HEK293-Zellen durchgeführt. Als Kontrollen dienten Vektor-transfizierte HEK293-Zellen. Als Substrat wurde $\left[{ }^{3} \mathrm{H}\right]$-markiertes para-Aminohippurat (PAH) eingesetzt. Bevor die in dieser Arbeit erzielten Ergebnisse diskutiert werden, sollen einige Probleme bei der Versuchsdurchführung besprochen werden.

Obwohl die Zellen immer mit $2 \cdot 10^{5}$ Zellen pro Well ausgesät wurden, ergaben sich, wenn man die absoluten Transportraten der einzelnen Experimente vergleicht, teilweise recht große Abweichungen für die Transportraten bei Standardbedingungen (5-minütige Inkubation mit pH 7,4 Ringer mit 0,5 $\left.\mu \mathrm{M}\left[{ }^{3} \mathrm{H}\right]-\mathrm{PAH}\right)$. Die absoluten Transportraten reichten von 0,83 - 4 pmol PAH pro 5 Minuten (Vgl. Tab. 3.1). Diese Schwankungen können folgende Ursachen haben:

- Generelle Fehler bei der Auszählung der Zellen, die sich durch das nachfolgende 3tägige Wachstum erhöhen: Die Zellen wurden mitunter von unterschiedlichen Personen ausgezählt. Außerdem setzen sich die Zellen vor der Aussaat in die Wells am Boden der Suspension ab. Die Zellsuspension wurde zwar durch Auf- und Abpipettieren so gut wie möglich homogenisiert, ein Restfehler bei Verteilung der Zellen in der Suspension ist jedoch nicht auszuschließen

- Unterschiedlich lange Wachstumszeiten: Aus logistischen Gründen war es nicht immer möglich, die Zellen für genau 72 Stunden bis zum Experiment wachsen zu lassen, sodass die effektive Wachstumszeit bei $72 \pm 3$ Stunden lag.

- Unterschiedliche Zellpassagen: Es wurde schon häufig beobachtet, dass unterschiedliche Zellpassagen ihr Substrat unterschiedlich effizient transportieren. 
Zudem wurden im Institut auch immer wieder Unterschiede zwischen frisch aufgetauten und länger in Kultur gehaltenen Zellen festgestellt. Eine Pauschalisierung dahingehend, dass eine erhöhte Zellpassage mit einer verringerten Transportrate einhergeht, ließ sich aus den in Tab. 3.1 zusammengefassten Daten jedoch nicht ableiten.

- Unterschiedliche $\left[{ }^{3} \mathrm{H}\right]-\mathrm{PAH}-$ Chargen: Da sich die Versuche über eine längere Zeit hinzogen, mussten unterschiedliche Chargen von [ $\left.{ }^{3} \mathrm{H}\right]-\mathrm{PAH}$ verwendet werden, die eventuell unterschiedlich gut transportiert werden.

- Zellverlust: Trotz größter Sorgfalt werden Zellen - sowohl beim Waschen vor Beginn des Versuches als auch nach erfolgter Aufnahme - von Boden abgelöst und gehen somit verloren.

Die Methodik könnte dahingehend verbessert werden, dass bei jedem Experiment auch Zellen zur Proteinbestimmung ausgesät werden. Dadurch könnte in jedem einzelnen Experiment die Proteinmenge relativ exakt bestimmt werden und dadurch Schwankungen bei der Zellzahl ausgeglichen werden. Proteinbestimmungen wurden zwar auch im Rahmen dieser Doktorarbeit durchgeführt (vgl. Kapitel 3.9), jedoch nicht bei jedem Experiment. In den in dieser Arbeit durchgeführten Messungen zur Bestimmung des Proteingehalts nach Bradford konnte kein Unterschied zwischen OAT1- und Vektor-transfizierten HEK293-Zellen detektiert werden. Dies lässt darauf schließen, dass die Aussaat und die weitere Handhabung der Zellen sehr standardisiert abliefen, sodass solche Fehlerquellen weitgehend auszuschließen sind. Für die durchgeführte Methodik sprechen auch die geringen Standardabweichungen innerhalb der einzelnen Experimente.

Um die optimale Aufnahmedauer für die Transportversuche zu bestimmen, wurde zunächst eine Zeitreihe angefertigt. Wie in Abb. 3.1 und 3.2 zu sehen ist, verläuft die wahrscheinlich durch Diffusion bedingte Aufnahme von $\left[{ }^{3} \mathrm{H}\right]-\mathrm{PAH}$ in den Vektor-transfizierten Zellen linear, wohingegen die Aufnahme von $\left[{ }^{3} \mathrm{H}\right]-\mathrm{PAH}$ in OAT1-transfizierten Zellen ab einer Inkubationszeit von ca. 7,5 Minuten Sättigungscharakter zeigt. Bei einer 30-minütigen Inkubation wird sogar eine Abnahme der Aufnahme von PAH beobachtet. Dies könnte durch eine Substrathemmung zu erklären sein. In dieser langen Zeitspanne ist so viel PAH in die Zellen aufgenommen worden, dass $\mathrm{PAH}$ sich unterhalb der Zellmembran angesammelt hat und möglicherweise die Bindungsstellen so modifiziert, dass die Umsatzrate reduziert wird. 


\subsection{Mögliche Transportmodi}

Aus den Versuchen zur Zeitabhängigkeit der Aufnahme von PAH bei pH 7,4 und pH 6,4 wird deutlich, dass die PAH-Aufnahme, wie in Kapitel 1.4 erwähnt, bei saurem pH-Wert im Inkubationsmedium (entspricht dem extrazellulären $\mathrm{pH}$-Wert $\mathrm{pH}_{\mathrm{ex}}$ ) zunimmt. Diese Beobachtung konnte in allen folgenden Versuchen bestätigt werden.

Gründe für die pH-Wert abhängige Aufnahme des Leitsubstrats sind bisher nicht geklärt. Ein sehr einfacher Grund wäre, dass aufgrund der Variation des extrazellulären pH-Wertes das OAT1-Substrat bei pH 6,4 in höherer Konzentration vorliegt als bei pH 7,4.

Diese kann zumindest für PAH ausgeschlossen werden: $\mathrm{PAH}$ besitzt einen $\mathrm{pK}_{\mathrm{S}}$-Wert von 3,83. Die Gesamtkonzentration (C) an PAH liegt bei allen $\mathrm{pH}$-Werten als Summe aus Säure $(H A)$ und Anion $\left(A^{-}\right)$vor: $C=H A+A^{-}$. Setzt man diese Beziehung in die HendersonHasselbalch'sche Gleichung ein, ergibt sich folgende Formel:

$\mathrm{pH}=\mathrm{pK}_{\mathrm{S}}+\log \left(\mathrm{A}^{-} / \mathrm{HA}\right)=\mathrm{pK}_{\mathrm{S}}+\log \left(\mathrm{A}^{-} /\left(\mathrm{C}-\mathrm{A}^{-}\right)\right)$

Für $\mathrm{PAH}$ lassen sich für $\mathrm{pH} 7,4$ und $\mathrm{pH}$ 6,4 folgende Anionenkonzentrationen berechnen:

$\mathrm{pH} 7,4: \mathrm{A}^{-}=10^{3,57} /\left(1+10^{3,57}\right) \cdot \mathrm{C}=0,9997 \cdot \mathrm{C}$

$\mathrm{pH} 6,4: \mathrm{A}^{-}=10^{2,57} /\left(1+10^{2,57}\right) \cdot \mathrm{C}=0,9973 \cdot \mathrm{C}$

Diese Berechnungen zeigen, dass beispielsweise bei einer Gesamtkonzentration von 100 $\mu \mathrm{M}$ bei beiden $\mathrm{pH}$-Werten mehr als $99 \%$ des PAH als Anionen vorliegen und somit die Anionenkonzentration weit über den in Tab. 3.4 zusammengefassten $\mathrm{K}_{\mathrm{m}}$-Werten liegt.

Neben einem PAH/a-KG-Austausch könnte auch, zumindest ein Teil der Aufnahme von PAH als $\mathrm{PAH} /$ Hydrogencarbonat- oder als $\mathrm{PAH} /$ Hydroxyl/Hydrogencarbonat-lonen-Austauscher oder sogar als PAH-Protonen-Symport fungieren. Die in Abbildung 3.12 dargestellten Versuche zum Einfluss von Hydrogencarbonat auf die Aufnahme von PAH lassen jedoch einen $\mathrm{PAH} / \mathrm{Hydrogencarbonat-Austausch}$ als sehr unwahrscheinlich erscheinen, da die Aufnahme von $\mathrm{PAH}$ unabhängig von Hydrogencarbonat war. Experimentell kann nicht zwischen einem PAH/Hydroxyl-Ionen-Austauscher oder einem PAH-Protonen-Symport unterschieden werden. Die Versuche mit CCCP (Abbildungen 3.8 - 3.11) sprechen jedoch gegen solche Transportmechanismen. In der Literatur sind bisher keine Experimente zum Einfluss von CCCP auf den OAT1 zu finden. Falls, wie oben vermutet, für den Transport von $\mathrm{PAH}$ über die Zellmembran ein Symport mit einem Proton oder ein Austausch gegen ein negativ geladenes Teilchen wie ein Dicarboxylat, oder allgemeiner gesprochen, ein Hydrogencarbonat oder ein Hydroxylion vorliegt, sollte ein über der Zellmembran liegender $\mathrm{pH}$-Gradient, wobei der intrazelluläre $\mathrm{pH}-$ Wert $\mathrm{pH}_{\mathrm{i}}>\mathrm{pH}_{\mathrm{ex}}$, die Aufnahme der prototypischen 
Substrate stimulieren. CCCP bewirkt ein Zusammenbrechen des $\mathrm{pH}$-Gradienten, sodass sich $\mathrm{pH}_{\mathrm{i}}$ und $\mathrm{pH}_{\mathrm{ex}}$ angleichen. In den in Abb. 3.8 gezeigten Versuchen wurde mit 2,5 $\mu \mathrm{M}$ CCCP gearbeitet, was zu einer deutlichen Hemmung der PAH-Aufnahme führte. Trotzdem wurde unter Einfluss des CCCP bei pH 6,4 wesentlich mehr PAH transportiert als bei pH 7,4. In einer zweiten Versuchsreihe (Abb. 3.9) wurden die Zellen 10 Minuten mit der jeweiligen CCCP-haltigen Ringerlösung vorinkubiert. Bei Vergleich von Abb. 3.8 und 3.9 wird deutlich, dass die Inhibition durch Zugabe von 2,5 $\mu \mathrm{M}$ CCCP bei 10-minütiger Vorinkubation deutlich größer ausfällt. Dies könnte dadurch bedingt sein, dass der pH-Gradient eine Rolle bei der $\mathrm{PAH}-A$ ufnahme spielt und die Inhibition bei Vorinkubation deshalb größer ist, weil mehr Zeit vorhanden war, sodass sich $\mathrm{pH}_{\mathrm{i}}$ und $\mathrm{pH}_{\mathrm{ex}}$ besser annähern konnten.

Bei der Bestimmung der $\mathrm{IC}_{50}$ für CCCP in Kapitel 3.5.3 wird zunächst deutlich, dass sich die PAH-Aufnahme bei ausreichend hoher Konzentration von CCCP nahezu vollständig auf das Niveau der Kontrollzellen, deren Aufnahme auf Diffusion basiert, hemmen lässt. Da in der Literatur keine Versuche zur Interaktion von CCCP und OAT1 zu finden sind, lassen sich auch die Ergebnisse zur $I_{50}$ nicht leicht einordnen. Die geringe Schwankungsbreite innerhalb der Experimente lässt jedoch darauf schließen, dass der Mittelwert mit 2,5 $\pm 0,5$ $\mu \mathrm{M}$ relativ genau ist.

Wenn wir davon ausgehen, dass sich $\mathrm{pH}_{\mathrm{i}}$ und $\mathrm{pH}_{\mathrm{ex}}$ komplett angeglichen haben, würde dies dafür sprechen, dass nicht der $\mathrm{pH}$-Gradient für den Anstieg der $\mathrm{PAH}-A$ ufnahme bei saurem $\mathrm{pH}_{\mathrm{ex}}$ ausschlaggebend ist, sondern vielleicht ein $\mathrm{pH}$-Effekt auf das Transportprotein selbst wie eine Umladung der Histidine (Abb. 4.1) den Effekt auslöst. Versuche mit Diethylpyrocarbonat, einem Histidin- und auch Lysin-, Cystein- und Tyrosin- modifizierendem Agens, müssten sich anschließen, um die Rolle dieser Aminosäurereste an der Aufnahme von PAH zu erklären. 


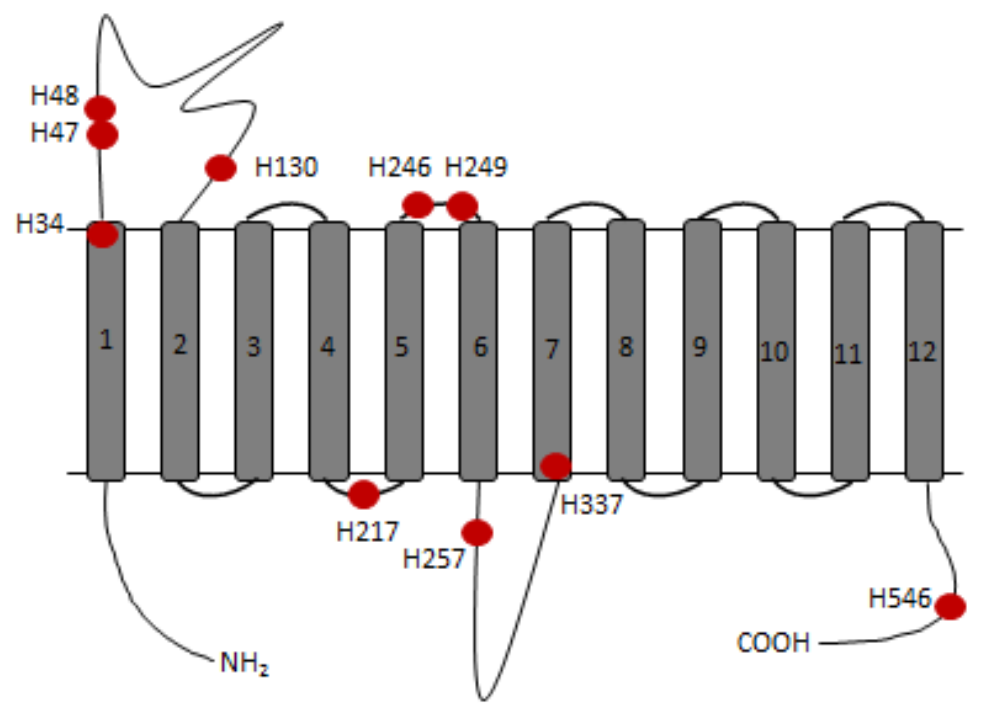

Abbildung 4.1: Lokalisation der Histidine in OAT1. Die Histidine wurden an den Positionen eingetragen, an denen sie nach dem Topologiemodell für OAT1 von Hong (Hong et al. 2007) zu erwarten sind. (Diese Abbildung ist identisch mit Abb. 1.3 (A), wurde jedoch aus Gründen der Lesbarkeit hier erneut aufgeführt)

\subsection{Probenecid-abhängige Hemmung}

Ursprünglich wurde Probenecid dazu entwickelt, die renale Ausscheidung von Penicillin zu verringern (Beyer et al. 1951). In unterschiedlichen Test-Systemen wurde die OAT1abhängige Substrataufnahme durch Probenecid gehemmt (Cihlar und Ho 2000, Ho et al. 2000, Mulato et al. 2000, Jung et al. 2001, Takeda et al. 2001, Ichida et al. 2003, Hashimoto et al. 2004, Khamdang et al. 2004, Chu et al. 2007). Probenecid wird nicht von rOAT1 transportiert (Uwai et al. 1998). Daher ist es sehr wahrscheinlich, dass Probenecid durch die Bindung an den OAT1 den Transport von anderen organischen Anionen verhindert, ohne dabei selbst transportiert zu werden.

Wie in Abb. 3.3 zu sehen, hemmte $100 \mu \mathrm{M}$ Probenecid die [ $\left.{ }^{3} \mathrm{H}\right]-\mathrm{PAH}-$ Aufnahme unabhängig vom $\mathrm{pH}_{\mathrm{ex}}$ auf das gleiche Niveau, d.h. die Bindungsstelle, an die Probenecid am OAT1 bindet, ist sehr wahrscheinlich nicht pH-empfindlich. Allerdings wurde in den in dieser Arbeit beschriebenen Versuchen eine hohe Konzentration an Probenecid eingesetzt. Andere Autoren konnten in einer Zelllinie aus dem zweiten Segment des proximalen Tubulus die 
Aufnahme von $\mathrm{PAH}$ mit einer $\mathrm{IC}_{50}$ von 10,7 (Hashimoto et al. 2004) bzw. 11,9 $\pm 1,4 \mu \mathrm{M}$ (Srimaroeng et al. 2005) an Probenecid hemmen. Allerdings wurden dort eine PAHKonzentration von $5 \mu \mathrm{M}$ und ein anderes Testsystem verwendet, was die Vergleichbarkeit stark einschränkt.

Hong et al. haben 2004 durch Alanin-Scaning in der großen extrazellulären Schleife des OAT1 versucht, Rückschlüsse auf die Substratabhängigkeit und den Einbau des OAT1 in die Plasmamembran zu ziehen. In allen von innen gemessenen Mutanten wurde die Aufnahme von PAH durch Probenecid um den gleichen Faktor reduziert. Das heißt, dass die Bindungstaschen für das Substrat $\mathrm{PAH}$ und den Hemmstoff Probenecid an unterschiedlichen Stellen des Proteins sitzen und dass die große extrazelluläre Schleife beide Bindungstaschen unterschiedlich beeinflusst.

\section{4 $\mathrm{K}_{\mathrm{m}}$ für $\mathrm{PAH}$}

In Abschnitt 3.4 wurden Michaelis-Menten Konstanten für die PAH-Aufnahme bei pH 6,4 und 7,4 bestimmt. Der Durchschnittswert lag bei pH 6,4 mit 12,50 $\pm 3,63 \mu \mathrm{M}$ ungefähr auf dem gleichen Niveau wie bei pH 7,4 (11,42 $\pm 2,59 \mu \mathrm{M})$. Ein signifikanter Unterschied konnte nicht festgestellt werden. In der Literatur (VanWert et al. 2010) werden unter physiologischem $\mathrm{pH}$ Wert $\mathrm{K}_{\mathrm{m}}$-Werte von 20,1 $\mu \mathrm{M} \pm 1,4 \mu \mathrm{M}$ (Deguchi et al. 2004) bis 47,8 $\mu \mathrm{M} \pm 19,5 \mu \mathrm{M}$ (Sakurai et al. 2004) angegeben.

Obwohl die $\mathrm{V}_{\max }$ unter Einbezug von allen 4 Experimenten bei $\mathrm{pH}$ 6,4 statistisch gesehen nicht signifikant höher als bei $\mathrm{pH}$ 7,4 gewesen ist, lässt sich jedoch erkennen, dass die Transportrate bei pH 6,4 erhöht ist. Dies wird auch durch die Auftragung nach Eadie-Hofstee (Abb. 3.6) und beim direkten Vergleich der $V_{\max }$ (Abb. 3.7) deutlich. Eine Änderung von $V_{\max }$ bedeutet, dass sich entweder die Umsatzrate des Transporters geändert hat oder dass sich der Gehalt an Transportprotein geändert hat. Ein in Abhängigkeit des extrazellulären pHWertes geänderter Einbau oder Abbau des Transportproteins ist in den in dieser Arbeit beschriebenen Versuchen auszuschließen, da der pH-Wert nur während der Inkubation mit dem Substrat geändert wurde. Da keine Änderung der $\mathrm{K}_{\mathrm{m}}$ beobachtet wurde, ist eine Änderung der Bindungsaffinität aufgrund des sauren pH-Wertes höchstwahrscheinlich auszuschließen. 


\subsection{Einfluss von Hydrogencarbonat}

Wie bereits in Kapitel 4.2 erwähnt, ist eine $\mathrm{HCO}_{3}{ }^{-}$-Abhängigkeit des Transporters aufgrund der Versuchsergebnisse relativ unwahrscheinlich. Weitere Versuche wurden deshalb in diesem Bereich nicht durchgeführt. Es besteht jedoch weiterhin die Möglichkeit, dass sich bei höheren als den physiologisch gewählten Konzentrationen ein Einfluss von $\mathrm{HCO}_{3}{ }^{-}$auf die $\mathrm{PAH}-A$ ufnahme bemerkbar machen könnte. Dies gilt besonders dann, wenn $\mathrm{HCO}_{3}{ }^{-}$gegen $\mathrm{Cl}^{-}$ ausgetauscht wird, da Rizwan et al. 2007 zeigen konnten, dass die Aufnahme von PAH über den OAT1 chloridabhängig verläuft.

\subsection{Einfluss von Acetazolamid und SITS}

Die Carboanhydrasen spielen bei der Rückresorption von Hydrogenkarbonat im proximalen Tubulus entscheidende Rollen, indem sie das Gleichgewicht zwischen Kohlensäure, $\mathrm{HCO}_{3}$, $\mathrm{CO}_{2}$ und einem Proton verschieben. Ursprünglich war geplant, dass durch die Hemmstoffe der Carboanhydrasen - Acetazolamid und SITS - Aussagen zum Einfluss des Hydrogencarbonats auf die Aufnahme von PAH und zu einem PAH/Hydroxyl-lonenAustauscher oder PAH-Protonen-Symporter gemacht werden können. Da Acetazolamid jedoch auch die Aufnahme von PAH in S2-Zellen, die stabil mit dem humanen OAT1 transfiziert sind, mit einer $I_{50}$ von $75 \mu \mathrm{M}$ (Hasannejad et al. 2004) hemmt, ist die Aussage dieser Experimente begrenzt, zumal in einem anderen Experiment gezeigt werden konnte, dass die Aufnahme von PAH unabhängig von Hydrogenkarbonat ist (siehe Kapitel 4.5).

SITS gehört zur Gruppe der Stilbenderivate und blockiert den $\mathrm{Cl}^{-} / \mathrm{HCO}_{3}{ }^{-}$-Antiporter (Del Cuca et al. 2012). Für andere Stilbenderivate wie 4,4-Diisothiocyanato-Stilben-2,2-Disulfonsäure (DIDS) wurde eine inhibitorische Wirkung auf die Substrataufnahme des OAT1 (Ichida et al. 2003) nachgewiesen. Dies trifft auch auf SITS zu. Durch SITS fand unabhängig vom extrazellulären $\mathrm{pH}$-Wert eine komplette Hemmung des durch den OAT1 vermittelten Transportes statt. Dies ist dadurch erkennbar, dass die Ansätze mit SITS auf dem Niveau der Kontrollzellen lagen (vgl. Abb. 3.13). Da dies unabhängig vom Vorhandensein von Natrium der Fall war, spielt der Natriumgradient hierbei anscheinend keine Rolle. Weitere Schlussfolgerungen über den Transportmechanismus ergeben sich aus den Ergebnissen für SITS jedoch nicht, da die Aufnahme von PAH wie erwähnt unabhängig von Hydrogencarbonat ist (Kapitel 4.5). 


\subsection{Einfluss von Amilorid}

Eigentlich sollte Amilorid dazu eingesetzt werden, Einflüsse des Natriums auszuschalten, indem es den $\mathrm{Na}^{+} / \mathrm{H}^{+}$-Austauscher hemmt.

Die Arbeitsgruppe um Race (Race et al. 1999) hat in OAT1-exprimierenden Xenopus laevisOozyten keine Hemmung der PAH-Aufnahme durch Amilorid detektieren können. Im Gegensatz dazu konnte ich eine Hemmung der Aufnahme von PAH durch Amilorid in Anund auch in Abwesenheit von Natrium feststellen. HEK293-Zellen besitzen einen endogenen, Amilorid-sensitiven $\mathrm{Na}^{+} / \mathrm{H}^{+}$-Austauscher (Lang et al. 2003). Da in den in dieser Arbeit vorgestellten Versuchen die Aufnahme von PAH sowohl in An- als auch in Abwesenheit von Natrium durch Amilorid reduziert wurde, spricht dies für einen Transport oder zumindest für eine Interaktion von Amilorid mit OAT1, da unter natriumfreien Bedingungen der $\mathrm{Na}^{+}-\mathrm{H}^{+}$-Austauscher nicht mehr aktiv sein dürfte. Die Diskrepanz zwischen den Beobachtungen von Race und mir mag auf den unterschiedlichen Expressionssystemen beruhen.

\subsection{Ausblick}

In weiterführenden Untersuchungen, die allerdings nicht Gegenstand dieser Dissertation sind und waren, muss nun durch Einsatz von Diethylpyrocarbonat (DEPC) der Einfluss der in Kapitel 4.2 bereits erwähnten Histidine auf das Transportgeschehen weiter untersucht werden. DEPC modifiziert ausschließlich extrazelluläre Histidine. Sollten diese in das Transportgeschehen involviert sein, müsste die Aufnahme von PAH unter DEPC-Applikation reduziert oder nicht mehr vorhanden sein. Zielführend müssten dann alle extrazellulären Histidine einzeln und in Kombination mutiert werden, um das oder diejenigen Histidine zu identifizieren, die für das Transportgeschehen verantwortlich sind. 


\section{Zusammenfassung}

Ziel dieser Arbeit war es, den hauptsächlich in den Nieren lokalisierten OAT1 näher zu untersuchen und Gründe für den Anstieg der Substrataufnahme bei saurem pH-Wert zu finden.

Deshalb wurden Aufnahmeversuche mit dem Leitsubstrat von OAT1 - dem PAH - an OAT1transfizierten und an ausschließlich Vektor-transfizierten HEK293-Zellen durchgeführt.

Dabei wurden die Zellen für eine gewisse Zeit mit unterschiedlichen Lösungen inkubiert und die Aufnahme von radioaktiv markiertem PAH in die Zellen gemessen. Die Aufnahmezeit wurde dabei nach der Herstellung einer Zeitreihe auf 5 Minuten festgelegt, da die Aufnahme in dieser Zeit noch linear erfolgt.

Um die pH-Abhängigkeit zu erklären, werden unterschiedliche Transportmodi diskutiert (siehe Kapitel 1.4). Folgende Ergebnisse wurden erzielt:

- Grundsätzlich ist die OAT1-vermittelte Aufnahme von PAH bei pH 6,4 im Vergleich zu pH 7,4 erhöht,

- Probenecid hemmt OAT1 unabhängig vom extrazellulärem pH-Wert, und die Bindungsstelle von Probenecid ist wahrscheinlich nicht $\mathrm{pH}$-empfindlich,

- Bei sauren pH bleibt die $\mathrm{K}_{\mathrm{m}}$, also die Affinität, unverändert, $\mathrm{V}_{\max }$ ist erhöht (Aufgrund der hohen absoluten Schwankungen zwischen den einzelnen Experimenten sollten zur Abklärung noch weitere Experimente durchgeführt werden.),

- CCCP hemmt die Aufnahme von PAH mit einer $\mathrm{IC}_{50}$ von 2,5 $\pm 0,5 \mu \mathrm{M}(\mathrm{Ob}$ dies ausschließlich auf dem Angleichen von intra- zu extrazellulärem $\mathrm{pH}$-Wert beruht, ist unklar, da die pH-Abhängigkeit unter CCCP bestehen bleibt),

- Hydrogencarbonat hat keinen Einfluss auf die PAH-Aufnahme über OAT1. Dies schließt einen Antiport mit Hydrogencarbonat-Ionen aus,

- Acetazolamid, SITS und Amilorid hemmen die PAH-Aufnahme über OAT1.

Zur weiteren Untersuchung der pH-Abhängigkeit des OAT1 sollte in weiteren Experimenten, die nicht Teil dieser Arbeit sind, der Einfluss der Histidine untersucht werden. 


\section{Anhang}

\subsection{Abkürzungsverzeichnis}

\begin{tabular}{|c|c|}
\hline$\alpha-K G$ & a-Ketoglutarat \\
\hline Abb. & Abbildung \\
\hline ACE & angiotensin converting enzyme \\
\hline ASS & Acetylsalicylsäure \\
\hline ATP & Adenosintriphosphat \\
\hline BSA & bovines Serumalbumin \\
\hline ca. & circa \\
\hline CCCP & Carbonylcyanid-3-Chlorophenylhydrazon \\
\hline cos-7 & Zelllinie des Cercopithecus aethiops \\
\hline cRNA & kodierte Ribonukleinsäure \\
\hline DEPC & Diethylpyrocarbonat \\
\hline DMEM & Dulbecco's Modified Eagle's Medium \\
\hline DMSO & Dimethylsulfoxid \\
\hline DNS & Desoxyribonukleinsäure \\
\hline DPM & decays per minute \\
\hline FCS & fetal calf serum \\
\hline H34A & Histidin34Alanin \\
\hline $\mathrm{IC}_{50}$ & halbmaximale inhibitorische Konzentration \\
\hline $\mathrm{K}_{\mathrm{m}}$ & Michaelis-Menten-Konstante \\
\hline n. s. & nicht signifikant \\
\hline NaDC3 & Natrium-abhängige Dicarboxylat-Transporter 3 \\
\hline NSAIDs & non-steroidal anti-inflammatory drugs \\
\hline OAT & (humaner) organischer Anionentransporter \\
\hline $\mathrm{PAH}$ & para-Aminohippurat \\
\hline PBS & phosphatgepufferte Salzlösung \\
\hline
\end{tabular}




$\begin{array}{ll}\mathrm{pH}_{\mathrm{ex}} & \text { extrazellulärer } \mathrm{pH}-\text { Wert } \\ \mathrm{pH}_{\mathrm{i}} & \text { intrazellulärer } \mathrm{pH}-\text { Wert } \\ \text { RAAS } & \text { Renin-Angiotensin-Aldosteron-System } \\ \text { rOAT } & \text { organischer Anionentransporter der Ratte } \\ \text { SEM } & \text { standard error of the mean (Standardfehler) } \\ \text { SITS } & \text { Acetamido-4-Isothiocyanato-Stilben-2,2-Disulfonsäure } \\ \text { SLC } & \text { Solute Carrier } \\ \text { Tab. } & \text { Tabelle } \\ \text { TMH } & \text { Transmembranhelix } \\ \text { URAT } & \text { urate anion exchanger } \\ \mathrm{V}_{\max } & \text { maximale Umsatzgeschwindigkeit }\end{array}$




\subsection{Abbildungsverzeichnis}

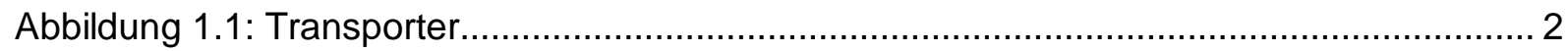

Abbildung 1.2: Schematische Zeichnung einer proximalen Tubuluszelle der Niere ............... 3

Abbildung 1.3: Lokalisation der Histidine in OAT1 …......................................................... 5

Abbildung 1.4 Schematische Darstellung der Sekretion von Acetylsalicylsäure (ASS) .......... 6

Abbildung 1.5: pH-Abhängigkeit der Aufnahme von PAH in OAT1- und Vektor-transfizierten

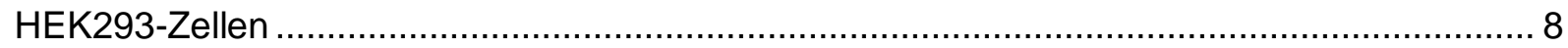

Abbildung 2.1: OAT1-transfizierte Zellen im Vergleich zu den Vektor-transfizierten Zellen... 14

Abbildung 2.2: Zellkulturwerkbank Biowizard Silverline .................................................... 15

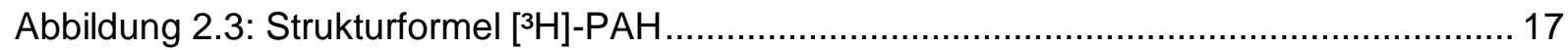

Abbildung 2.4: Der Szintilationscounter Tri Carb 2900 TR von Packard .............................. 18

Abbildung 3.1: Aufnahme von 0,5 $\mu \mathrm{M}\left[{ }^{3} \mathrm{H}\right]-\mathrm{PAH}$ als Funktion der Inkubationszeit bei pH 7,4 22

Abbildung 3.2: Aufnahme von 0,5 $\mu \mathrm{M}\left[{ }^{3} \mathrm{H}\right]-\mathrm{PAH}$ als Funktion der Inkubationszeit bei pH 6,4 24

Abbildung 3.3: Probenecid-abhängige Hemmung der Aufnahme von PAH ........................... 26

Abbildung 3.4: Konzentrationsabhängigkeit der Aufnahme von $\mathrm{PAH}$ bei pH 7,4 und 6,4 ..... 27

Abbildung 3.5: Aufnahme von PAH nach Abzug der Vektor-transfizierten Zellen.................. 28

Abbildung 3.6: Auftragen der Daten nach Eadie-Hofstee ................................................. 29

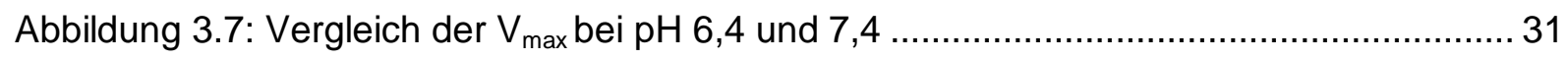

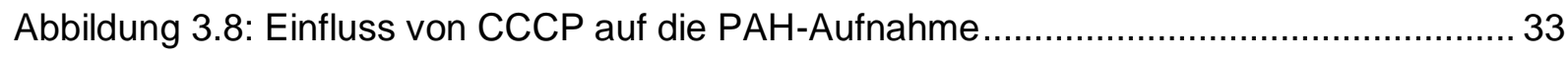

Abbildung 3.9: Einfluss von CCCP auf die PAH-Aufnahme bei 10-minütiger Vorinkubation . 34

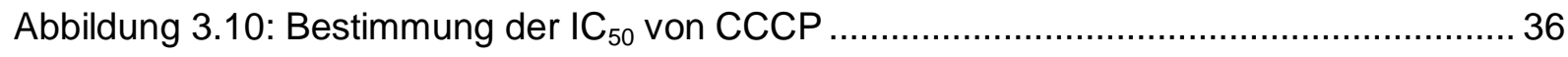

Abbildung 3.11: Zusammenfassung der 3 Experimente zur Bestimmung der $\mathrm{IC}_{50}$ von CCCP

Abbildung 3.12: Aufnahme von PAH in An- und Abwesenheit von Hydrogencarbonat ......... 38

Abbildung 3.13: Relative Aufnahme von PAH bei unterschiedlichen Hemmstoffen............... 39

Abbildung 3.14: Relative Aufnahme von PAH unter Einfluss von Amilorid ............................ 41

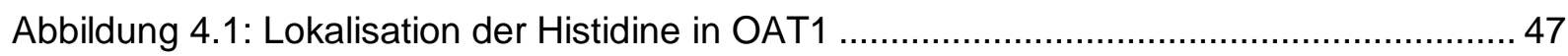




\subsection{Tabellenverzeichnis}

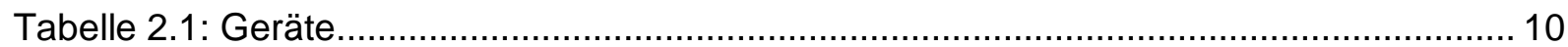

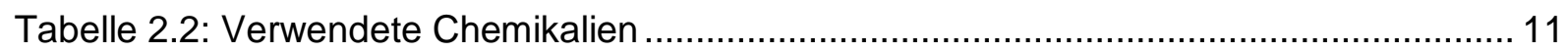

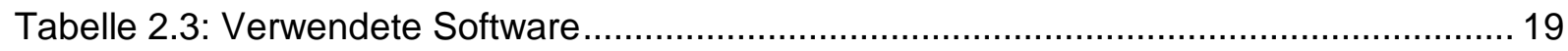

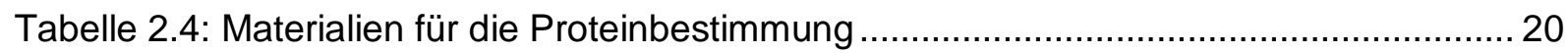

Tabelle 3.1: Aufnahme von PAH in Abhängigkeit von der Zellpassage ................................. 24

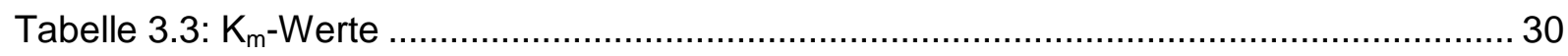

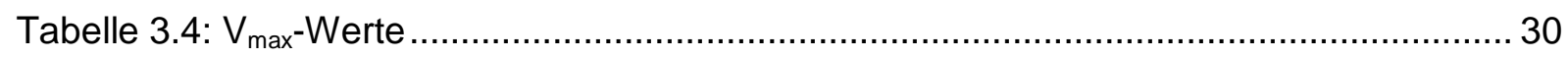




\section{Literaturverzeichnis}

Beyer K, Russo H, Tillson E, Miller A, Verwey W, Gass S (1951): 'Benemid,' p-(di-npropylsulfamyl)-benzoic acid; its renal affinity and its elimination. Am J Physiol $\underline{166}, 625$ - 649

Bleasby K, Hall LA, Perry JL, Mohrenweiser HW, Pritchard JB (2005): Functional consequences of single nucleotide polymorphisms in the human organic anion transporter hOAT1 (SLC22A6). J Pharmacol Exp Ther 314, 923 - 931

Bleasby K, Castle JC, Robert CJ, Cheng C, Bailey WJ, Sina JF, Kulkarni AV, Hafey MJ, Evers R, Johnson JM, Ulrich RG, Slatter JG (2006): Expression profiles of 50 xenobiotic transporter genes in humans and pre-clinical species: a resource for investigations into drug disposition. Xenobiotica $\underline{36}, 963-988$

Buist SCN, Klaassen CD (2004): Rat and mouse differences in gender-predominant expression of organic anion transporter (Oat1-3, Slc22a6-8) mRNA levels. Drug Metab Dispos $\underline{32}, 620-625$

Buist SCN, Cherrington NJ, Choudhuri S, Hartley DP, Klaassen CD (2002): Gender-specific and developmental influences on the expression of rat organic anion transporters. $J$ Pharmacol Exp Ther $\underline{301}, 145$ - 151

Burckhardt BC, Burckhardt G (2003): Transport of organic anions across the basolateral membrane of proximal tubule cells. Rev Physiol Biochem Pharmacol $\underline{146}, 95-158$

Burckhardt G (2012): Drug transport by organic anion transporters (OATs). Pharmacol Ther $\underline{136}, 106-130$

Chu X-Y, Bleasby K, Yabut J, Cai X, Chan GH, Hafey MJ, Xu S, Bergman AJ, Braun MP, Dean DC, Evers R (2007): Transport of the dipeptidyl peptidase-4 inhibitor sitagliptin by human organic anion transporter 3, organic anion transporting polypeptide $4 \mathrm{C} 1$, and multidrug resistance P-glycoprotein. J Pharmacol Exp Ther $\underline{321}, 673-683$ 
Cihlar T, Ho ES (2000): Fluorescence-based assay for the interaction of small molecules with the human renal organic anion transporter 1. Anal Biochem $\underline{283}, 49-55$

Cihlar T, Lin DC, Pritchard JB, Fuller MD, Mendel DB, Sweet DH (1999): The antiviral nucleotide analogs cidofovir and adefovir are novel substrates for human and rat renal organic anion transporter 1. Mol Pharmcol $\underline{56}, 570-580$

Cropp CD, Yee SW, Giacomini KM (2008): Genetic variation in drug transporters in ethnic populations. Clin Pharmacol Ther $\underline{84}, 412-416$

Deguchi T, Kusuhara H, Takadate A, Endou H, Otagiri M, Sugiyama Y (2004): Characterization of uremic toxin transport by organic anion transporters in the kidney. Kidney Int $\underline{65}, 162$ - 174

Del Cuca O, Nasirian A, Galperin V, Donini A (2012): Pharmacological characterisation of apical $\mathrm{Na}+$ and $\mathrm{Cl}-$ transport mechanisms of the anal papillae in the larval mosquito Aedes aegypti. J Exp Biol 214, 3992 - 3999

Ekaratanawong S, Anzai N, Jutabha P, Miyazaki H, Noshiro R, Takeda M, Kanai Y, Sophasan S, Endou H (2004): Human organic anion transporter 4 is a renal apical organic anion/dicarboxylate exchanger in the proximal tubules. J Pharmacol Sci $\underline{94}, 297$ - 304

Fujita T, Brown C, Carlson EJ, Taylor T, de la Cruz M, Johns SJ, Stryke D, Kawamoto M, Fujita K, Castro R, Chen CW, Lin ET, Brett CM, Burchard EG, Ferrin TE, Huang CC, Leabman MK, Giacomini KM (2005): Functional analysis of polymorphisms in the organic anion transporter, SLC22A\& (OAT1). Pharmacogenet Genomics 15, 201 - 209

Hagos Y, Krick W, Braulke T, Mühlhausen C, Burckhardt G, Burckhardt BC (2008): Organic anion transporters OAT1 and OAT4 mediate the high affinity transport of glutarate derivatives accumulating in patients with glutaric acidurias. Pflugers Arch $\underline{457}, 223-231$ 
Hasannejad H, Takeda M, Taki K, Shin HJ, Babu E, Jutabha P, Khamdang S, Aleboyeh M, Onozato ML, Tojo A, Enomoto A, Anzai N, Narikawa S, Huang XL, Niwa T, Endou H (2004): Interactions of human organic anion transporters with diuretics. J Pharmacol Exp Ther $\underline{308}$, $1021-1029$

Hashimoto T, Narikawa S, Huang X-L, Minematsu T, Usui T, Kamimura H, Endou H (2004): Characterization of the renal tubular transport of zonampanel, a novel alpha-amino-3hydroxy-5-methylisoxazole-4-propionic acid receptor antagonist, by human organic anion transporters. Drug Metab Dispos 32, 1096 - 1102

Hediger MA, Romero MF, Peng J-B, Rolfs A, Takanaga H, Bruford EA (2004): The ABCs of solute carriers: physiological, pathological and therapeutic implications of human membrane transport proteins. Pflugers Arch 447, $465-468$

Ho ES, Lin DC, Mendel DB, Cihlar T (2000): Cytotoxicity of antiviral nucleotides adefovir and cidofovir is induced by the expression of human renal organic anion transporter 1 . J Am Soc Nephrol $\underline{11}, 383-393$

Hong M, Zhou F, You G (2004): Critical amino acid residues in transmembrane domain 1 of the human organic anion transporter hOAT1. J Biol Chem 279, $31478-31482$

Hong M, Tanaka K, Pan Z, Ma J, You G (2007): Determination of the external loops and the cellular orientation of the $\mathrm{N}$ - and the $\mathrm{C}$-termini of the human organic anion transporter hOAT1. Biochem J $\underline{401}, 515$ - 520

Hosoyamada M, Sekine T, Kanai Y, Endou H (1999): Molecular cloning and functional expression of a multispecific organic anion transporter from human kidney. Am J Physiol Renal Physiol 276, F122 - F128

Ichida K, Hosoyamada M, Kimura H, Takeda M, Utsunomiya Y, Hosoya T, Endou H (2003): Urate transport via human PAH transporter hOAT1 and its gene structure. Kidney Int $\underline{63}, 143$ $-155$ 
Jacobsson JA, Haitina T, Lindblom J, Frederiksson R (2007): Identification of six putative human transporters with structural similarity to the drug transporter SLC22 family. Genomics $\underline{90}, 595-609$

Jung KY, Takeda M, Kim DK, Tojo A, Narikawa S, Yoo BS, Hosoyamada M, Cha SH, Sekine T, Endou H (2001): Characterization of ochratoxin A transport by human organic anion transporters. Life Sci $\underline{69}, 2123-2135$

Kaufhold M, Schulz K, Breljak D, Gupta S, Henjakovic M, Krick W, Hagos Y, Sabolic I, Burckhardt BC, Burckhardt G (2011): Differential interaction of dicarboxylates with human sodium-dicarboxylate cotransporter $3(\mathrm{NaDC} 3)$ and organic anion transporters 1 and 3 (OAT1 and OAT3). Am J Physiol Renal Physiol 301, F1026 - F1034

Khamdang S, Takeda M, Shimoda M (2004): Interaction of human- and rat-organic anion transporters with pravastatin and cimetidine. J Pharmacol Sci $\underline{94}, 197$ - 202

Kobayashi Y, Ohshiro N, Sakai R, Ohbayashi M, Kohyama N, Yamamoto T (2005):

Transport mechanism and substrate specificity of human organic anion transporter 2 (hOAT2 [SLC22A7]). J Pharm Pharmacol 57, 573 - 578

Koepsell H (2013): The SLC22 family with transporters of organic cations, anions and zwitterions. Mol Aspects Med 34, 413 - 435

Koepsell H, Endou H (2004): The SLC22 drug transporter family. Pflugers Arch 447, 666 676

Lang K, Wagner C, Haddad G, Burnekova O, Geibel J (2003): Intracellular pH Activates Membrane-Bound $\mathrm{Na}+\mathrm{H}+$ Exchanger and Vacuolar $\mathrm{H}_{+}-\mathrm{ATPase}$ in Human Embryonic Kidney (HEK) Cells. Cell Physiol Biochem 13, 257 - 262 
Lopez-Nieto CE, You G, Bush KT, Barros EJ, Beier DR, Nigam SK (1997) Molecular cloning and characterization of NKT, a gene product related to the organic cation transporter family that is almost exclusively expressed in the kidney. J Biol Chem $\underline{272}, 6471-6478$

Lu R, Chan BS, Schuster VL (1999): Cloning of the human PAH transporter: narrow substrate specificity and regulation by protein kinase C. Am J Physiol Renal Physiol $\underline{276}$, F295 - F303

Motohashi H, Sakurai Y, Saito H, Masuda S, Urakami Y, Goto M, Fukatsu A, Ogawa O, Inui K-I (2002): Gene expression levels and immunolocalization of organic ion transporters in the human kidney. J Am Soc Nephrol 13: 866 - 874

Mulato AS, Ho ES, Cihlar T (2000): Nonsteroidal anti-inflammatory drugs efficiently reduce the transport and cytotoxicity of adefovir mediated by the human renal organic anion transporter 1. J Pharmacol Exp Ther $\underline{295}, 10-15$

Nishimura M, Naito S (2005) Tissue-specific mRNA expression profiles of human ATPbinding cassette and solute carrier transporter families. Drug Metab Pharmacokinet $\underline{20}, 452$ 477

Parks SK, Chiche J, Pouyssegur J (2011). PH Control Mechanisms of Tumor Survival and Growth. J Cell Physiol 226, 299 - 308

Pfennig T, Herrmann B, Bauer T, Schömig E, Gründemann D (2013): Benzoic acid and specific 2-oxo acids activate hepatic efflux of glutamate at OAT2. Biochim Biophys Acta $\underline{1826}, 491-498$

Race JE, GrassI SM, Williams WJ, Holtzmann EJ (1999): Molecular cloning and characterization of two novel human renal organic anion transporters (hOAT1 and hOAT3). Biochem Biophys Res Commun 255, 508 - 514 
Riedmaier AE, Nies AT, Schaeffeler E, Schwab M (2012): Organic anion transporters and their implications in pharmacotherapy. Pharmacol Rev $\underline{64}, 421-449$

Rizwan AN, Krick W, Burckhardt G (2007): The chloride dependence of the human organic anion transporter 1 (hOAT1) is blunted by mutation of a single amino acid. J Biol Chem $\underline{282}$, $13402-13409$

Roth M, Obaidat A, Hagenbuch B (2012): OATPs, OATs and OCTs: the organic anion and cation transporters of the SLCO and SLC22A gene superfamilies. Br J Pharmacol $\underline{165}, 1260$ $-1287$

Sakurai Y, Motohashi H, Ueo H, Masuda S, Saito H, Okuda M, Mori N, Matsuura M, Doi T, Fukatsu A, Ogawa O, Inui K (2004): Expression Levels of Renal Organic Anion Transporters (OATs) and Their Correlation with Anionic Drug Excretion in Patients with Renal Diseases. Pharm Res $\underline{21}, 61-67$

Sato M, Mamada H, Anzai N, Shirasaka Y, Nakanishi T, Tamai I (2010): Renal secretion of uric acid by organic anion transporter 2 (OAT2/SLC22A7) in human. Biol Pharm Bull $\underline{33}, 498$ $-503$

Sekine T, Watanabe N, Hosoyamada M, Kanai Y, Endou H (1997): Expression cloning and characterization of a novel multispecific organic anion transporter. J Biol Chem $\underline{272}, 18526-$ 18529

Srimaroeng C, Jutabha P, Pritchard JB, Endou H, Chatsudthipong V (2005): Interaction of stevioside and steviol with renal organic anion transporters in S2 cells and mouse renal cortical. Pharm Res $\underline{22}, 858$ - 866

Sun W, Wu RR, van Poelje PD, Erion MD (2001): Isolation of a family of organic anion transporters from human liver and kidney. Biochem Biophys Res Commun 283, 417 - 423 
Takeda M, Narikawa S, Hosoyamada M, Cha SH, Sekine T, Endou H et al (2001):

Characterization of organic anion transport inhibitors using cells stably expressing human organic anion transporters. Eur J Pharmacol $\underline{419}, 113$ - 120

The International Transporter Consortium (2010): Membrane transporters in drug development. Nat Rev Drug Discov $\underline{9}, 215$ - 236

Uwai Y, Okuda M, Takami K, Hashimoto Y, Inui K (1998): Functional characterization of the rat multispecific organic anion transporter OAT1 mediating basolateral uptake of anionic drugs in the kidney. FEBS Lett $\underline{438}, 321$ - 324

Uwai Y, Saito H, Hashimoto Y, Inui K (2000): Interaction and transport of thiazide diuretics, loop diuretics, and acetazolamide via rat renal organic anion transporter rOAT1. J Pharmacol Exp Ther 295, $261-265$

VanWert AL, Gionfriddo MR, Sweet DH (2010): Organic Anion Transporters: Discovery, Pharmacology, Regulation and Roles in Pathophysiology. Biopharm Drug Dispos 31, 1 - 71

Wang L, Sweet DH (2013): Renal organic anion transporters (SLC22 family): Expression, regulation, roles in toxicity, and impact on injury and disease. AAPS J $\underline{15}, 53-69$

Wohlrab D, Hein W (2000): Der Einfluss von lonenkanalmodulatoren auf das Membranpotential humaner Chondrozyten. Orthopade 29, 80 - 8 


\section{Danksagung}

Als Allererstes möchte ich mich bei Frau Prof. Dr. Birgitta Burckhardt für ihre erstklassige Betreuung bei dieser Arbeit bedanken. Sie stand mir jederzeit mit Rat und Tat zur Seite und hat diese Arbeit dadurch erst möglich gemacht.

Vielen herzlichen Dank an Herrn Prof. Dr. Yohannis Hagos, der mir bei der Auswertung der Versuchsdaten geholfen hat und auch für andere Probleme stets ein offenes Ohr hatte.

Ganz besonders möchte ich mich auch bei Herrn Sören Petzke bedanken, der mich in sämtliche Angelegenheiten der Zellkultur mit unaufhörlichem Engagement eingewiesen und im weiteren Verlauf unterstützt hat.

Des Weiteren möchte ich allen Mitarbeitern der Vegetativen Physiologie in Göttingen für die nette Aufnahme in ihrem Team und die Unterstützung danken. 


\section{Lebenslauf}

Am 14.01.1986 wurde ich als jüngerer von zwei Söhnen der Medizinisch-technischen Radiologieassistentin Heike Detmers-Engelke und des Mund-Kiefer-Gesichtschirurgen Prof. Dr. Dr. Wilfried Engelke in Göttingen geboren.

Von 1992-1996 besuchte ich die Grundschule Diemarden. Darauf folgten von 1996 bis 1998 die Orientierungsstufe Jahnschule Göttingen und von 1998 bis 2005 das Felix-KleinGymnasium Göttingen, welches ich 2005 mit der Erlangung der allgemeinen Hochschulreife abschloss.

Nach der schulischen Ausbildung leistete ich von September 2005 bis Mai 2006 meinen Zivildienst auf der neurologischen Station 3013 im Universitätklinikum Göttingen ab. Vom Wintersemester 2006 bis zum Sommersemester 2007 studierte ich Physik an der GeorgAugust-Universität in Göttingen bis ich im Wintersemester 2007 das Studium der Zahnmedizin an eben dieser Universität begann. Dieses schloss ich am 5.12.2012 mit dem Staatsexamen ab.

Seit April 2013 arbeite ich als Assistenzzahnarzt in der Zahnarztpraxis Rossow \& Kollegen in Nörten-Hardenberg. 